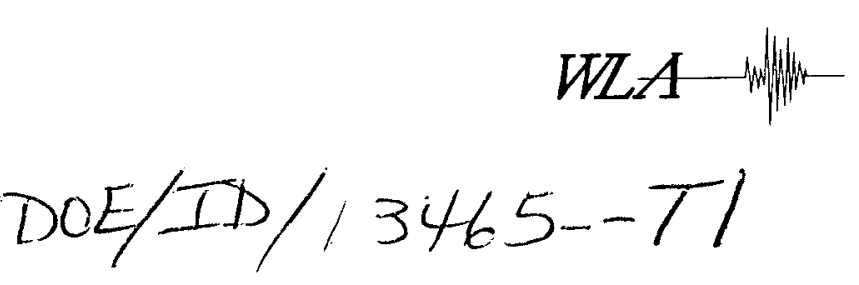

\title{
APPLICATION OF ADVANCED SEISMIC REFLECTION IMAGING TECHNIQUES TO MAPPING PERMEABLE ZONES AT DIXIE VALLEY, NEVADA
}

\section{FINAL TECHNICAL REPORT}

\begin{abstract}
A cooperative research effort of the Consortium for Economic Migration and Tomography (CEMAT), Lawrence Berkeley National Laboratory, the University of Nevada, Reno and Oxbow Geothermal Corporation
\end{abstract}

\author{
Submitted by: \\ William Lettis \& Associates, Inc. \\ CEMAT Administrator \\ 1777 Botelho Drive, Suite 262 \\ Walnut Creek, California 94596 \\ and the University of Nevada, Reno
}

Submitted to:

U.S. Department of Energy

Washington, D. C.

MASTER

February 18, 1998

William Lettis \& Associates, Inc.

Earth Science Consultants

DISTRIBUTION OF THIS DOCUMENT IS UNLIMTED

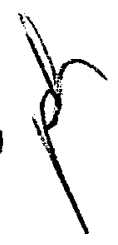




\section{DISCLAIMER}

This report was prepared as an account of work sponsored by an agency of the United States Government. Neither the United States Government nor any agency Thereof, nor any of their employees, makes any warranty, express or implied, or assumes any legal liability or responsibility for the accuracy, completeness, or usefulness of any information, apparatus, product, or process disclosed, or represents that its use would not infringe privately owned rights. Reference herein to any specific commercial product, process, or service by trade name, trademark, manufacturer, or otherwise does not necessarily constitute or imply its endorsement, recommendation, or favoring by the United States Government or any agency thereof. The views and opinions of authors expressed herein do not necessarily state or reflect those of the United States Government or any agency thereof. 


\section{DISCLAIMER}

Portions of this document may be illegible in electronic image products. Images are produced from the best available original document. 


\section{$W L A-n^{\prime \prime}$}

\section{APPLICATION OF ADVANCED \\ SEISMIC REFLECTION IMAGING TECHNIQUES \\ TO MAPPING PERMEABLE ZONES \\ AT DIXIE VALLEY, NEVADA}

\section{FINAL TECHNICAL REPORT}

A cooperative research effort of the Consortium for Economic Migration and Tomography (CEMAT), Lawrence Berkeley National Laboratory, the University of Nevada, Reno and Oxbow Geothermal Corporation

Submitted by:

William Lettis \& Associates, Inc.

CEMAT Administrator

1777 Botelho Drive, Suite 262

Walnut Creek, California 94596

and the University of Nevada, Reno

Submitted to:

U.S. Department of Energy

Washington, D. C.

February 18, 1998 
Multifold seismic reflection data from the Dixie Valley geothermal field in Nevada were reprocessed using a nonlinear optimization scheme called simulated annealing to model subsurface acoustic velocities, followed by a pre-stack Kirchhoff migration to produce accurate and detailed depth-migrated images of subsurface structure. In contrast to conventional processing techniques, these methods account for significant lateral variations in velocity and thus have the potential ability to image steeply-dipping faults and fractures that may affect permeability within geothermal fields. The optimization scheme develops two-dimensional velocity models to within $6 \%$ of velocities obtained from well and surface geologic data (Honjas, 1997a, 1997b). Only the seismic data (i.e., first arrival times of $\mathrm{P}$ waves) are used to construct the velocity models and pre-stack migration images, and no other a priori assumptions are invoked. Velocities obtained by processing individual seismic tracks were integrated to develop a block diagram of velocities to $2.3 \mathrm{~km}$ depth within the Dixie Valley geothermal field. Details of the tectonic and stratigraphic structure allowed three dimensional extension of the interpretations of two dimensional data. Interpretations of the processed seismic data are compared with well data, surface mapping, and other geophysical data.

The Dixie Valley fault along the southeastern Stillwater Range piedmont is associated with a pronounced lateral velocity gradient that is interpreted to represent the juxtaposition of relatively low velocity basin-fill strata in the hanging wall against higher velocity crystalline rocks in the footwall. The down-dip geometry of the fault was evaluated by inverting arrival times from a negative move-out event, which we associate with the dipping fault plane, on individual shot gathers for seismic line SRC-3 for the location and depth of the associated reflection points on the fault. The reflection points delineate a planar feature dipping approximately $57^{\circ}$ to the southeast, which is steeper than the $47^{\circ}$ to $50^{\circ}$ dip inferred by previous workers by projecting the surface trace to a fault cut by well \#82-5 in the basin to the southeast. Analysis of a depth-migrated image of seismic line SRC-3 shows that the fault in well \#82-5 is associated with the western margin of a discrete, asymmetric syncline located approximately $2 \mathrm{~km}$ east of the boundary between the Stillwater Range and Dixie Valley. We propose that the fault cut by the well may be a separate structure associated with development of the syncline, rather than the down-dip extension of the Dixie Valley range-front fault.

Analyses of other seismic lines reveal evidence for additional faults and synformal folds within the basin southeast of the Dixie Valley range-front fault. In particular, the reprocessing methods successfully imaged moderately to steeply dipping faults, including the fault associated with the 
syncline described above (depth-migrated seismic line 5). These structures are spatially associated with many of the producing wells in the Dixie Valley field.

The reprocessed data provide new insights into tectonic structure that may affect subsurface permeability within the Dixie Valley geothermal field. Major tectonic subsidence of Dixie Valley relative to the Stillwater Range is accommodated by southeast-down slip on the Dixie Valley fault bounding the northwestern margin of the basin. Previous workers interpreted conventionallyprocessed seismic reflection data to show that the basin is a broad synformal "sag" in the hanging wall of the Dixie Valley fault. Based on our analysis, we show that rather than a "sag", the basin probably is subsiding along high-angle faults, consistent with the interpretation of other workers that at least some of the total basin subsidence is accommodated by "piedmont faults" located basinward of the range-front fault. In addition to Dixie Valley, the tectonic "sag" model has been applied to other fault-bounded valleys in the Basin and Range province (e.g., Fallon basin; Grass Valley basin), primarily on the basis of conventional migration of seismic reflection data. Many of the high temperature hot spring systems in the Basin and Range province are associated with this style of deformation. The reprocessed data from Dixie Valley suggests that such "sag" basins may be deforming along discrete, previously unrecognized piedmont faults, which may represent zones of enhanced permeability and thus present new opportunities for geothermal exploration and development in areas with no surface manifestations of hydrothermal activity. 


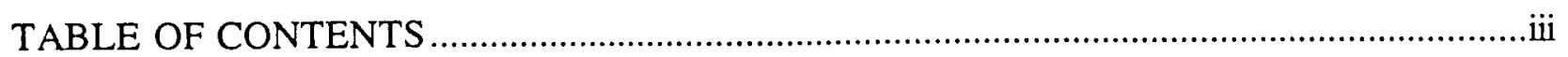

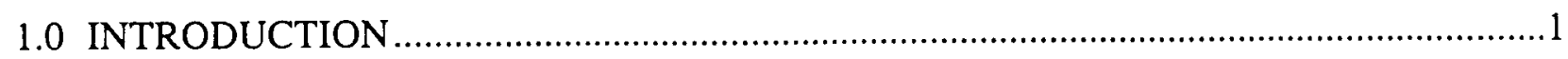

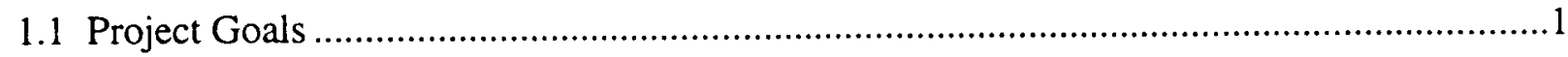

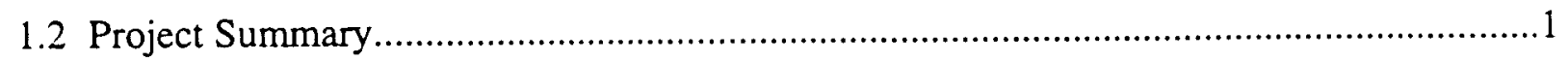

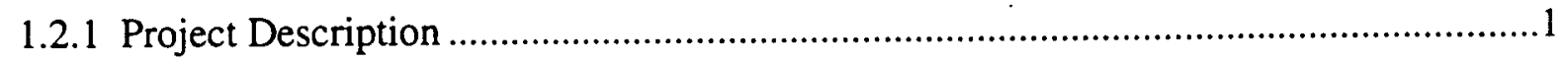

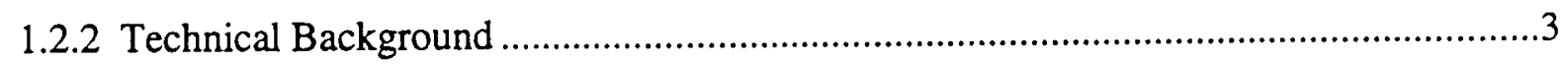

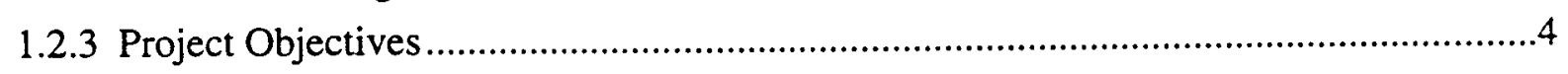

1.3 Geology and Setting of Dixie Valley Geothermal Field....................................................

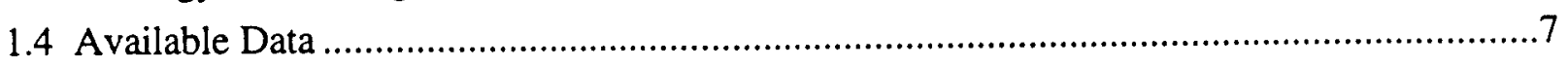

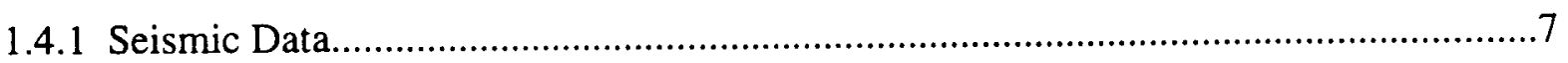

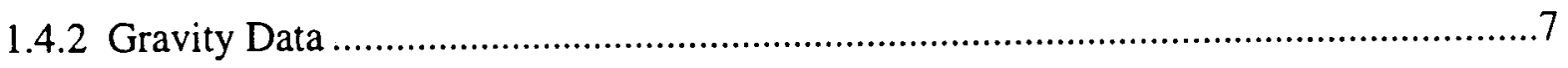

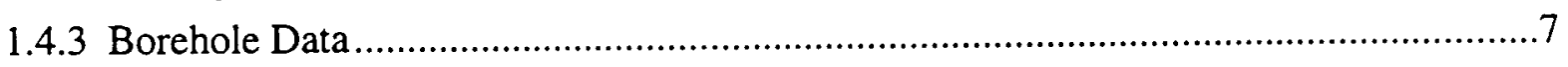

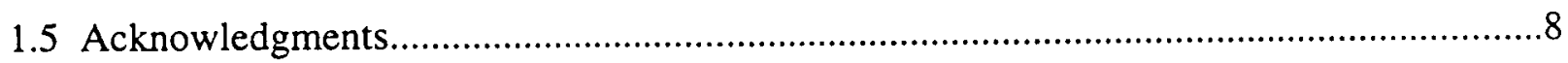

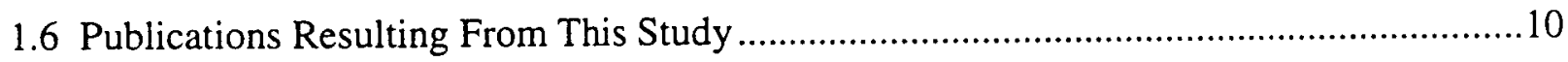

2.0 PROCESSING AND DATA INTEGRATION TECHNIQUES …..................................

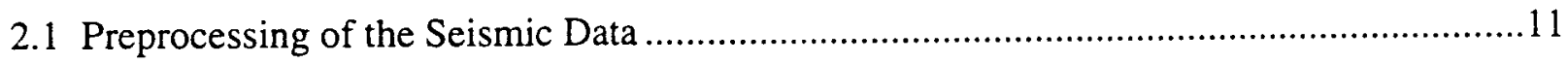

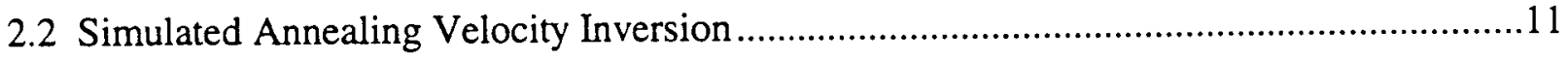

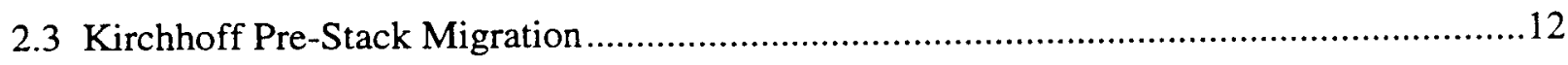

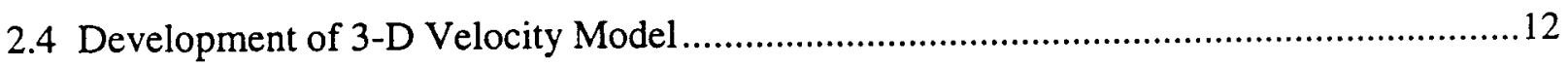

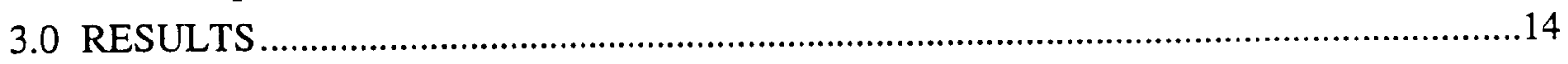

3.1 2-D Simulated Annealing Velocity Models.......................................................................14

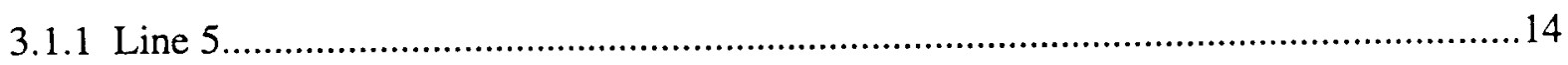

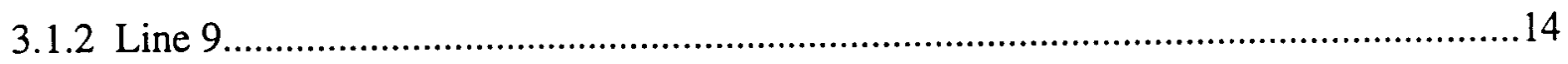

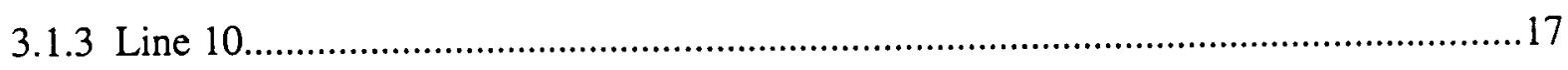

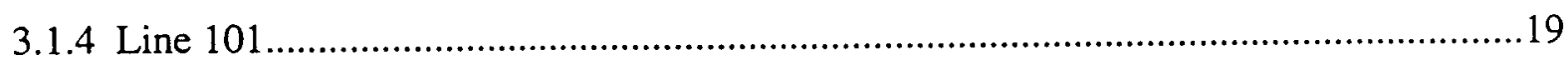

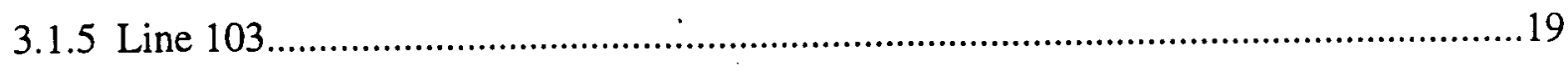

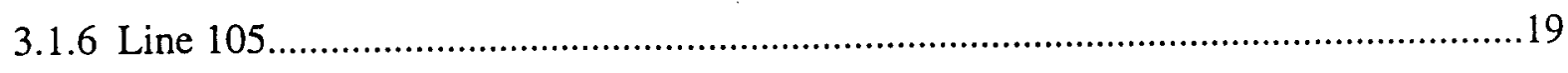

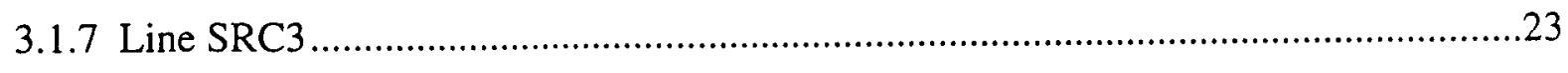

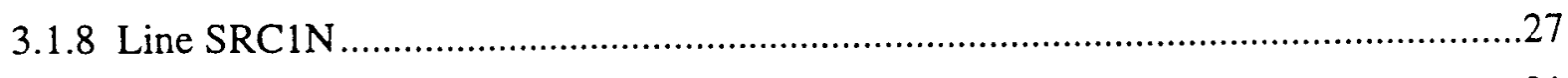

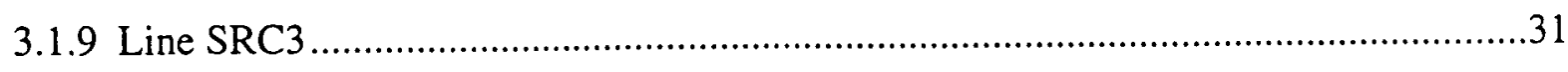




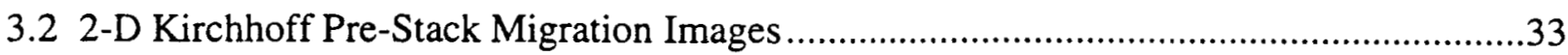

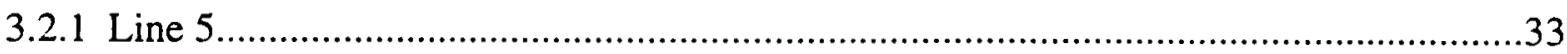

3.2.2 Line 9

3.2.3 Line 10

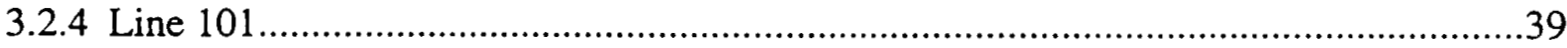

3.2.5 Line 103

3.2.6 Line 105

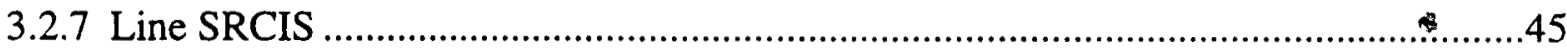

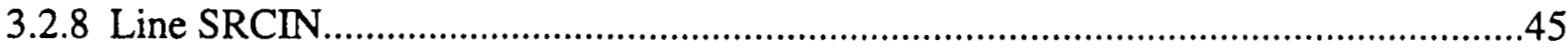

3.2.9 Line SRC3

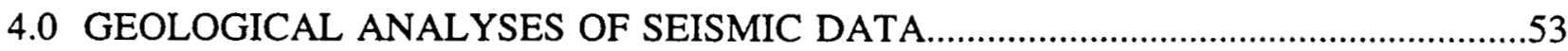

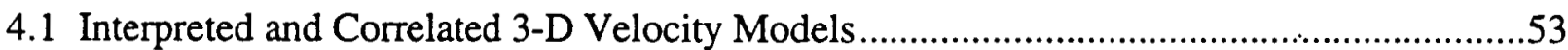

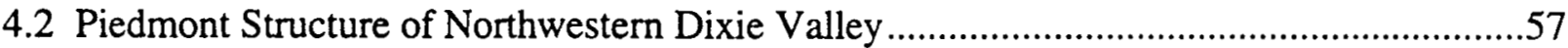

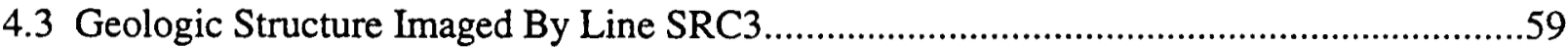

4.4 Comparison of Conventional Processing with Simulated Annealing and Pre-Stack

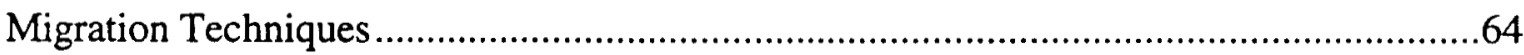

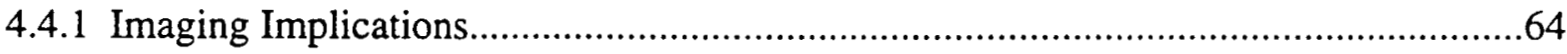

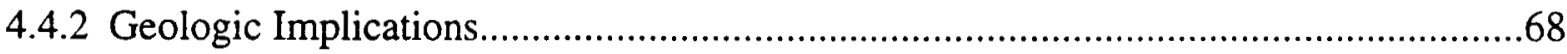

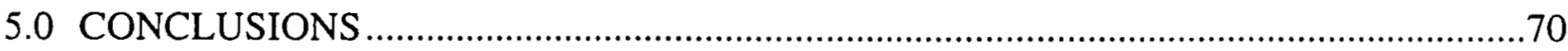

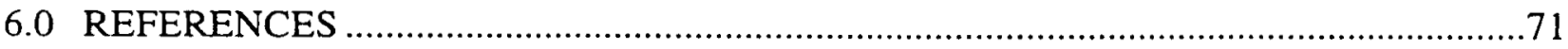

\section{List of Tables}

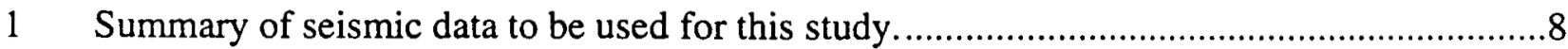

2 Summary of borehole data available for this study...........................................................

List of Figures

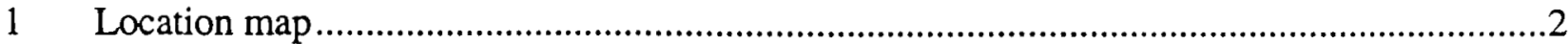

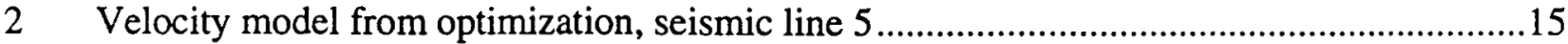

3 Velocity model from optimization, seismic line 9 ..............................................................16

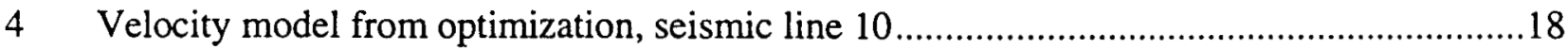

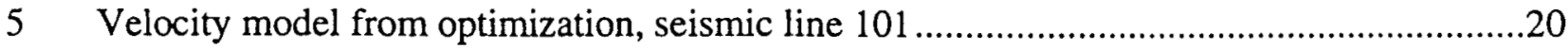




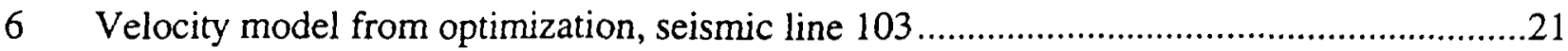

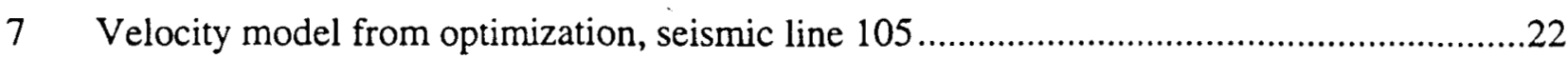

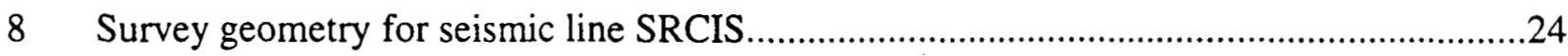

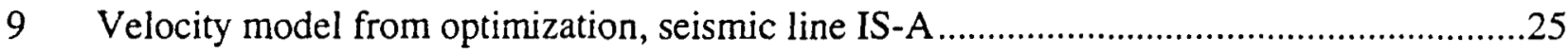

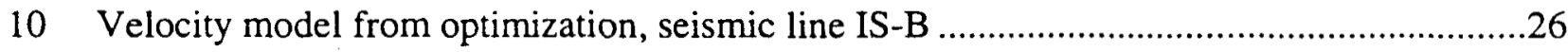

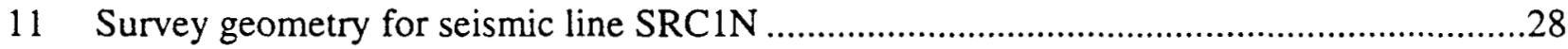

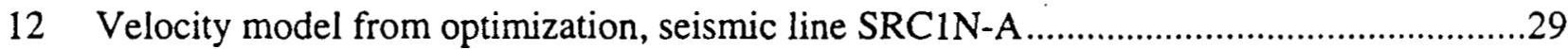

13 Velocity model from optimization, seismic line SRC1N-B ..................................................30

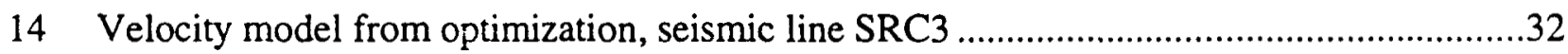

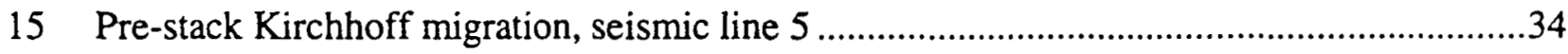

16 Interpreted prestack Kirchhoff migration, seismic line 5

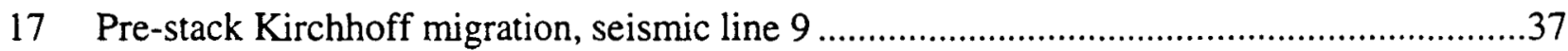

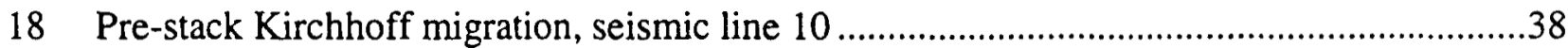

19 Interpreted prestack Kirchhoff migration, seismic line 10 ................................................40

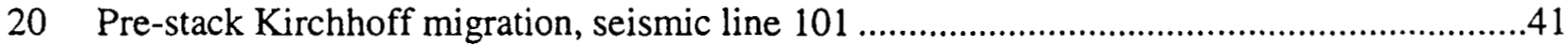

21 Interpreted prestack Kirchhoff migration, seismic line 103 ..............................................43

22 Pre-stack Kirchhoff migration, seismic line 105 .............................................................4

23 Pre-stack Kirchhoff migration, seismic line SRCIS-A.....................................................46

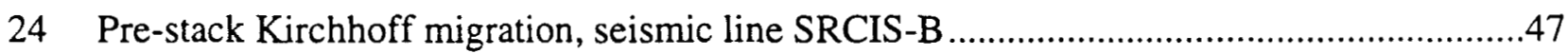

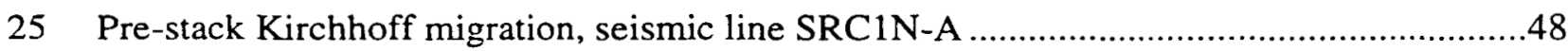

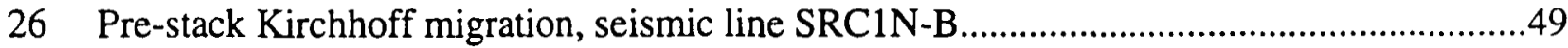

27 Pre-stack Kirchhoff migration, seismic line SRC3 ...........................................................51

28 Interpreted prestack Kirchhoff migration, seismic line SRC3 …......................................52

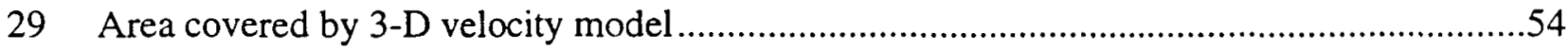

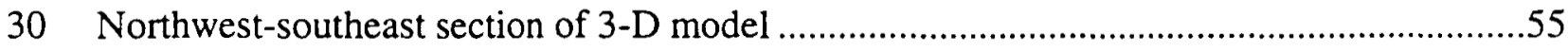

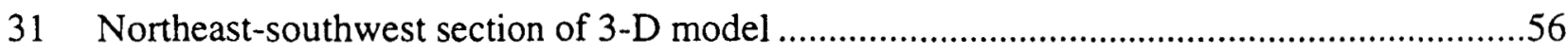

32 Comparison of seismic and gravity interpretations of Piedmont structure in northern

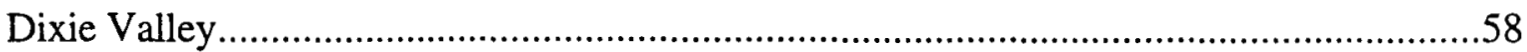

33 Velocity model and reflection points, seismic line SRC3

34 Structural interpretation (model 1) of seismic line SRC3 ..................................................62

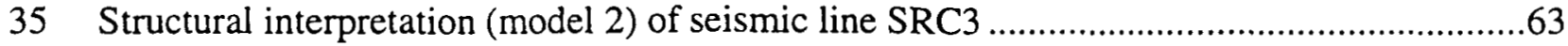

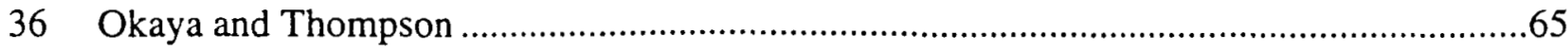




\subsection{Project Goals}

The goal of this project is to test the ability of new seismic reflection data processing methods to map the subsurface location of permeable fractures, lithologic boundaries, and faults within the Dixie Valley Geothermal field, Nevada (Figure 1). Geothermal development depends on subsurface permeability to produce high flow rates of water or steam. To date, fractures and tectonic structures that affect subsurface permeability have been difficult to locate using conventional seismic imaging methods due to the lateral complexity and typically non-reflective nature of the geothermal environment. The new seismic processing techniques used in this study, simulated annealing optimization and Kirchhoff pre-stack migration, were applied to 38.6 miles of previously acquired seismic reflection data from Dixie Valley. The images obtained from the reprocessing were compared with other geologic and geophysical data provided by Oxbow Geothermal Corporation and other workers (Dick Benoit, personal communication; G. Plank, M.S. thesis research, in progress). Our results, which are presented in this report, demonstrate that the new seismic processing techniques can contribute significantly to predicting the location and down-dip geometry of faults that bound geothermal fields and control permeability at depth.

\subsection{Project Summary}

\subsubsection{Project Description}

Dixie Valley is one of several well publicized, high temperature fields in the Basin and Range province that are associated with range-front normal faults or structures parallel to them (Zoback and Anderson, 1983). Other such fields include Beowawe, Bradys, and Roosevelt (Benoit and Butler, 1983). At every producing geothermal field within the Basin and Range wells have been drilled into hot, but dry, rock. This project tests and further develops a potentially reliable geophysical technique for predicting subsurface velocity structure and constraining the location of permeable and non-permeable faults in the subsurface using no a priori data, thereby facilitating increased drill success rates and new exploration for thermal anomalies that have no surface manifestations.

Dixie Valley is an excellent site for demonstrating the ability of these new seismic processing methods. The Dixie Valley geothermal field is covered by the most extensive data base of existing 


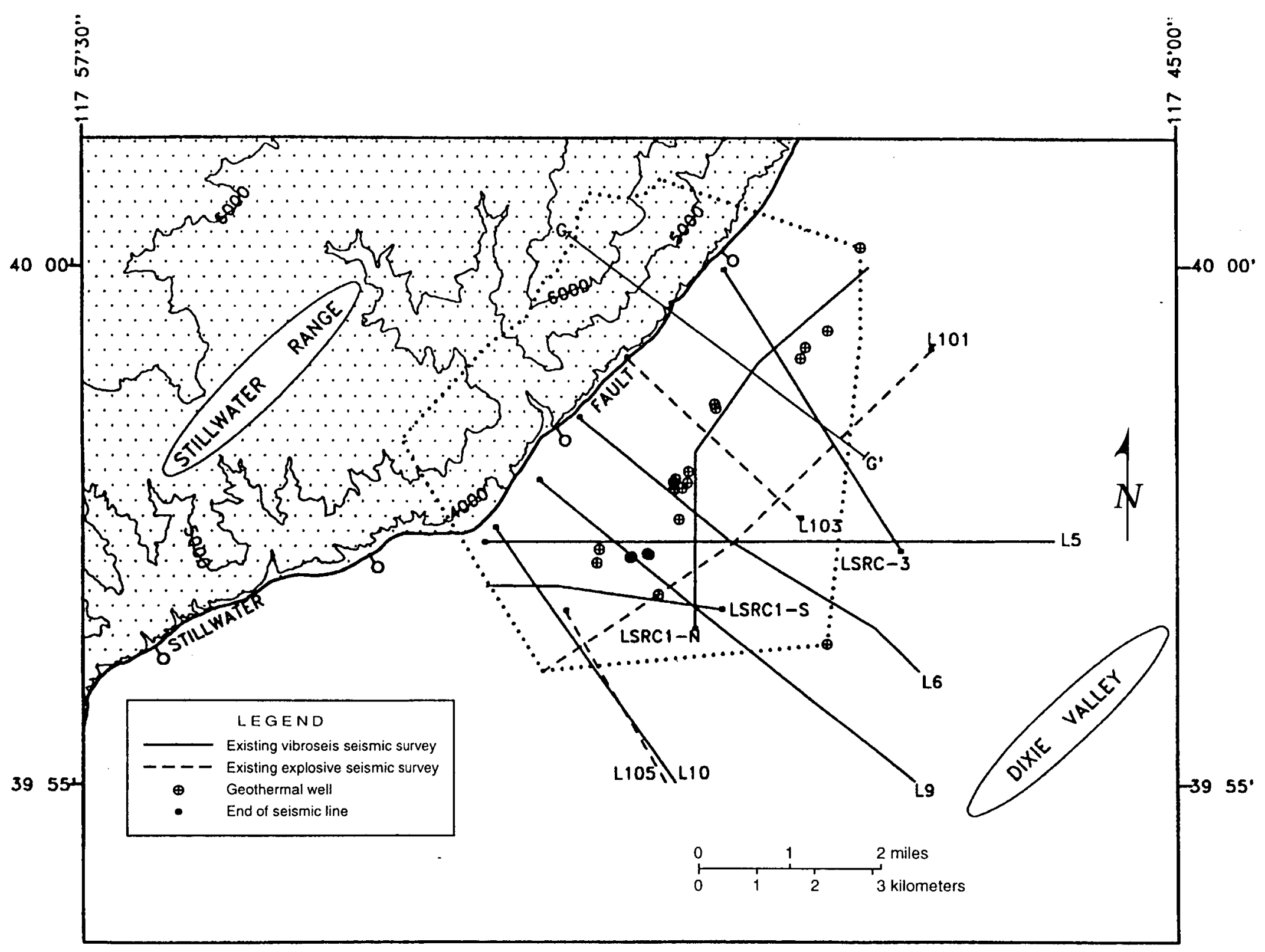

Figure 1. Location map of geothermal wells and existing seismic reflection surveys, northwestern Dixie Valley. 
seismic reflection profiles in the geothermal industry (Dick Benoit, personal communication). In addition, production from the Dixie Valley geothermal field is closely associated with a fault or fault system that bounds the Stillwater Range on the west, and Dixie Valley on the east (Figure 1). In past studies, we have demonstrated the ability of our processing techniques to image the truedepth location and down-dip geometry of similar faults in the Basin and Range province (Louie and Qin, 1991; Pullammanappallil and Louie, 1993; Chavez-Perez et al., 1993), and adjacent to the offshore Santa Maria Basin, California (Honjas et al., 1993). Thus, Dixie Valley presents an opportunity to test these new, advanced methods for imaging such structures in a relatively wellunderstood, active geothermal environment.

Other attributes that make Dixie Valley the ideal setting for this project include the abundance of geologic and borehole data that available to verify the commercial effectiveness of the seismic analysis (see Section 1.4 for list of data available for this study). For example, the entire section of geothermal reservoir rocks at depth is exposed in the footwall of the Dixie Valley fault, which borders the eastern face of the Stillwater range (Figure 1). Previous drilling efforts in Dixie Valley have documented faulting in the Neogene and younger strata to about $10,000 \mathrm{ft}$ depth. In addition, results from a number of ongoing geologic, borehole and geophysical studies undertaken in Dixie Valley were made available for this study. We therefore were able to correlate salient geophysical signatures derived from our processing methods with known subsurface geology and features inferred from previous geophysical studies.

\subsubsection{Technical Background}

Geothermal development in the United States has been hampered by an overall lack of adequate technology to locate new geothermal resources that have no surface manifestations. Virtually all commercial development to date has been in areas where the resource was identified by thermal features at the surface, or through analysis of thermal data acquired at depth.

Production from most geothermal reservoirs depends on the presence of discrete permeable zones that produce high flow rates of water or steam. The inability of current technology to reliably and consistently locate faults, fractures, and other permeable features at depth has resulted in lower drilling success rates and, consequently, higher costs. The ultimate goal in geothermal exploration is the development of methods that can map the true-depth location of permeable features before drilling. Such technology would be indispensable in developing exploration strategies for drilling within thermal anomalies, and designing directional drilling programs for enhanced recovery in developed reservoirs. 
Several workers have attempted to use conventional seismic reflection methods to image and map permeable zones for geothermal exploration (e.g., Okaya and Thompson, 1985). These methods originally were developed for use in petroleum-bearing marine sedimentary environments, where rocks typically exhibit modest and relatively predictable lateral variations in acoustic velocity. Standard processing techniques used by the petroleum industry exploit these characteristics of sedimentary environments by minimizing or discounting lateral velocity variations to simplify the analysis. In contrast, the geothermal environment typically is characterized by strong lateral variations in velocity, commonly due to the presence of steeply-dipping faults and fractures, as well as abrupt volcanic and sedimentary facies changes. These features violate the simple assumptions of lateral homogeneity in conventional processing, and because their effect on the velocity structure is not incorporated into the analysis they cannot be effectively imaged or mapped using conventional techniques. Consequently, the success of seismic reflection techniques in petroleum environments generally has not been duplicated in attempts to map steeply-dipping permeable zones in the geothermal environment.

\subsubsection{Project Objectives}

The primary objective of this project is to test the ability of recently developed seismic reflection analysis methods for locating and characterizing faults, fractures, and other features that affect subsurface permeability within the Dixie Valley geothermal field. In so doing, we accomplished a number of secondary objectives, including: (a) integration of processed and analyzed seismic reflection data with previously collected geologic and borehole information to evaluate the correspondence of reflection anomalies and subsurface velocity structure to locations of known permeable features in the subsurface; (b) demonstration of new technology that will benefit geothermal exploration, identify fractures, and locate areas of fracture permeability prior to drilling; (c) demonstration of technology that will increase drill success rates and lower drilling costs; (e) characterization of geothermal reservoirs and their boundaries; (f) a test of the ability of new seismic processing methods to predict subsurface geology and structure using no a priori data, and; (g) determining seismic data acquisition parameters that will optimize the results that can be gained by employing new seismic processing techniques.

\subsection{Geology and Setting of Dixie Valley Geothermal Field}

Dixie Valley trends northeast-southwest, is roughly seventy-five miles long and twelve miles wide, and is bounded to the west by the Stillwater Range and to the east by the Clan-Alpine Mountains (Figure 1). The valley supports an elongated geothermal area and maintains a high heat 
flow relative to the surrounding Great Basin (Blackwell, 1992). A heat source whose specific nature is unknown manifests itself at the surface by fumaroles and hot springs at the north end of the valley along the Dixie Valley range front fault. The commercial development of this field began in 1979 with exploratory drilling and today comprises one $62 \mathrm{MW}$ plant that became operational in 1988. Exploration and development of the field continues, albeit partially impeded by diverse reservoir structure.

The complex geology exposed in the Stillwater and Clan Alpine ranges is present in the reservoir rocks of the down-dropped Dixie Valley block, which is buried beneath approximately $1.8 \mathrm{~km}$ of Tertiary and Quaternary basin fill deposits. At least two and possibly as many as four separate tectonic events have affected the crystalline basement rocks (Speed, 1976). These events span the range from brittle to ductile deformation, and have deformed a variety of igneous, sedimentary, and metamorphic rocks.

The structural development of the geothermal area began with the emplacement of the Golconda allochthon during the early Triassic Sonoma orogeny. In the middle Triassic time, shelf carbonates of the Star Peak Group (Silberling and Roberts, 1962) and clastic marine sediments (Speed, 1976) were deposited on the Golconda allochthon. Later, Middle or Late Jurassic contractional deformation thrust these marine and shelfal deposits to the northeast along the Fencemaker thrust, a major structure in western Nevada that subtends the Fencemaker allochthon (Speed et al., 1988). The Fencemaker thrust exists locally in a zone of highly strained, greenschist grade marbles and phyllites, and may have been active at a depth of between nine and twelve kilometers.

Quartz arenites and basal dolomitic conglomerates of the Boyer Ranch Formation (Speed, 1969) overlie the Fencemaker allochthon along the Boyer thrust. In contrast to the Fencemaker thrust, the Boyer thrust is marked by a relatively narrow zone of brittle deformation. Although the age of the Boyer Ranch Formation is inferred to be between late Triassic and late early Jurassic, the age of the thrust is poorly constrained and may be as young as Laramide (i.e., late Cretaceous-early Tertiary). Furthermore, the origin of the Boyer Ranch Formation is enigmatic because the conglomerates appear to be locally derived while the arenites are highly matured Navajo sandstone-type deposits.

In the tectonostratigraphy of the geothermal area, the structurally highest unit comprises gabbros, diorites, granodiorites, monzogranites, basaltic to intermediate dike swarms, and associated volcanic rocks of the Jurassic Humboldt igneous complex (Dilek and Moores, 1995). the 
Humboldt complex overlies both the Boyer Ranch Formation and the Fencemaker allochthon, along a brittle fault of yet unknown nature and geometry. All the rocks within the complex have been metamorphosed to upper greenschist to amphibolite facies conditions, and have been altered by hydrothermal activity.

During the early to mid Tertiary, around 550 meters (1800 feet) of andesitic to basalt flows and rhyolitic tuffs accumulated depositionally above the fault bounded packages described above (Speed, 1976). These volcanic units cap the Stillwater and Clan Alpine ranges and are present in similar thicknesses beneath the Tertiary and Quaternary basin fill of Dixie Valley, as shown by geothermal well lithologic logs. While some of the tuffs have been identified and correlated with regional volcanic centers, others remain to be investigated (Dave John, personal communication). Paleomagnetic surveys of these rocks have shown that between 10 to 30 degrees of counterclockwise vertical axis rotation has occurred since their deposition, with the majority of rotation constrained to within the Oligocene to Miocene epochs (Hudson and Geissman, 1991), indicating that extensional and/or strike slip tectonics were well underway by mid-Tertiary time.

Dixie Valley itself is established as having been active over the last 15 m.y., placing the inception of faulting in early Miocene (Okaya and Thompson, 1985). Hastings (1979) suggests, however, that the late Miocene basalt (about $8 \mathrm{Ma}$ ) was deposited on a surface of low relief and thus predates the extensional faulting that caused the formation of Dixie Valley. If this paleogeographic interpretation is correct, subsidence of the asymmetric Dixie Valley graben may date from the late Neogene. The modern configuration of the Dixie Valley geothermal field is characterized by active extensional faulting along the west margin of the down-dropping Dixie Valley block.

The valley occupies a part of the Central Valley Seismic Belt, a generally north-northeast-trending zone of late Quaternary faulting and historical seismicity that has been the locus of several moderate to large magnitude earthquakes during the past 100 years, including the 1954 Dixie Valley and 1915 Pleasant Valley earthquakes (Savage et al., 1995; Caskey et al., 1996). The geothermal field is located between the endpoints of the 1954 and 1915 surface ruptures (Slemmons, 1956) along a segment of the Stillwater Fault which has remained unruptured in historic times. This segment, known as the Stillwater seismic gap (Wallace and Whitney, 1984), may be influenced by several regional structural features. The seismic gap falls within a major tilt domain boundary or transverse zone between the east-tilted Tobin range to the north and the westtilted Stillwater range (Slemmons, 1967). Also, the gap coincides with a possible pre-Cenozoic fault-barring structure within the Sou Hills to the north (Fonseca, 1988). How or whether these regional features affect the Dixie Valley geothermal system is not known. 


\subsection{Available Data}

The seismic lines and borehole data used in this study were provided by Dick Benoit of Oxbow Geothermal Corporation. Mr. Gabe Plank, a graduate student at the Department of Geological Sciences, UNR, compiled the well log information. A gravity map compiled at Southern Methodist University (SMU) under the direction of Dr. David Blackwell was provided to us for the purpose of comparing the reprocessed seismic lines with structural models based on gravity data. The gravity map is discussed in detail in Section 4.2. We did not have access to the gravity data, which are proprietary.

\subsubsection{Seismic Data}

Our study used data recorded along nine seismic lines (Figure 1), covering an area of approximately 161.92 square km. Parts of seismic lines SRC1N and SRC1S and all of Line 101 are subparallel to the strike of the range-front fault. Line 10, Line 105, SRC3, Line 103, Line 9, and Line 5 are oriented perpendicular or at an angle to the range front. This variety of orientations allowed us to construct three-dimensional models for the study area from the seismic data (Section 4.1). Detailed information about each seismic line, including approximate length, type of source and recording parameters, is listed in Table 1.

\subsubsection{Gravity Data}

A gravity map compiled by Dr. David Blackwell of Southern Methodist University was provided for us to use in interpreting the seismic data. This map is part of a report (Blackwell and Wisian, 1997) prepared for Oxbow Geothermal Corporation (Reno, Nevada) and Caithness Resources, Inc. (Denver, Colorado). The gravity data are confidential, and only abstractions or interpretations of the data were available for the present study.

\subsubsection{Borehole Data}

Table 2 lists all borehole data available for this project. We used lithology log information to identify and correlate different units with velocity models and prestack migration images. Sonic logs from selected wells were used to evaluate the accuracy of the simulated annealing velocity models obtained in this study. Variations between observed and modeled velocities typically were found to be within five to six percent. 
Table 1: $\quad$ Summary of seismic data to be used for this study.

\begin{tabular}{|c|c|c|c|c|c|c|c|c|c|}
\hline $\begin{array}{c}\text { Line } \\
\text { Number }\end{array}$ & $\begin{array}{c}\text { Line } \\
\text { Length }\end{array}$ & $\begin{array}{c}\text { Source } \\
\text { Type }\end{array}$ & $\begin{array}{c}\text { Record } \\
\text { Length }\end{array}$ & $\begin{array}{c}\text { Sample } \\
\text { Rate }\end{array}$ & $\begin{array}{c}\text { Pattern } \\
(\text { CMP) }\end{array}$ & $\begin{array}{c}\text { Number of } \\
\text { Groups }\end{array}$ & $\begin{array}{c}\text { Group } \\
\text { Interval }\end{array}$ & $\begin{array}{c}\text { Shot Point } \\
\text { Interval }\end{array}$ & $\begin{array}{c}\text { Maximum } \\
\text { Fold }\end{array}$ \\
\hline \hline SRC1-N & $4.6 \mathrm{miles}$ & Vibroseis & $4.1 \mathrm{sec}$. & $2 \mathrm{msec}$. & Inline & 48 & $110^{\prime}$ & $220^{\prime}$ & 12 \\
\hline SRC1-S & $3.6 \mathrm{miles}$ & Vibroseis & $4.1 \mathrm{sec}$. & $2 \mathrm{msec}$. & Inline & 48 & $110^{\prime}$ & $220^{\prime}$ & 12 \\
\hline SRC3 & $4.8 \mathrm{miles}$ & Vibroseis & $4.1 \mathrm{sec}$. & $2 \mathrm{msec}$. & Inline & 48 & $110^{\prime}$ & $220^{\prime}$ & 12 \\
\hline 101 & $5.7 \mathrm{miles}$ & Explosive & $6 \mathrm{sec}$. & $2 \mathrm{msec}$. & Inline & 48 & $165^{\prime}$ & $165^{\prime}$ & 24 \\
\hline 103 & $2.5 \mathrm{miles}$ & Explosive & $6 \mathrm{sec}$. & $2 \mathrm{msec}$. & Inline & 48 & $165^{\prime}$ & $165^{\prime}$ & 24 \\
\hline 105 & $2.2 \mathrm{miles}$ & Explosive & $6 \mathrm{sec}$. & $2 \mathrm{msec}$. & Inline & 48 & $165^{\prime}$ & $165^{\prime}$ & 6 \\
\hline 5 & $6.3 \mathrm{miles}$ & Vibroseis & $16 \mathrm{sec}$. & $4 \mathrm{msec}$. & Inline & 96 & $165^{\prime}$ & $330^{\prime}$ & 24 \\
\hline $6 * *$ & $4.8 \mathrm{miles}$ & Vibroseis & $16 \mathrm{sec}$. & $4 \mathrm{msec}$. & Inline & 96 & $165^{\prime}$ & $330^{\prime}$ & 24 \\
\hline 9 & $5.4 \mathrm{miles}$ & Vibroseis & $16 \mathrm{sec}$. & $4 \mathrm{msec}$. & Inline & 96 & $165^{\prime}$ & 330 & 24 \\
\hline 10 & $3.5 \mathrm{miles}$ & Vibroseis & $16 \mathrm{sec}$. & $2 \mathrm{msec}$. & Inline & 96 & $165^{\prime}$ & $660^{\prime}$ & 12 \\
\hline
\end{tabular}

Total Line 43.4 miles

*CMP = Common Mid-Point

** Data for Line 6 processed by Okaya in 1986. These data are not available.

\subsection{Acknowledgments}

This research has been funded under the U. S. Department of Energy Geothermal Program (USDOE Contract Number DE-FG07-97ID13465). Special thanks are extended to Marshall Reed for his support of our research. We also thank Willettia Amos, Wendy Huggins, Kara Twitchell and Mark Tyner at the USDOE Idaho Operations Office for their assistance throughout the project. We would also like to thank Bob Creed at the Idaho National Engineering Laboratory (INEL) for the personal interest he has shown in our project since our first meeting at the Stanford Geothermal Program Annual Meeting last January. Also, we would like to thank Earni Majer at Lawrence Berkeley National Laboratory (LBNL) for reviewing our results and providing valuable input during the course of this research.

This research would not have been possible were it not for the outstanding cooperation and data provided by Oxbow Geothermal Corporation. In particular, we would like to thank Dick Benoit for his support and review of our research, from preparation of our initial DOE proposal to presentation of these results. We would also like to thank Dick and Oxbow for hosting the "Friends of Dixie" workshop in Reno, Nevada last August. It was a unique opportunity to learn about other research going on in Dixie Valley, and a great sounding board for new ideas and future projects. 
Table 2: Summary of borehole data available for this study.*

\begin{tabular}{|c|c|c|c|c|c|c|c|}
\hline Well \# & $\begin{array}{c}\text { Lith. \& } \\
\text { Drillers Log }\end{array}$ & Sonic Log & $\begin{array}{c}\text { Static } \\
\text { Temp Log }\end{array}$ & $\begin{array}{c}\text { Neutron/ } \\
\text { Density Log }\end{array}$ & $\begin{array}{c}\text { Induction } \\
\text { Electrical } \\
\text { Log }\end{array}$ & $\begin{array}{c}\text { Dip } \\
\text { Meter Log }\end{array}$ & $\begin{array}{c}\text { Gamma } \\
\text { Ray Log** }\end{array}$ \\
\hline \hline $45-33$ & $\mathrm{X}$ & $\mathrm{X}$ & $\mathrm{X}$ & $\mathrm{X}$ & $\mathrm{X}$ & & $\mathrm{X}$ \\
\hline $27-33$ & $\mathrm{X}$ & & $\mathrm{X}$ & $\mathrm{X}$ & $\mathrm{X}$ & & $\mathrm{X}$ \\
\hline $28-33$ & $\mathrm{X}$ & $\mathrm{X}$ & $\mathrm{X}$ & $\mathrm{X}$ & & & $\mathrm{X}$ \\
\hline $82-5$ & $\mathrm{X}$ & & $\mathrm{X}$ & & $\mathrm{X}$ & & \\
\hline $45-5$ & $\mathrm{X}$ & $\mathrm{X}$ & $\mathrm{X}$ & $\mathrm{X}$ & $\mathrm{X}$ & & $\mathrm{X}$ \\
\hline $25-5$ & $\mathrm{X}$ & $\mathrm{X}$ & $\mathrm{X}$ & & & & $\mathrm{X}$ \\
\hline $82-7$ & $\mathrm{X}$ & $\mathrm{X}$ & $\mathrm{X}$ & $\mathrm{X}$ & & & $\mathrm{X}$ \\
\hline $73-7$ & $\mathrm{X}$ & $\mathrm{X}$ & $\mathrm{X}$ & $\mathrm{X}$ & & $\mathrm{X}$ & $\mathrm{X}$ \\
\hline $74-7$ & $\mathrm{X}$ & $\mathrm{X}$ & $\mathrm{X}$ & $\mathrm{X}$ & $\mathrm{X}$ & & $\mathrm{X}$ \\
\hline $63-7$ & $\mathrm{X}$ & $\mathrm{X}$ & $\mathrm{X}$ & & & & $\mathrm{X}$ \\
\hline $84-7$ & $\mathrm{X}$ & & $\mathrm{X}$ & $\mathrm{X}$ & & & \\
\hline $76-7$ & $\mathrm{X}$ & $\mathrm{X}$ & $\mathrm{X}$ & & & & $\mathrm{X}$ \\
\hline $41-18$ & $\mathrm{X}$ & $\mathrm{X}$ & $\mathrm{X}$ & $\mathrm{X}$ & & & $\mathrm{X}$ \\
\hline $32-18$ & $\mathrm{X}$ & $\mathrm{X}$ & $\mathrm{X}$ & $\mathrm{X}$ & & & $\mathrm{X}$ \\
\hline $52-18$ & $\mathrm{X}$ & & $\mathrm{X}$ & $\mathrm{X}$ & & & $\mathrm{X}$ \\
\hline $65-18$ & $\mathrm{X}$ & $\mathrm{X}$ & $\mathrm{X}$ & $\mathrm{X}$ & $\mathrm{X}$ & & $\mathrm{X}$ \\
\hline SWL-1 & $\mathrm{X}$ & & $\mathrm{X}$ & & $\mathrm{X}$ & & $\mathrm{X}$ \\
\hline SWL-2 & $\mathrm{X}$ & $\mathrm{X}$ & $\mathrm{X}$ & $\mathrm{X}$ & $\mathrm{X}$ & $\mathrm{X}$ & $\mathrm{X}$ \\
\hline SWL-3 & $\mathrm{X}$ & & $\mathrm{X}$ & $\mathrm{X}$ & $\mathrm{X}$ & & $\mathrm{X}$ \\
\hline $62-21$ & $\mathrm{X}$ & $\mathrm{X}$ & $\mathrm{X}$ & $\mathrm{X}$ & $\mathrm{X}$ & & \\
\hline $76-28$ & $\mathrm{X}$ & $\mathrm{X}$ & $\mathrm{X}$ & & $\mathrm{X}$ & & \\
\hline
\end{tabular}

*This table represents the borehole data that Oxbow has made available for this study.

**The gamma ray logs are for non-basin fill rocks only.

The Dixie Valley Power Partners and Dave Blackwell at Southern Methodist University also provided valuable corroborating data that allowed us to analyze the effectiveness of the seismic processing methods we tested for this study. Special thanks are also extended to Dr. Jim Brune and Dr. John Louie at the University of Nevada Seismological Laboratory for providing computing, administrative and technical resources via the Center for Economic Migration and Tomography (CEMAT). Dr. Richard Schweichert and Gabrial Plank at the University of Nevada 
Department of Geological Sciences provided us with geologic information that assisted us in analyzing the results of our reprocessing of the seismic data.

We acknowledge the Geothermal Resources Council and the Stanford Geothermal Program for providing an effective, international venue through which we could present the results of our research, and learn about research being performed in the geothermal industry. People like Dave Anderson, Mike Wright, Roland Horne, Shaun Fitzgerald, Graciela Mata, and Joyce Mitchell make it all happen, and all of their efforts and assistance has been deeply appreciated.

Personal thanks go out to Dave Anderson, who first encouraged us to apply to the USDOE Geothermal Program in order to test new processing methods for geothermal exploration and development, and for facilitating our introduction to the geothermal industry.

\subsection{Publications and Presentations Resulting From This Study}

Honjas, W., Pullammanappallil, S. K., Lettis, W. R., Plank, G. L., Louie, J. N., and Schweichert, R., 1997a, Predicting shallow Earth structure within the Dixie Valley geothermal field, Dixie Valley, Nevada, using a non-linear velocity optimization scheme: Proc. 22nd workshop on Geothermal Reservoir Engineering, Stanford University, California, p.153-160.

Honjas, W., Pullammanappallil, S. K., Lettis, W. R., Plank, G. L., Louie, J. N., and Schweichert, R., 1997b, Predicting shallow Earth structure within the Dixie Valley geothermal field, Dixie Valley, Nevada, using a non-linear velocity optimization scheme:

Geothermal Resources Council Bulletin, v. 26, p. 45-52.

Honjas, W., Pullammanappallil, S. K., and Unruh, J. R., 1997c, Effectiveness of simulated annealing velocity modeling and Kirchhoff pre-stack migration for imaging laterally complex geologic environments within the Dixie Valley geothermal field [abs.]: Geothermal Resources Council Annual Meeting, October 1997, Burlingame, California (Copy of paper available on request).

Unruh, J. R., Honjas, W., Pullammanappallil, S. K., 1997, Re-evaluation of tectonic structure in northern Dixie Valley, Nevada, from reprocessed seismic reflection profiles, and implications for subsurface permeability [abs.]: Geothermal Resources Council Annual Meeting, October 1997, Burlingame, California (Copy of paper available on request).

Oral Presentation: Honjas, W., Pullammanappallil, S. K., Lettis, W. R., Plank, G. L., Louie, J. N., and Schweichert, R., 1997a, Predicting shallow Earth structure within the Dixie Valley geothermal field, Dixie Valley, Nevada, using a non-linear velocity optimization scheme: Proc. 22nd workshop on Geothermal Reservoir Engineering, Stanford University, California.

Oral Presentation: Honjas, W., Pullammanappallil, S. K., and Unruh, J. R., 1997c, Effectiveness of simulated annealing velocity modeling and Kirchhoff pre-stack migration for imaging laterally complex geologic environments within the Dixie Valley geothermal field: Geothermal Resources Council Annual Meeting, October 1997, Burlingame, California. 


\subsection{Preprocessing of the Seismic Data}

The seismic data were provided by Oxbow Geothermal Corporation in SEG-Y IBM floating point format on digital $8 \mathrm{~mm}$ exabyte tapes. ProMAX seismic processing software was used to read the shot gathers corresponding to each seismic line from the tape. First arrivals were picked manually from the data. These picks, along with the corresponding source and receiver coordinate-ordinate information, are used in the first arrival optimization to develop velocity models. The coordinatesordinates were transformed from the field frame of reference (i.e., state plane coordinates) to the model reference frame. Bends in the line were accounted for by projecting the source positions on to a straight line, while keeping the source-receiver offset same as the original line (Pullammanappallil and Louie, 1994). This resulting velocity model then was used in a prestack migration, which used the amplitude information of reflections contained in the raw shot gathers. The only pre-processing of the raw data required was muting of first-arrivals, which are "noise" in this step of the processing. Some filtering can be done to remove cultural noise, if present.

\subsection{Simulated Annealing Velocity Inversion}

Simulated annealing is a Monte-Carlo estimation process that can match data to a model even where sophisticated non-linear inversion methods may fail (Pullammanappallil and Louie, 1993; Pullammanappallil and Louie, 1994). We use this method to invert P-wave arrival times from the seismic data to obtain a two-dimensional model of seismic velocities along an individual seismic line. The inversion algorithm randomly perturbs velocities in an arbitrary starting model until the synthetic seismic wave travel times computed through it match the travel times picked from the new data. New models producing less travel time error are accepted for further enhancements, and models having increased error can be accepted conditionally based on their total error. This process results in a progressive "annealing" of the model by gradually reducing the misfit between the predicted and observed travel times. As annealing proceeds, conditional acceptance becomes less and less likely. Unlike linearized iterative inversions, simulated annealing optimization will find the global velocity solution while avoiding local error minima. Also, the approach is completely insensitive to the starting velocity model, thus removing interpretational bias that may be involved in evaluating the velocity structure. 


\subsection{Kirchhoff Pre-Stack Migration}

We use velocity models obtained from the simulated annealing optimization as input for Kirchhoff pre-stack migration of the seismic data. In the pre-stack migration procedure, unsorted seismogram traces are mapped into a depth section by using the velocity model to compute the travel time from the source to the depth point and back to the receiver for each source-receiver pair. Travel times through the velocity model are calculated using a finite-difference solution to the eikonal equation (Vidale, 1988), which accounts strong lateral velocity variations. The travel-time calculation includes turning rays. The two-dimensional model used in the calculation accounts only for velocity variations in the vertical plane containing the seismic line. The same travel time computation method can be used for three-dimensional velocity models (Vidale, 1990), which account for both out-of-plane and in-plane velocity variations.

Once the travel times down to and up from every point in the data volume have been obtained, the value of the seismogram at each time increment is summed into the depth section. Coherent and continuous events for each time increment will constructively interfere. The summation of the value, or amplitude, of each seismogram at specified times will reveal seismically reflective earth structure, and can image steeply-dipping structures that cause lateral variations in velocity. The summation of arrival times may be made in any order, as the Kirchhoff summation method embraces the geometrical configuration of the source, receiver, and reflector as a function of time. Because every point in the model subsurface is assumed to be a scatterer, this procedure permits imaging structures that dip away from the seismic source and receivers, as well as structures that dip toward the source and receivers.

The Kirchhoff pre-stack migration does not require definition of ray path. The ability to calculate travel times from Vidale's (1988) method for laterally heterogeneous structures avoids the limitations of straight ray approximations. By computing travel times through a P-wave velocity model, we are assuming the coherent signal contained in the raw shot gathers are of the $\mathrm{P}$-wave mode. If mode-converted coherent signals are present in the data and need to be migrated, then travel times must be computed through an equivalent $\mathrm{S}$-wave velocity model.

\subsection{Development of 3-D Velocity Models}

We synthesized two-dimensional velocity sections to prepare block diagrams of the subsurface velocity structure in western Dixie Valley (Section 4.1), and to assess 3-D variations in velocity 
relative to geologic structures. The first step in constructing the 3-D velocity models consisted of choosing an appropriately scaled area that included all the seismic lines and wells used in the study. A local coordinate system, or frame of reference, was chosen for the model. Next, the seismic line and well coordinates were transformed to the model frame of reference. Velocities were interpolated between the lines at each depth horizon using a program written specially for this study. During the interpolation, care was taken to avoid introduction of spurious values by forcing the interpolated values to be within the range of velocities obtained by optimization along all the lines at that particular depth. Individual depth slices constructed by this approach were assembled to form the 3-D block diagrams. We emphasize that these diagrams are not mere extensions of two-dimensional models to three dimensions (i.e., a "2.5-D image"), but rather a grid of 2-D images with interpolation between them to fill the unsampled areas. Although the block diagrams differ from velocity images obtained by doing a formal 3-D seismic survey that includes crossline and inline data, the 3-D velocity images were obtained from a series of 2-D surveys laid out in a grid pattern. Smoothing was performed between the individual depth sections to ensure that the velocity field is continuous.

We used a software called SUNVISION, available at the Center for Economic Migration and Tomography (CEMAT) at the Seismological Laboratory, University of Nevada, Reno to assemble and display the 3-D images. The SUNVISION software allows color, opacity, and orientation to be adjusted to highlight any velocity features of structural/geological interest. The software also allows "slicing" the model volume in any direction to reveal the internal velocity structure. This approach differs from structural mapping using coherence continuity analysis commonly used in the oil industry because those methods rely on reflectivity data collected during a 3-D survey. In contrast, we construct a 3-D velocity model, either from a grid of 2-D surveys or a direct 3-D survey if available, and then correlate the velocity features with geologic and structural features. Performing a three-dimensional pre-stack migration through such a 3-D velocity model to image structures will be the subject of future research. 


\subsection{2-D Simulated Annealing Velocity Models}

\subsubsection{Line 5}

Seismic Line 5 is approximately $11.5 \mathrm{~km}$ long and trends east-west across the study area, oblique to the northeast-southwest strike of the Dixie Valley range-front fault and Basin-Range structure in this region (Figure 1). The velocity model obtained from the inversion (Figure 2) shows near surface-velocities of approximately 1.5 to $2.6 \mathrm{~km} / \mathrm{s}$, increasing to approximately 4.0 to $5.1 \mathrm{~km} / \mathrm{s}$ at depths ranging from approximately 0.75 to $1.0 \mathrm{~km}$. In general, the base of the low velocity upper layer deepens eastward to a maximum thickness of about $1.0 \mathrm{~km}$ at a horizontal distance of about $5.0 \mathrm{~km}$ from the west end of Line 5. There are several apparent steps in the base of the upper low velocity layer that may be the result of faulting beneath the western basin margin (Figure 2). These potentially fault-related steps may be more abrupt than they appear in the velocity model because the east-west orientation of the seismic line is oblique to northeast-southwest structural trends in Dixie Valley, and thus the apparent dip of structures crossed by the line probably is less than the true dip.

\section{$\underline{3.1 .2 \text { Line } 9}$}

Seismic Line 9 trends northwest-southeast and extends to within a few hundred meters of the Dixie Valley fault (Figure 1). The analysis and interpretation of this line are discussed in detail by G. L. Plank (M.S. thesis, in progress). For this study, 32 shot gathers from the northwestern $3 \mathrm{~km}$ of the line were reprocessed and analyzed (i.e., the part of the line closest to the Dixie Valley fault). First arrivals picked from the raw shot gathers constrain velocities to a depth of about $1.0 \mathrm{~km}$. A combined first-arrival/reflection coherency optimization (Pullammanappallil and Louie, 1997) was used to extend the depth of resolution somewhat below $1.0 \mathrm{~km}$; however, the maximum depth of velocity constraint along Line 9 is approximately $1.5 \mathrm{~km}$ due to the limited source-receiver offset of the data acquisition survey.

The velocity model obtained from the data inversion (Figure 3 ) shows a deepening of low velocity strata toward the valley, and a shallowing of high velocity rocks near the range front at the northwest end of the line. A prominent subvertical boundary located approximately $1.6 \mathrm{~km}$ southeast of the western basin margin abruptly separates relatively high velocity rocks 


\section{Sw}

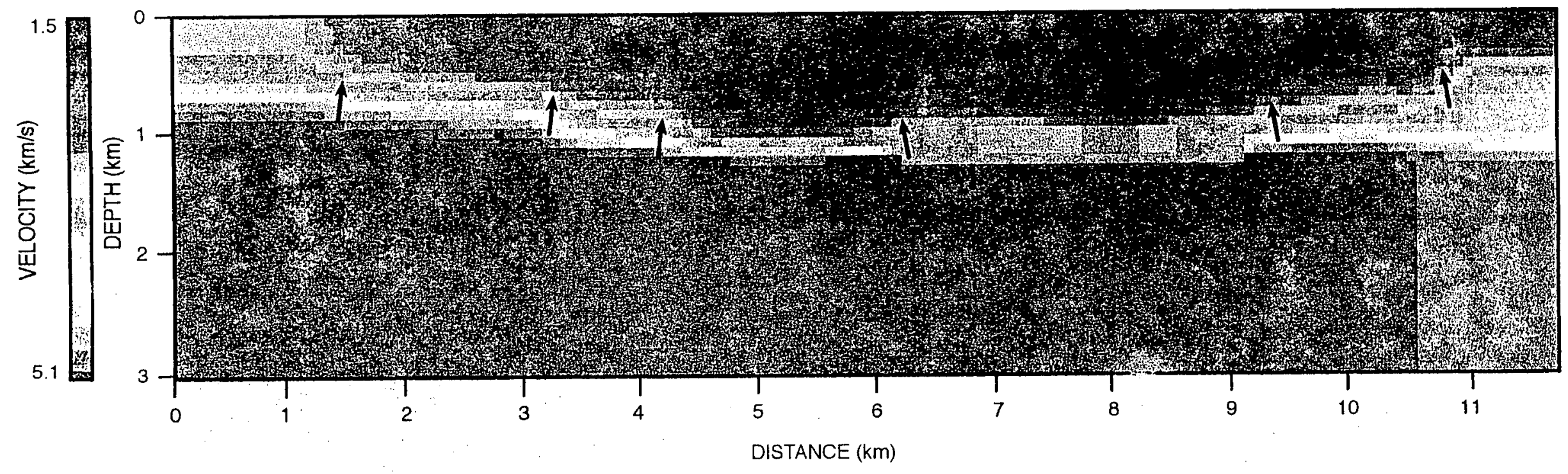

Figure 2. Velocity model from optimization, Seismic Line 5. Arrows indicate discrete stpes in base of shallow low velocity layer. 


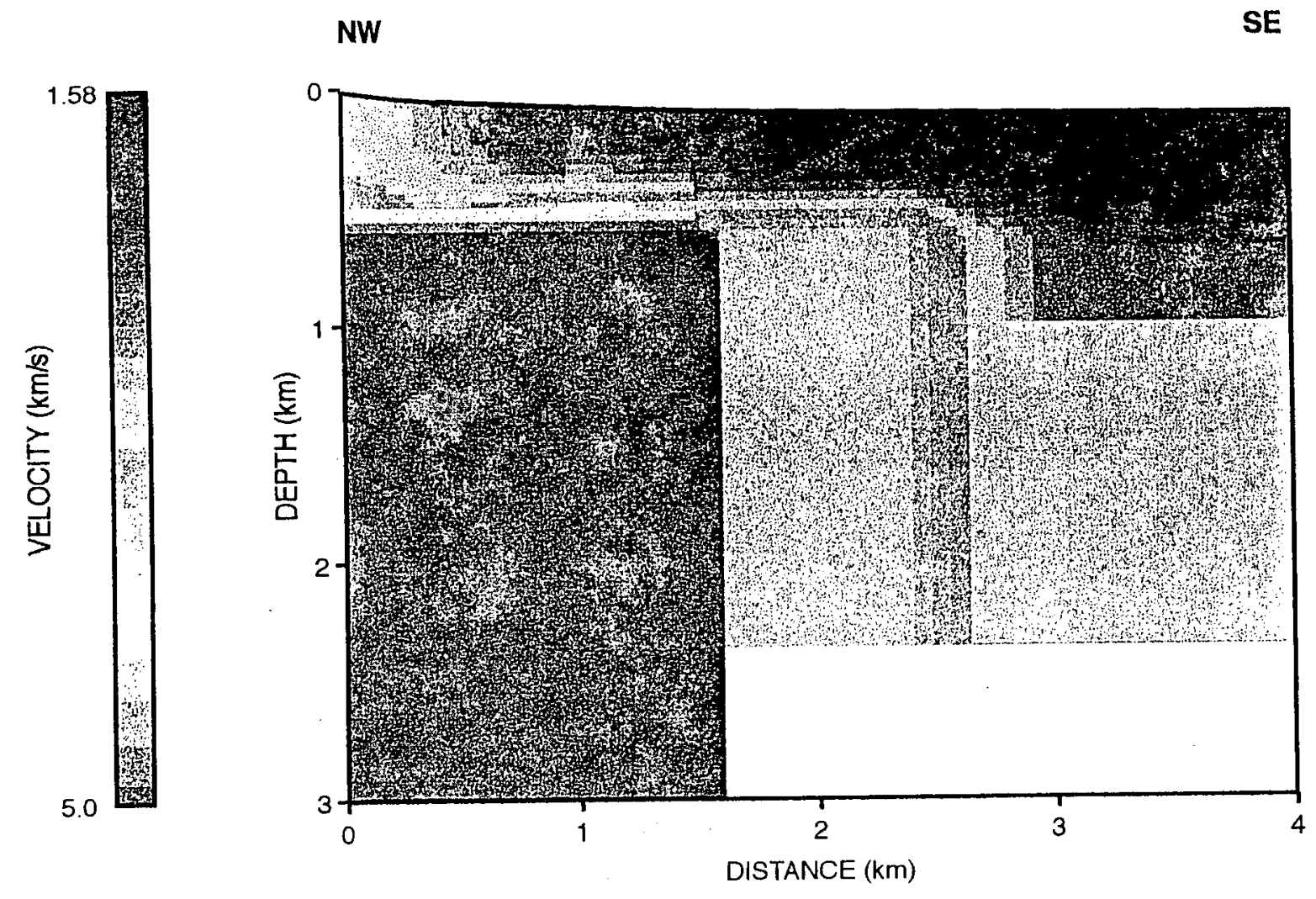

Figure 3. Velocity model from optimization, Seismic Line 9. 
(approximately $5.0 \mathrm{~km} / \mathrm{s}$ ) on the northwest from lower velocity rocks (approximately 3.5-4.0 $\mathrm{km} / \mathrm{s}$ ) on the southeast. The boundary can be traced to the upper $0.5 \mathrm{~km}$ of the model. We interpret that this steep velocity boundary corresponds to the contact between crystalline basement rocks and basin fill of the Dixie Valley graben. At shallower depths, a low velocity layer (approximately $1.6-2.0 \mathrm{~km} / \mathrm{s}$ ) that we associate with late Cenozoic basin fill strata steps abruptly down to the southeast approximately $2.6 \mathrm{~km}$ east of the west end of the line, possibly indicating the presence of a fault.

\subsubsection{Line 10}

Seismic Line 10 trends northwest-southeast and extends to within a few hundred meters of the Dixie Valley fault (Figure 1). For this study, we reprocessed and analyzed 15 shot gathers from the northwestern $4 \mathrm{~km}$ of the line (i.e., the part of the line closest to the Dixie Valley fault). The elevation varies from about 3600 feet at the west end of the line to about 3420 feet at the east end of the line. The top of the velocity model corresponds to the maximum elevation of 3600 feet.

The velocity model obtained from the inversion (Figure 4) indicates that the upper several hundred meters along the section line is composed of relatively low velocity basin sediments (i.e., approximately 1.6 to $2.0 \mathrm{~km} / \mathrm{s}$ ). The base of the shallow low velocity sediments deepens toward the basin to a maximum thickness of about $500 \mathrm{~m}$. Other distinct subhorizontal velocity layers are present between 500 and $640 \mathrm{~m}$ depth (average velocity of $2.3 \mathrm{~km} / \mathrm{s}$ ); between 640 and $730 \mathrm{~m}$ depth (average velocity of $2.6 \mathrm{~km} / \mathrm{s}$ ); and between $730 \mathrm{~m}$ and $1 \mathrm{~km}$ depth (average velocity of 3.1 $\mathrm{km} / \mathrm{s}$ ). We note that velocities are well constrained by first-arrival and coherency optimization to a maximum depth of $1.5 \mathrm{~km}$. The velocity model (Figure 4) was extended down to below this depth to a total of about $3 \mathrm{~km}$ using independent sonic log and geologic information (proprietary data provided by Oxbow Geothermal).

The subhorizontal boundary at the base of the upper low velocity layer is abruptly truncated at a horizontal offset distance of approximately $1.4 \mathrm{~km}$ by a subvertical feature that juxtaposes higher velocity rocks on the northwest (about $5 \mathrm{~km} / \mathrm{s}$ ) with lower velocity rocks to the southeast (about $3.0 \mathrm{~km} / \mathrm{s}$ ). The base of the low velocity rocks appears to be displaced down to the southeast across the vertical velocity boundary. Another subvertical velocity boundary, or a distinct horizontal velocity gradient, is suggested by the velocity model at a horizontal distance of about $2.5-3.0 \mathrm{~km}$, and at a depth of about $700 \mathrm{~m}$ to $1000 \mathrm{~m}$. 


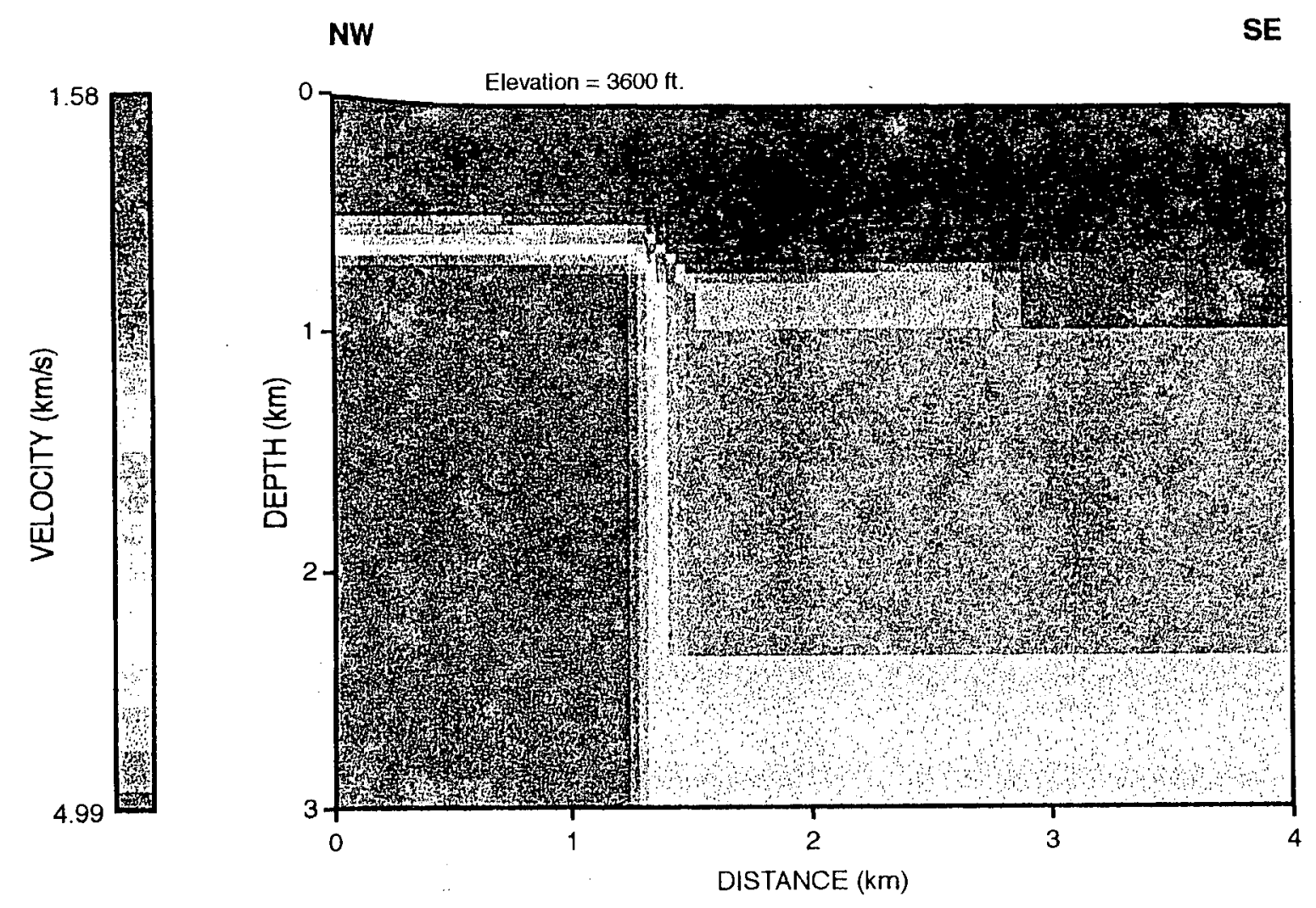

Figure 4. Velocity model from optimization, Seismic Line 10. 


\subsubsection{Line 101}

Seismic Line 101 is approximately $15 \mathrm{~km}$ long and trends northeast-southwest across the western margin of Dixie Valley basin (Figure 1), approximately parallel to and $3 \mathrm{~km}$ southeast the range front fault. From south to north, Line 101 crosses seismic Lines 10, 105, SRC1S, 9, SRC1N, 5 , 103 and SRC3.

The velocity model obtained from inversion of the data (Figure 5) shows a relatively sharp, nearly horizontal boundary between a layer of low velocity rocks (approximately 1.5 to $2.7 \mathrm{~km} / \mathrm{s}$ ) in the upper $0.5-0.75 \mathrm{~km}$ of the crust, and a layer of higher velocity rocks (approximately 4.5 to 5.1 $\mathrm{km} / \mathrm{s}$ ) extending to the maximum depth of the model. The depth range between $0.75 \mathrm{~km}$ and about $1.5 \mathrm{~km}$ appears to be a transitional zone marked by lateral variations in velocity. The higher velocity rocks at depth also appear to be juxtaposed against lower velocity rocks across a vertical boundary located at a distance of about $13.3 \mathrm{~km}$ from the northeast end of the line.

\subsubsection{Line 103}

Seismic Line 103 is approximately $3.6 \mathrm{~km}$ long, trends northwest-southeast, and extends to within a few hundred meters of the Dixie Valley fault (Figure 1).

The velocity model obtained from the inversion (Figure 6) reveals a subhorizontal boundary at about $500 \mathrm{~m}$ depth that separates shallow low velocity strata from significantly higher velocity strata (i.e., about $5 \mathrm{~km} / \mathrm{s}$ ) below. This horizontal boundary appears to step down to the southeast across a subvertical velocity boundary located about $3 \mathrm{~km}$ southeast of the basin margin. The subvertical boundary also juxtaposes higher velocity rocks (about $5 \mathrm{~km} / \mathrm{s}$ ) on the northwest with lower velocity rocks (about $3.3-3.5 \mathrm{~km} / \mathrm{s}$ ) on southeast in the 0.5 to $2.5 \mathrm{~km}$ depth range.

\subsubsection{Line 105}

Seismic Line 105 is about $4 \mathrm{~km}$ long and trends northwest-southeast, parallel and directly adjacent to Line 10 (Figure 1). The northwest end of Line 105 starts about $680 \mathrm{~m}$ from the west end of Line 10 and comprises 44 shot gathers with maximum source-receiver offset of $1.5 \mathrm{~km}$ (48 channel survey). Given this source-receiver geometry, the maximum depth to which velocities are constrained is about $700 \mathrm{~m}$. Elevation along the line varies between 3394 feet and 3408 feet. The top of the velocity model (Figure 7) corresponds to an elevation of 3408 feet. 


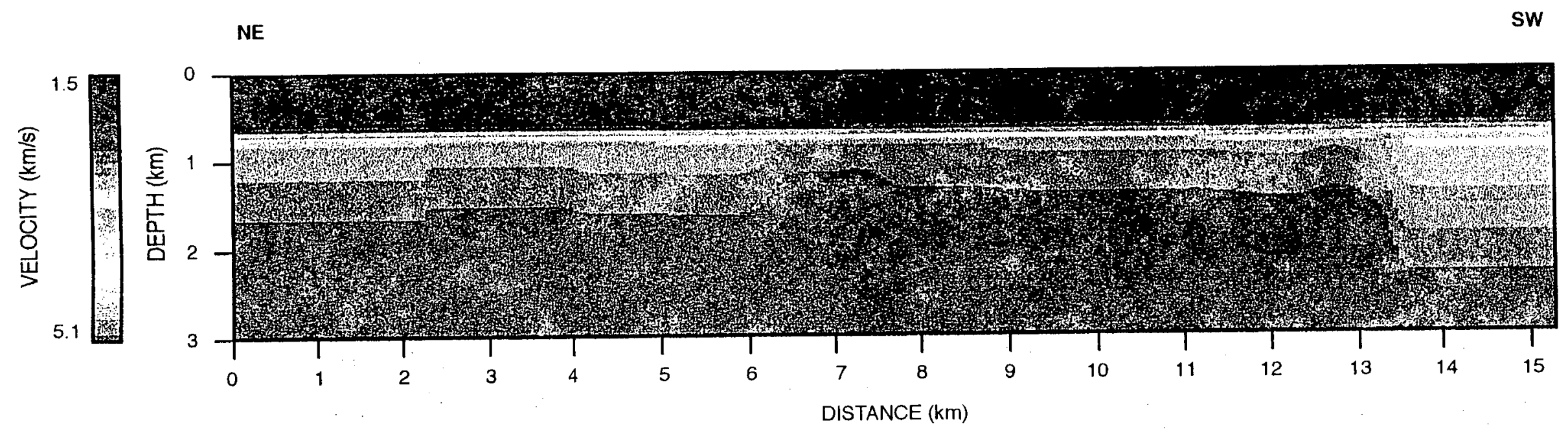

Figure 5. Velocity model from optimization, Seismic Line 101. 


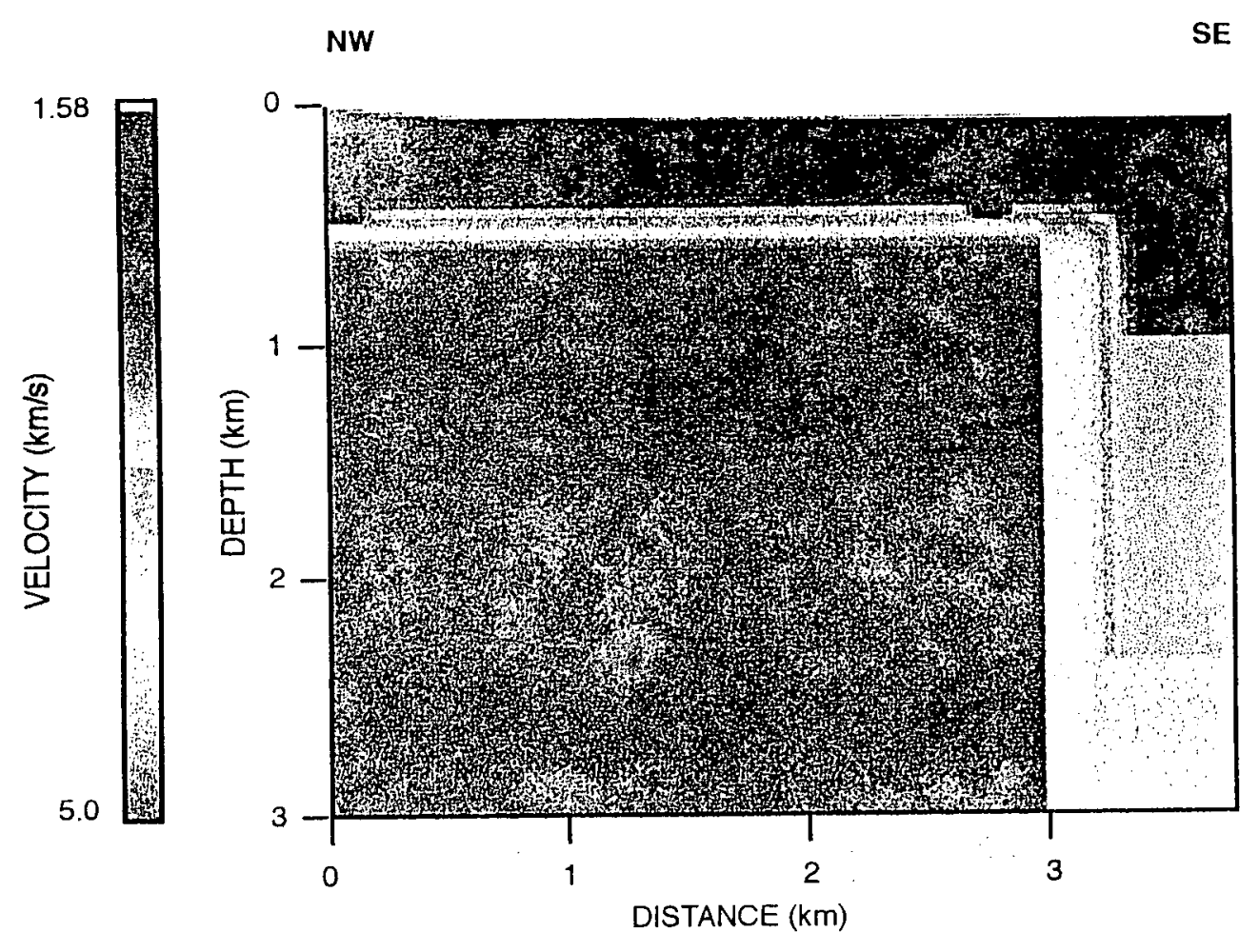

Figure 6. Velocity model from optimization, Seismic Line 103. 


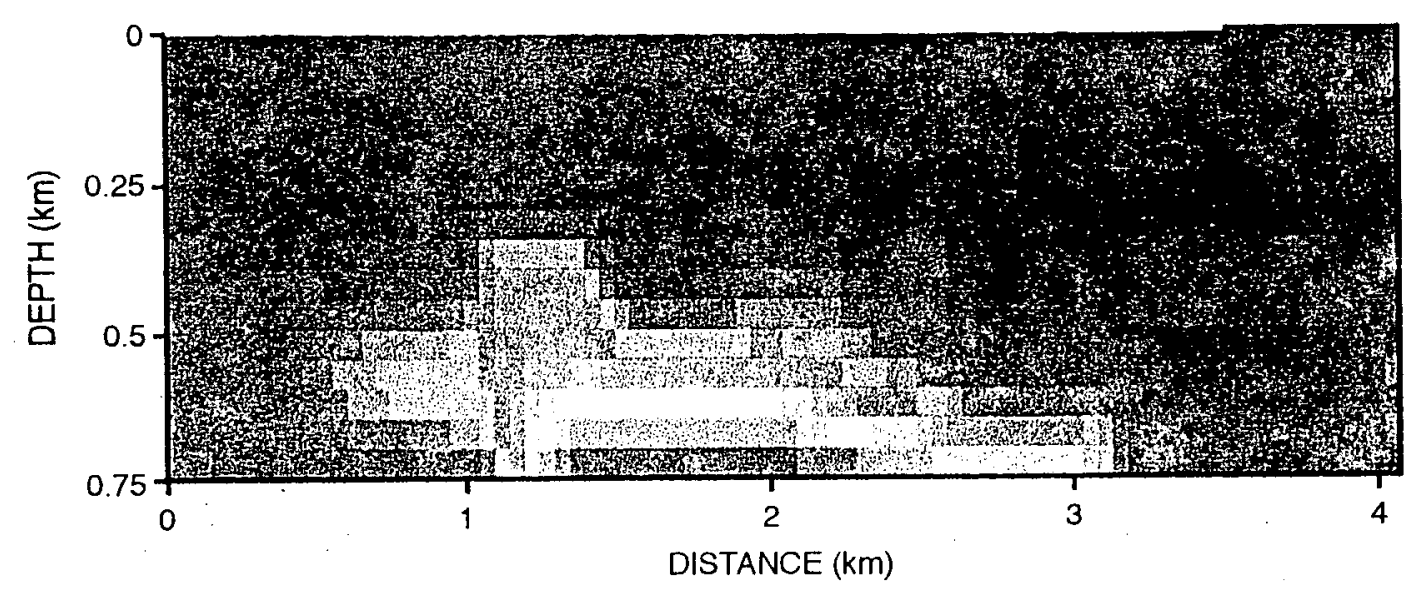

1.5 4.95

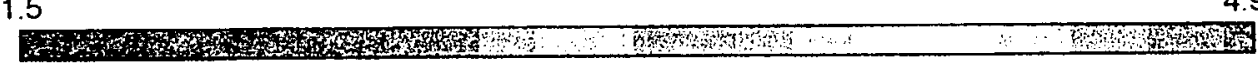

VELOCITY $(\mathrm{km} / \mathrm{s})$

Figure 7. Velocity model from optimization, Seismic Line 105. 
Velocities obtained from first-arrival optimization along Line 105 are shown in Figure 7. The high velocity layer ( $\sim 5 \mathrm{~km} / \mathrm{s}$ ) that was imaged along Line 10 (Figure 4) is present at a depth of $630 \mathrm{~m}$ in Line 105, which is just above the depth of maximum velocity constraint for this line. Given the probable geometry of ray paths, the areas lying within $300 \mathrm{~m}$ of the northwestern and southeastern edges of the model are not well determined, which probably explains why the top of the high velocity layer is not continuous along the entire length of the model (Figure 7).

Due to the availability of more data (44 gathers for Line 105 compared to 15 gathers for Line 10 ), the shallow velocity structure for Line 105 (Figure 7) is better resolved than in Line 10 (Figure 4). This is evident when comparing the geometry of the low velocity sediments $(1.5-2.0 \mathrm{~km} / \mathrm{s})$ as expressed in the velocity models for the two lines. In Line 105, these sediments are about $262 \mathrm{~m}$ thick on an average and appear to form a modest trough ( $400 \mathrm{~m}$ deep) at a distance of $1.67 \mathrm{~km}$ from the west end of the line. Such details are lost when fewer seismic data and thus less ray sampling is available as in the case of Line 10.

\section{$\underline{3.1 .7 \text { Line SRC1S }}$}

Line SRC1S is approximately $10 \mathrm{~km}$ long and has a curving geometry (Figure 1). To simplify analysis and processing of the data, we divided SRC1S into two parts: (1) SRC1S-A, which is 5.7 $\mathrm{km}$ long, includes 84 shot gathers, and trends northeast-southwest parallel to the range front; and (2) SRC1S-B, which is $4.3 \mathrm{~km}$ long, trends east-west and includes 67 shot gathers (Figure 8). The boundary between these two parts corresponds with the abrupt change in trend of Line SRC1S. The crooked line geometry of the east-west-trending SRC1S-B required that the seismic images be projected along a straight line (Figure 8), but our projection preserved the relative source-receiver offset of the original survey (Pullammanappallil and Louie, 1994). The optimization accounts for topographic variations along the length of the line, and the top of the velocity model corresponds to the maximum elevation along the profile (i.e., 3445 feet).

The velocity models obtained from optimization of first-arrival travel times along SRC1S-A and SRC1S-B are shown in Figures 9 and 10, respectively. The limited source-receiver offsets of the data acquisition do not allow the first arrival ray paths to penetrate very deeply, and thus the maximum depth of well-resolved velocities in these images is about $1.0 \mathrm{~km}$ (the models have been extended to $3 \mathrm{~km}$ depth by simply projecting velocities at $1.0 \mathrm{~km}$ depth vertically downward). The low velocity sediments $(<1.5 \mathrm{~km} / \mathrm{s})$ extend to depths of $100-200 \mathrm{~m}$, and high velocity rocks that we correlate with the crystalline basement rocks $(5.1 \mathrm{~km} / \mathrm{s})$ are at a depth of about $900 \mathrm{~m}$. The subhorizontal velocity boundary that we associate with the top of the high velocity rocks is present 


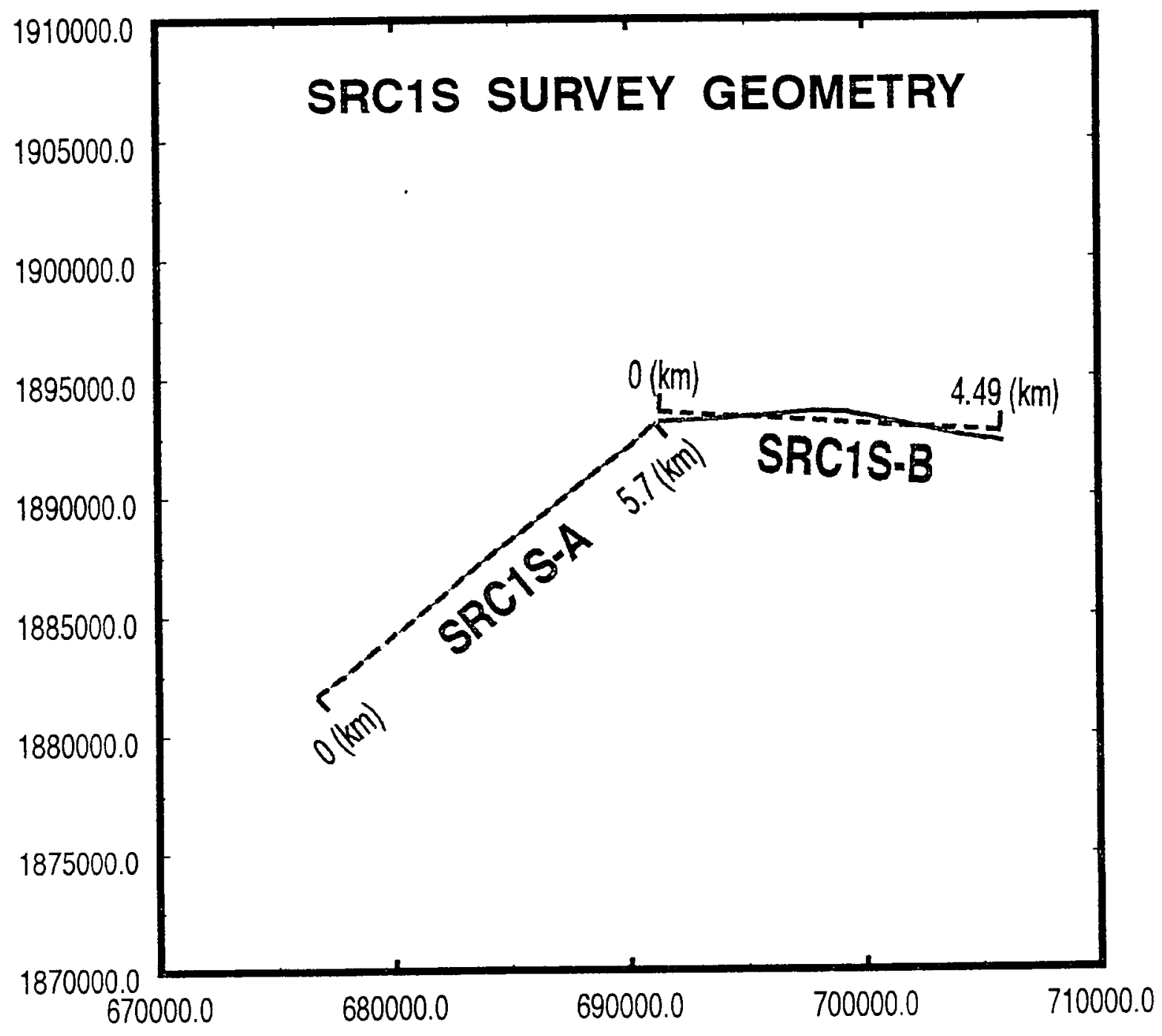

Figure 8. Survey geometry for Seismic Line SRC1S. 


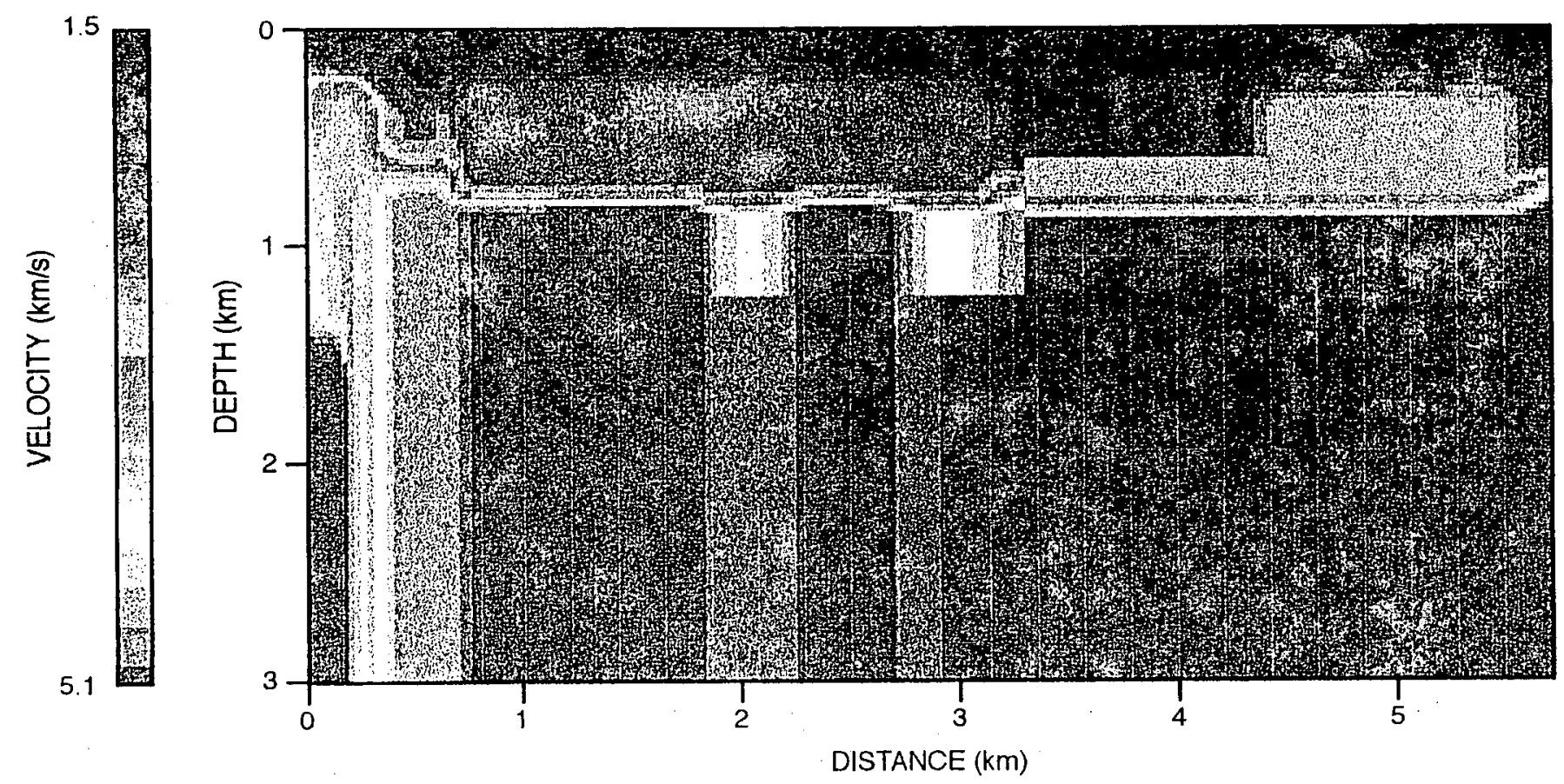

Figure 9. Velocity model from optimization, Seismic Line SRC1S-A. 


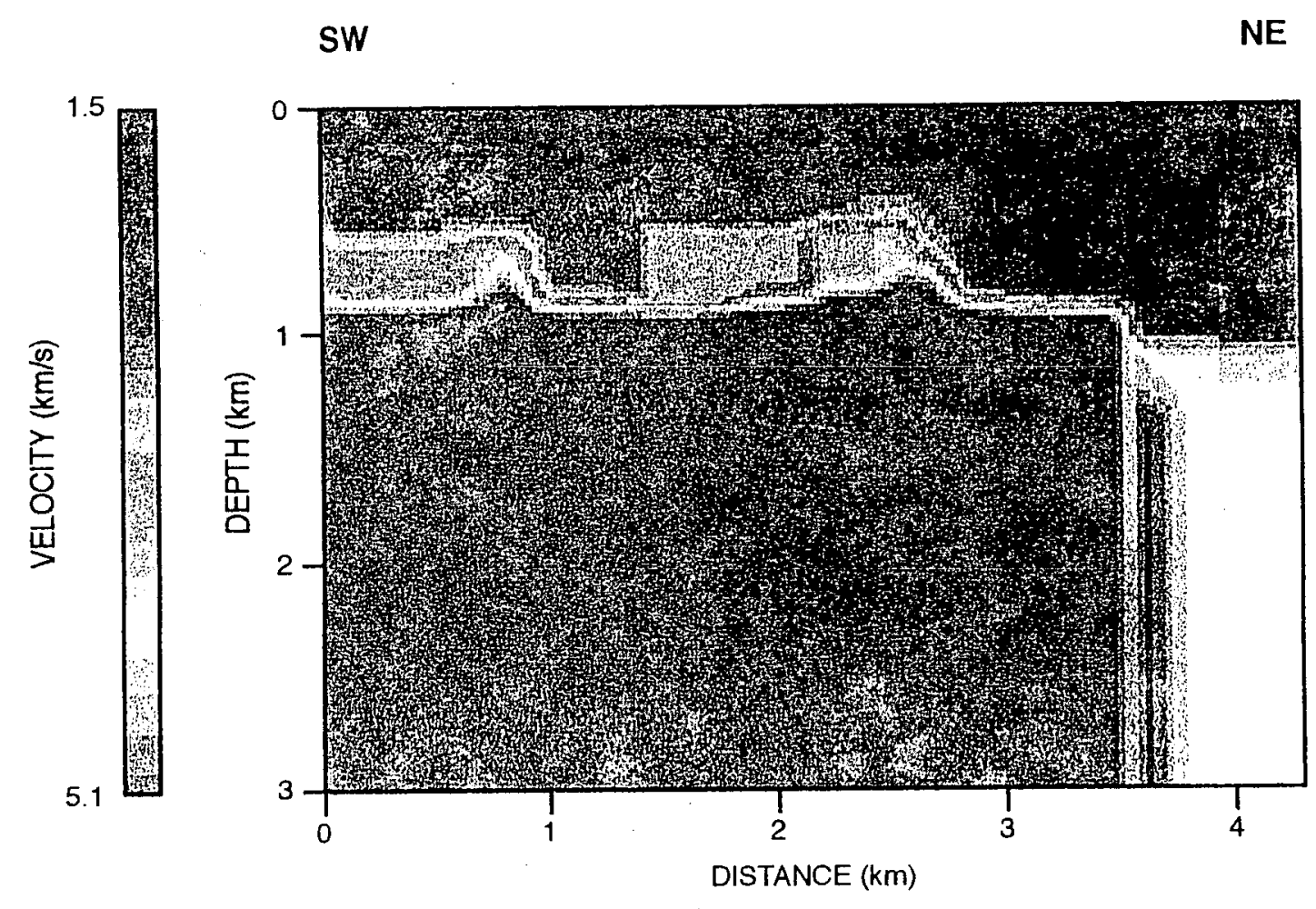

Figure 10. Velocity model from optimization, Seismic Line SRC1S-B. 
along most of the profile, except the region near the end of SRCIS-B (Figure 10) where the velocity decreases to about $4.6 \mathrm{~km} / \mathrm{s}$ at a depth of $1 \mathrm{~km}$. Again, we emphasize that this is near the lower depth limit of the well-constrained velocities.

The velocity models show that lateral velocity variations are most strongly expressed on Line SRCIS-B. For example, there is a limited region in the upper $700 \mathrm{~m}$ of Line SRC1S-B at horizontal offset distance $1.0 \mathrm{~km}$ where lower velocity rocks (about $2.7 \mathrm{~km} / \mathrm{s}$ ) are bounded on both sides by higher velocity strata (about $3.75 \mathrm{~km} / \mathrm{s}$ ). Another significant horizontal variation in velocity can be observed at offset distance $2.9 \mathrm{~km}$, where the velocity abruptly decreases from 2.7 $\mathrm{km} / \mathrm{s}$ to $2.0 \mathrm{~km} / \mathrm{s}$ (Figure 10 ). In contrast, the velocity along SRC1S-A exhibits a relatively simple layered structure, with minimum lateral velocity variations (Figure 9). We attribute the difference in velocity structure along the entire length of Line SRC1S to the fact that one reach of the seismic line is parallel to the range front and the other is oblique to the range front. Given the tectonic setting of Dixie Valley we assume that the most significant horizontal velocity gradients most likely will be normal to the range front. Line SRC1S-B, which is at an angle to the range front, exhibits more lateral variation in velocity than the range-parallel SRC1S-A, consistent with our expectations.

\subsubsection{Line SRC1N}

Line SRC1N is about $9.25 \mathrm{~km}$ long and has a curving geometry. Similar to the approach used to process and analyze line SRC1S (Section 3.1.7), we divided SRC1N into two segments: (1)

SRC1N-A, which is $3.03 \mathrm{~km}$ long, trends north-south and includes data from 43 shot gathers; and (2) SRC1N-B, which trends southwest-northeast, is $6.25 \mathrm{~km}$ long and includes 95 shot gathers (Figure 11). Elevation along SRC1N varies from 3420 to 3465 feet. The top of the velocity model and prestack migration images correspond to the maximum elevation (i.e., 3465 feet). Ray coverage dictated by the source-receiver geometry limits good velocity resolution to the upper $1.2 \mathrm{~km}$.

Figures 12 and 13 show velocity models obtained from first-arrival optimizations along SRC1NA and SRC1N-B, respectively. Line SRC1N-A (Figure 12) generally shows low velocity basin sediments $(1.5 \mathrm{~km} / \mathrm{s})$ extending to a depth of about $200 \mathrm{~m}$, except at a distance of about $1.3 \mathrm{~km}$ from the south end where the low velocity strata $(2 \mathrm{~km} / \mathrm{s})$ extend as deep as $1.0-1.3 \mathrm{~km}$. The velocities towards the north end of the line generally are lower $(<2.5 \mathrm{~km} / \mathrm{s})$ than velocities on the south end $(3 \mathrm{~km} / \mathrm{s})$. A low velocity "trough" or depression seems to divide these zones of differing velocities. The low velocity zone is spatially associated with several production wells (76-7, 74-7, 


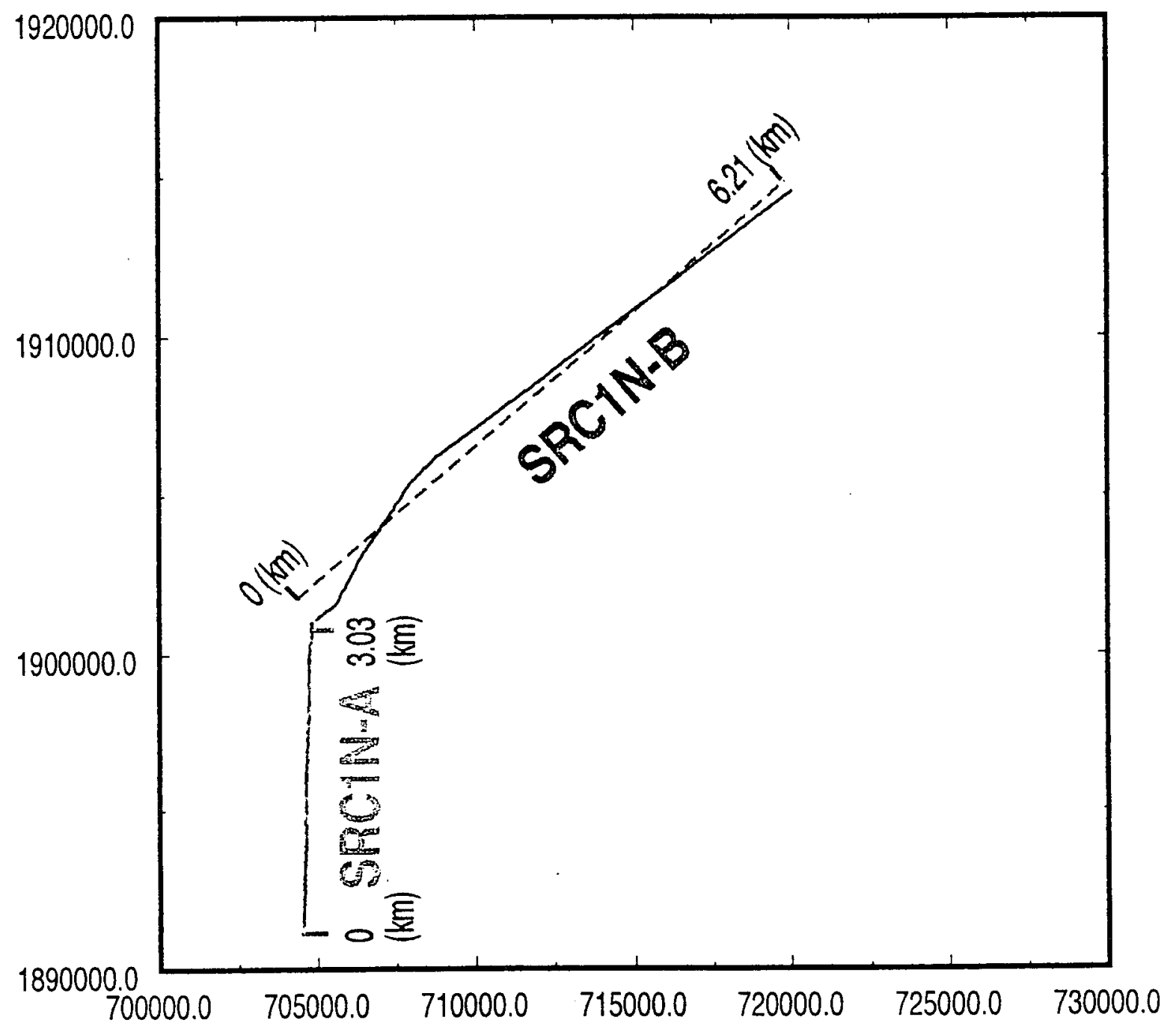

Figure 11. Survey geometry for Seismic Line SRC1N. 


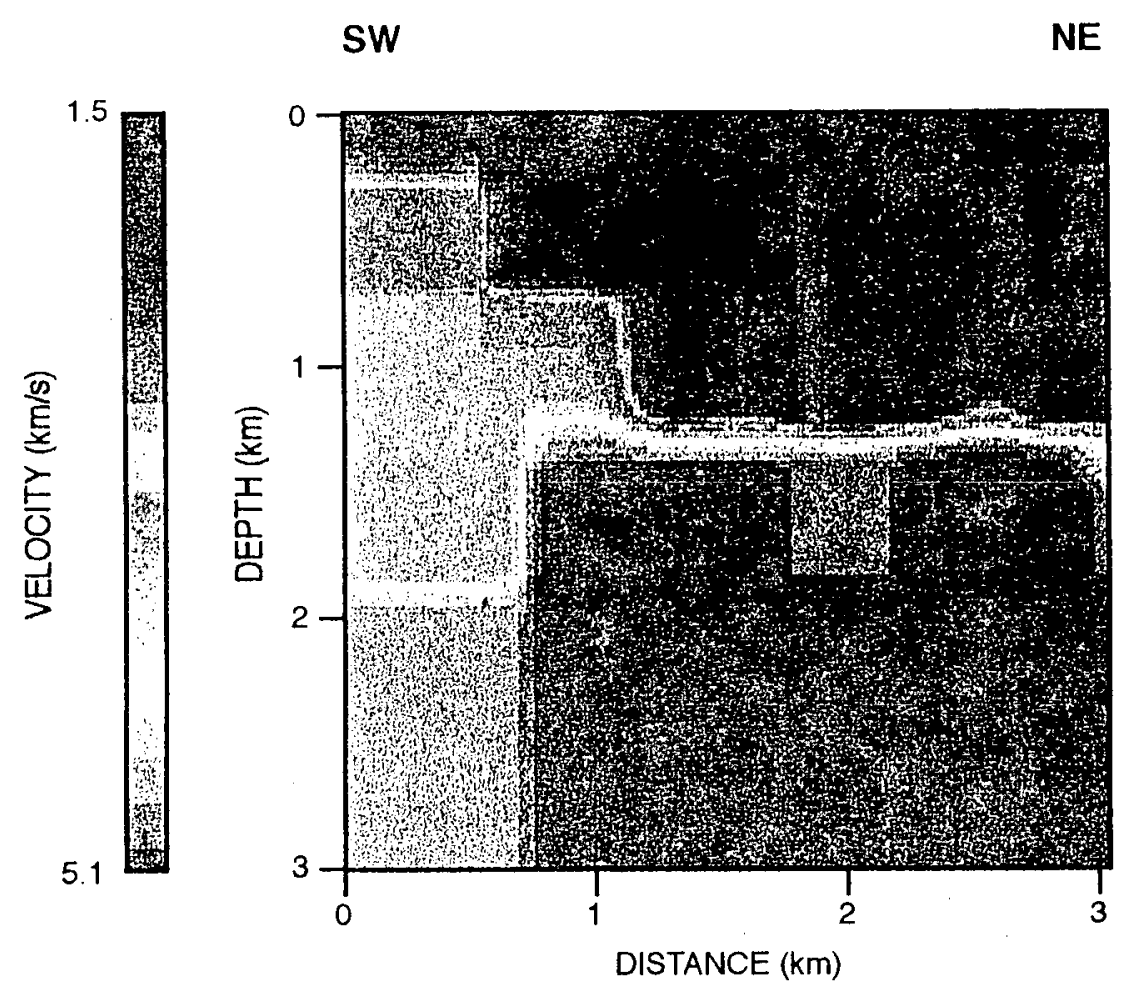

Figure 12. Velocity model from optimization, Seismic Line SRCIN-A. 


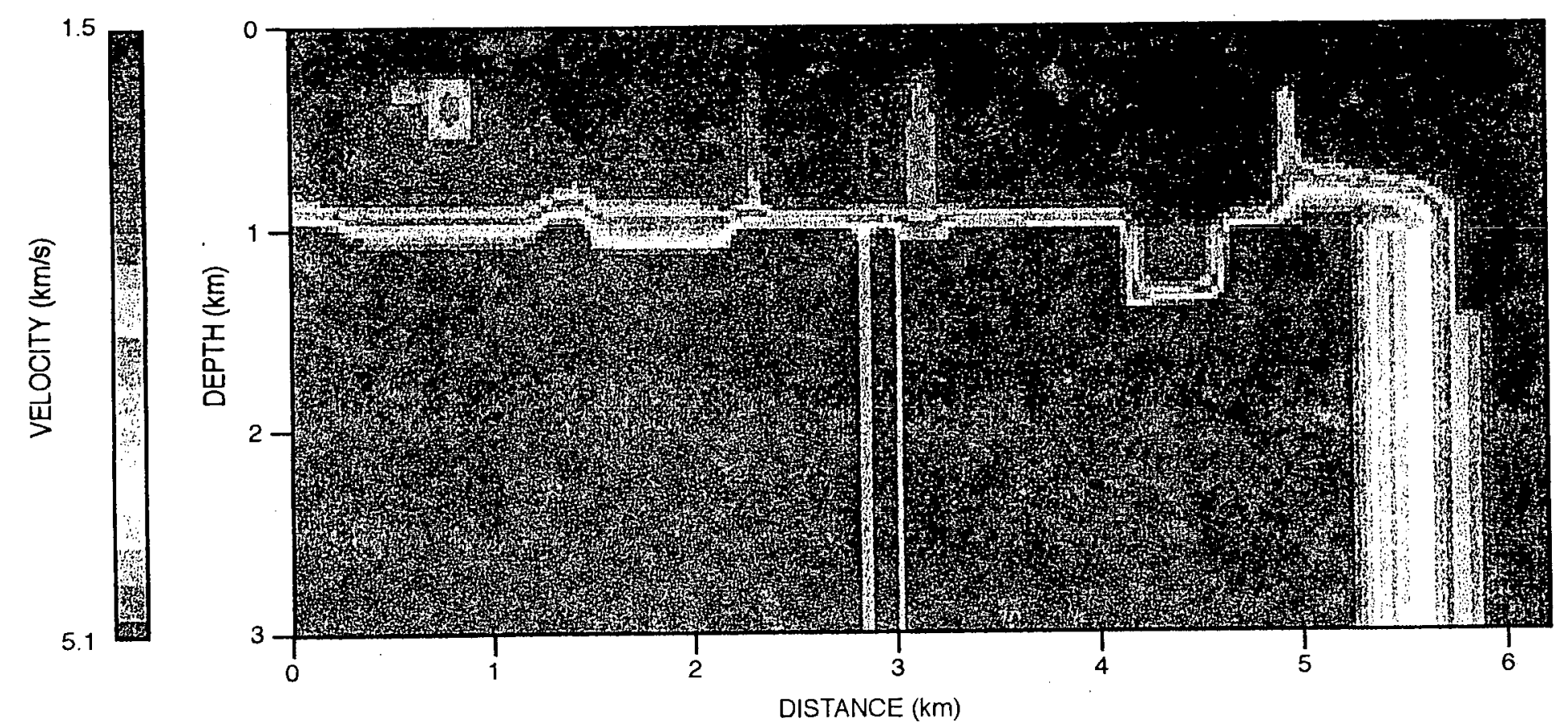

Figure 13. Velocity model from optimization, Seismic Line SRC1N-B. 
84-7 and 82-7; Figure 12), which may suggest that acoustic velocities are inversely correlated with permeability.

The model for Line SRC1N-A also shows a zone with an average velocity of about $5.1 \mathrm{~km} / \mathrm{s}$ present at a depth of $1.3 \mathrm{~km}$. This zone can be traced along the length of the profile to the southern end, where the zone probably is not imaged due to insufficient ray coverage. A comparison of the velocity models for both SRC1N-B (Figure 13) and SRC1N-A shows that high velocity rocks or sediments $(5.1 \mathrm{~km} / \mathrm{s})$ typically occur at a shallower depth $(1.0 \mathrm{~km})$ along SRC1N-B than SRC1NA. If it is assumed that these velocities are associated with crystalline basement rocks, then the relations visible in the models indicate that the depth to basement increases moving southeast of the range front, consistent with previous models of subsurface structure in this region (Okaya and Thompson, 1985). The abrupt change in depth of the $5.1 \mathrm{~km} / \mathrm{s}$ layer visible in SRC1N-A may indicate the presence of a fault that cannot be clearly imaged because it falls at the intersection of the two segments. The apparent abrupt termination of the high velocity layer $(5.1 \mathrm{~km} / \mathrm{s})$ about 800 $\mathrm{m}$ from the northeastern edge of the velocity model (Figure 13) probably is due to poor ray coverage.

The velocity model along segment SRC1N-B suggests that the base of the low velocity sediments $(1.5-2.0 \mathrm{~km} / \mathrm{s})$ may be irregular or have an undulating structure. These changes in the depth to the base of the low velocity zone are spatially associated with producing wells $82-5$ and 45-33, which are offset about $300-400 \mathrm{~m}$ from the line. The southwest end of the line is close to well $82-7$ and is associated with a deepening of low velocities in the model.

\subsubsection{Line SRC3}

Seismic Line SRC3 is approximately $6 \mathrm{~km}$ long, trends NW-SE, and extends to within a few hundred meters of the surface trace of the Dixie Valley range-front fault. This line previously was processed by Okaya and Thompson (1985), who used conventional techniques to stack and migrate the seismic data.

The velocity model obtained from the inversion (Figure 14) shows near-surface velocities of approximately $1.5-2.6 \mathrm{~km} / \mathrm{s}$, increasing to approximately $4.0 \mathrm{~km} / \mathrm{s}$ at depths of approximately 2.0 $\mathrm{km}$. The model generally shows relatively high velocity rocks (approximately $5.0 \mathrm{~km} / \mathrm{s}$ ) at depths of $1.0 \mathrm{~km}$ or greater beneath the western end of the basin juxtaposed against lower velocity rocks (approximately $4.0 \mathrm{~km} / \mathrm{s}$ ) along steeply dipping to subvertical boundaries. The step-like geometry of the boundary or boundaries between the rocks of different velocities may be an artifact of the 


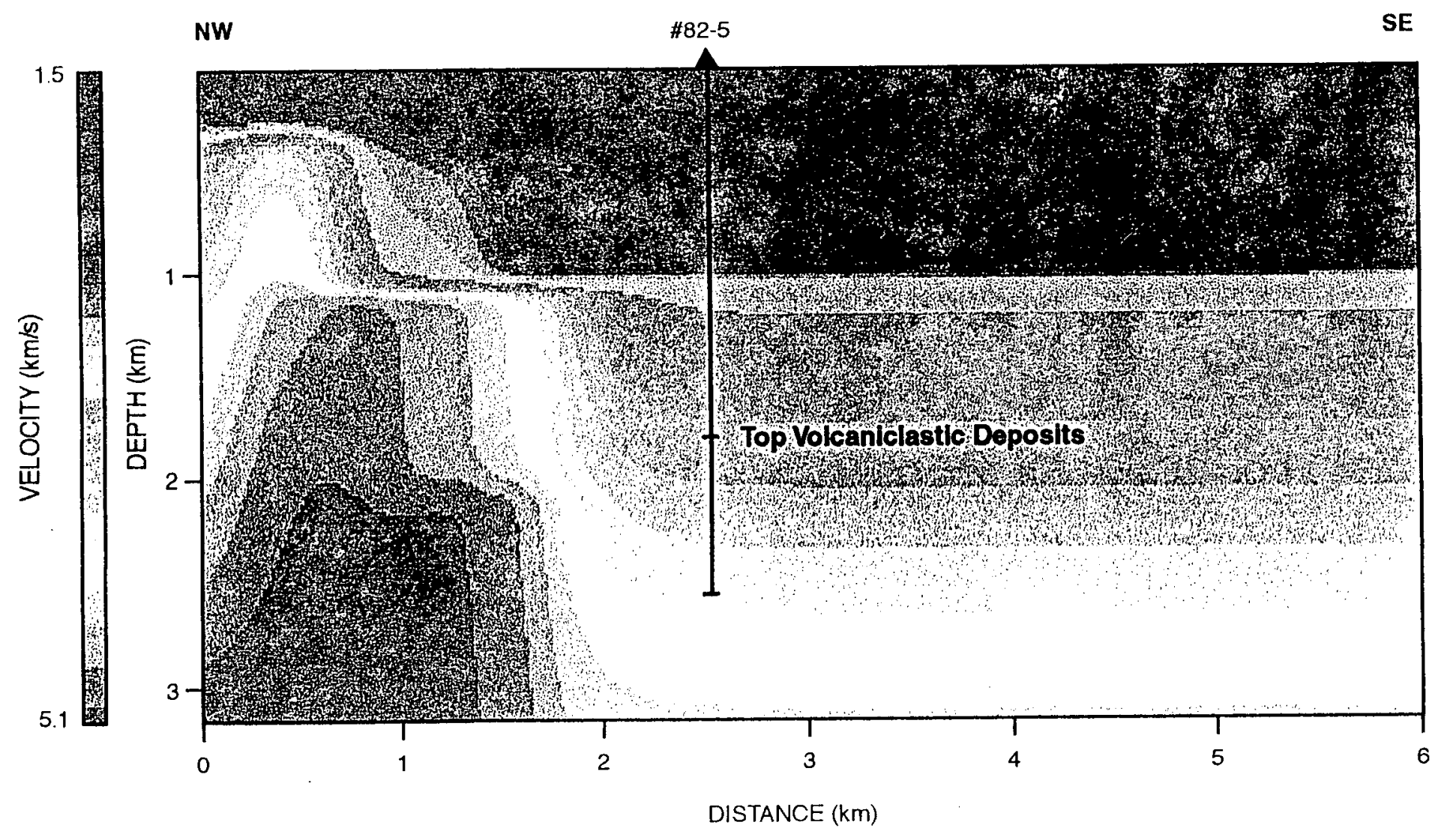

Figure 14. Velocity model from optimization, Seismic Line SRC3. 
inversion algorithm, but the model strongly indicates the presence of a strong lateral velocity contrast near the boundary between the basin and the uplifted Stillwater range. As indicated by the projection of well $82-5$ on the velocity model (Figure 14), the top of the Tertiary volcanic rocks is not associated with a strong vertical velocity contrast, although there is a modest vertical gradient in velocity near the depth the volcanic rocks were encountered by the well.

\subsection{2-D Kirchhoff Pre-Stack Migration Images}

\subsubsection{Line 5}

The pre-stack Kirchhoff migration image of Seismic Line 5 reveals well-defined, laterallycontinuous, coherent layered reflectors in the upper 0.5 to $1.0 \mathrm{~km}$ that we correlate with the late Cenozoic fill of the Dixie Valley graben (Figure 15). The layered basin sediments are clearly visible to about $1.0 \mathrm{~km}$ depth in the central and eastern parts of profile, and probably extend to at least $2.0 \mathrm{~km}$ depth in the central part of the profile based on patterns of west-dipping reflectors in the lower part of the image at horizontal offset distances of $4 \mathrm{~km}$ and $6 \mathrm{~km}$ (Figure 15). The southwestern $3.5 \mathrm{~km}$ of the image is relatively devoid of layered reflectors below a depth of approximately 1.25 to $1.5 \mathrm{~km}$.

The layered reflectors that we associate with late Cenozoic basin deposits can be confidently traced from the southeast to within about $3.3 \mathrm{~km}$ of the northwest end of the seismic line. At this point the reflectors appear to be abruptly terminated against a steeply east-dipping feature located in the depth range of approximately 0.5 to $1.5 \mathrm{~km}$. We interpret this feature to be an east-dipping fault with east-side down separation (Figure 16). The fault appears to be relatively steep in the migrated depth section; given the obliquity of Seismic Line 5 to regional structural trends, it is likely that the true dip of this fault is greater than it appears in the seismic line. The fault is associated with a small asymmetric syncline in the hanging wall. Layered reflectors east of the fault thicken abruptly and diverge in dip down-section within the syncline, consistent with syntectonic sedimentation. Also, there appears to be reduced continuity and minor loss of coherency of the layered reflectors in the hanging wall of the fault. We tentatively attribute this to minor tectonic disruption of the strata, and/or slip on one or more of the less well-defined east-dipping features that lie east of the interpreted fault.

Other east- or northeast-dipping faults probably are present southwest of the well-imaged fault and associated syncline (Figure 16). The faults are interpreted based on a series of discrete, down-tothe-northeast steps in the base of a shallow layer in the upper $0.5 \mathrm{~km}$ that has a distinctive 


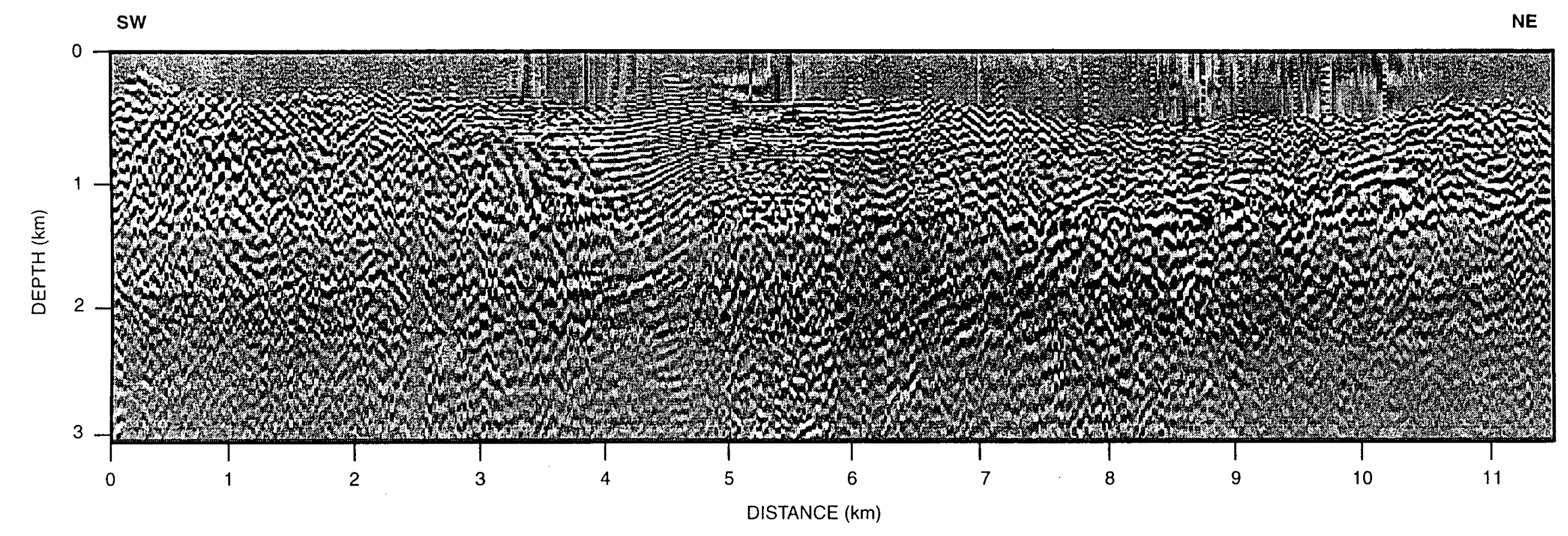

Figure 15. Prestack Kirchhoff migration, Seismic Line 5. 


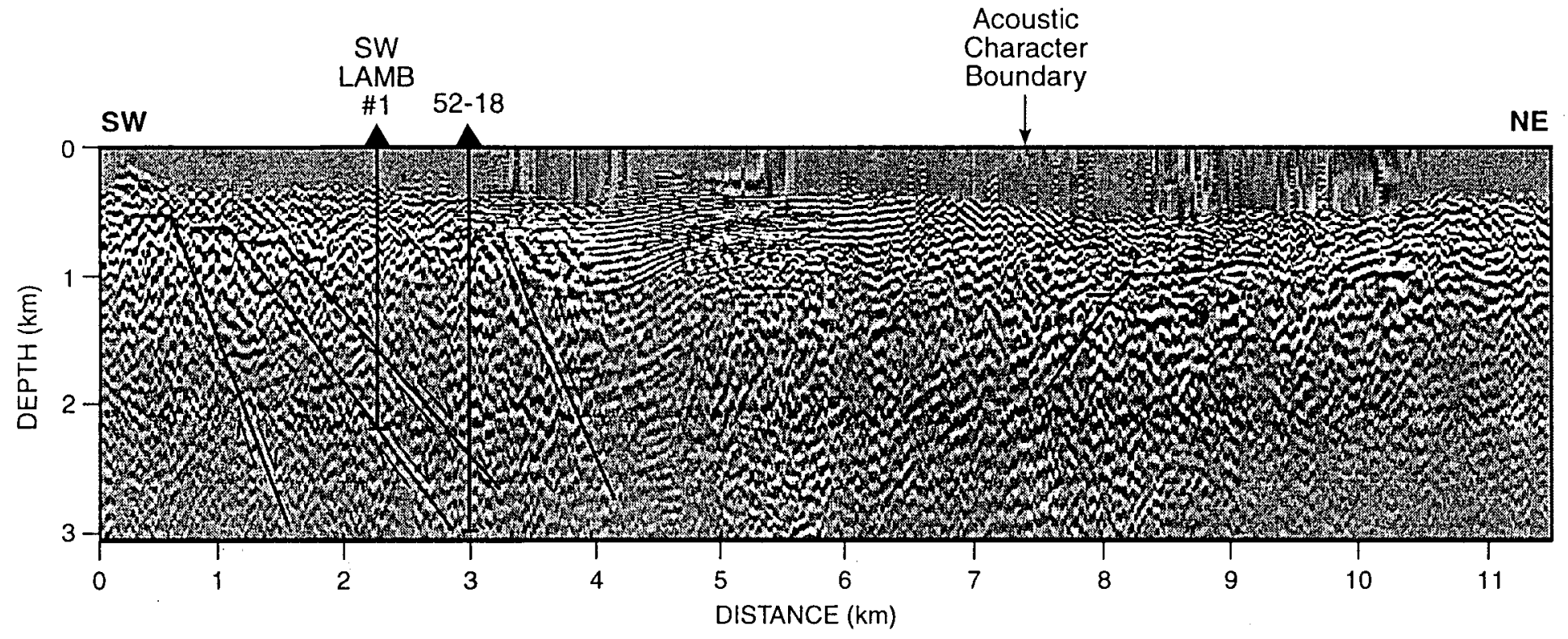

Figure 16. Interpreted prestack Kirchhoff migration, Seismic Line 5. 
"granular" character in the image, and which may reflect the presence of coarser alluvial fan sediments deposited along the western margin of the basin. These interpreted faults also are consistent with possible truncations of faint layered reflectors between 1.0 and $2.0 \mathrm{~km}$ depth (Figure 16). When projected down dip to intersect the SW Lamb \#1 well and Well 52-18, the faults intersect strata that are noted on lithologic logs to be cut or disrupted by faulting (proprietary data owned by Oxbow Geothermal, Inc.). The interpretation of the faults in the migrated images thus is consistent with lithologic drill hole data.

We also interpret the presence of a possible southwest-dipping fault at a distance of about $8 \mathrm{~km}$ from the southwest end of Line 5 based on an apparent down-on-the-west displacement of reflectors in the upper $1.0 \mathrm{~km}$, and on a change in the acoustic character of the basin fill strata (Figure 16). There are no well log data available to support or constrain this interpretation, and the nature of the acoustic character boundary at present is unknown.

\subsubsection{Line 9}

The pre-stack migration image of Line 9 (Figure 17) lacks well-defined reflective layers or other structures that can be reliably interpreted in terms of depositional or tectonic processes. Faint horizontal layering within the shallow sediments can be discerned, but reflectors become incoherent at depths of $700 \mathrm{~m}$ or greater. The poor quality of image directly reflects the poor quality of the raw shot gathers. Note that even though the reflectivity data are poor, the processing techniques used in this study still are capable of generating a relatively detailed and informative 2D velocity model (Figure 3 ) because the simulated annealing optimization relies primarily on firstarrival travel times, which are almost always easy to pick even from noisy data.

\subsubsection{Line 10}

The pre-stack migration image (Figure 18) of Line 10 shows that low velocity strata in the upper $500 \mathrm{~m}$ of the profile are layered sediments of the western Dixie Valley basin (see discussion of velocity model in Section 3.1.3). In the southeastern half of the profile, laterally continuous, coherent layered reflections are recognizable to at least $2.0 \mathrm{~km}$ depth, and arguably to the base of the reprocessed image (i.e., about $2.75 \mathrm{~km}$ ). In the northwestern part of the profile, the layered character of the shallow strata is poorly expressed, and layered reflections cannot be confidently recognized below about 1.5-2.0 km depth. Rocks imaged in the western half of the profile below $2.0 \mathrm{~km}$ appear to be acoustically transparent. 


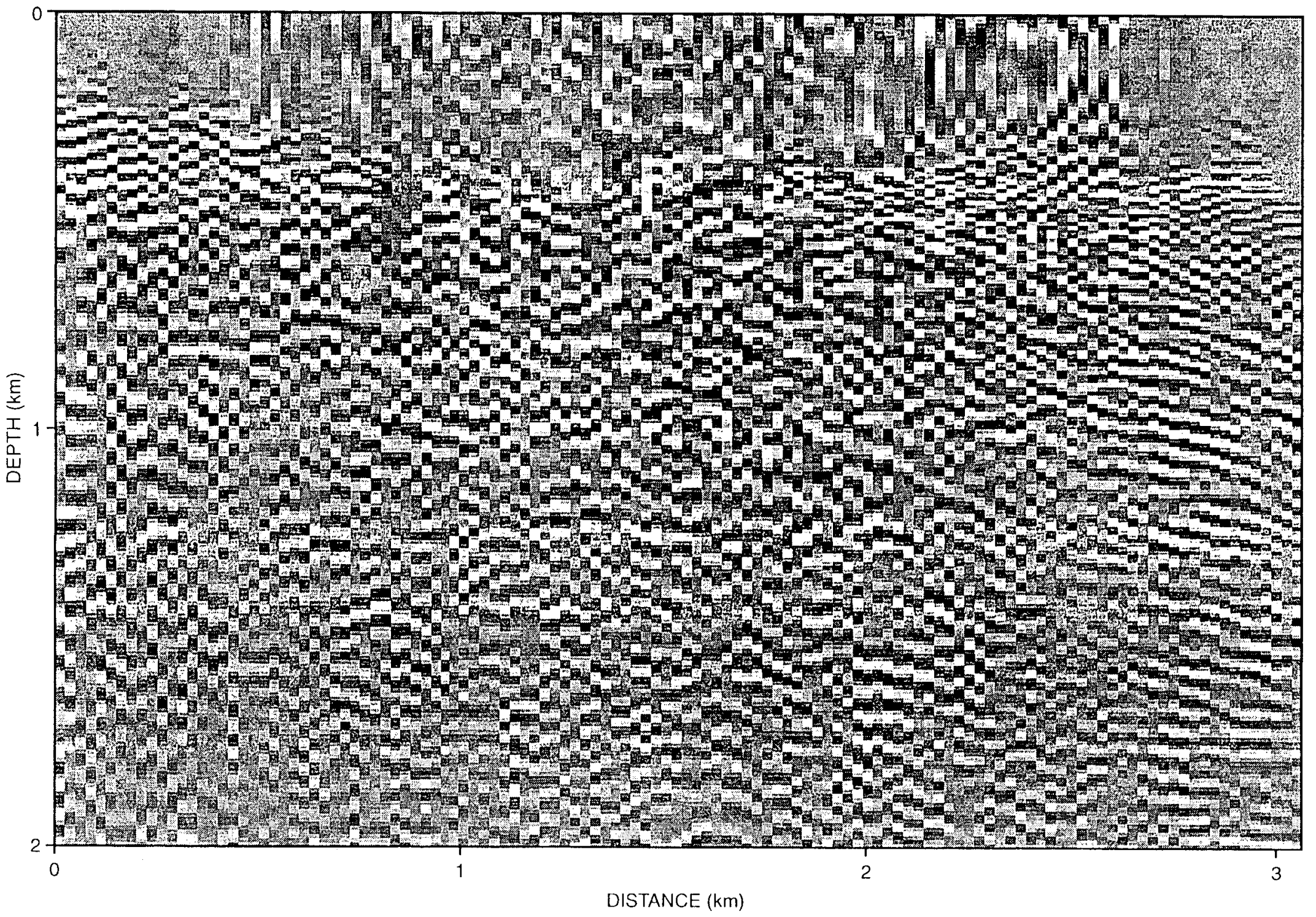

Figure 17. Prestack Kirchhoff migration, Scismic Line 9. 


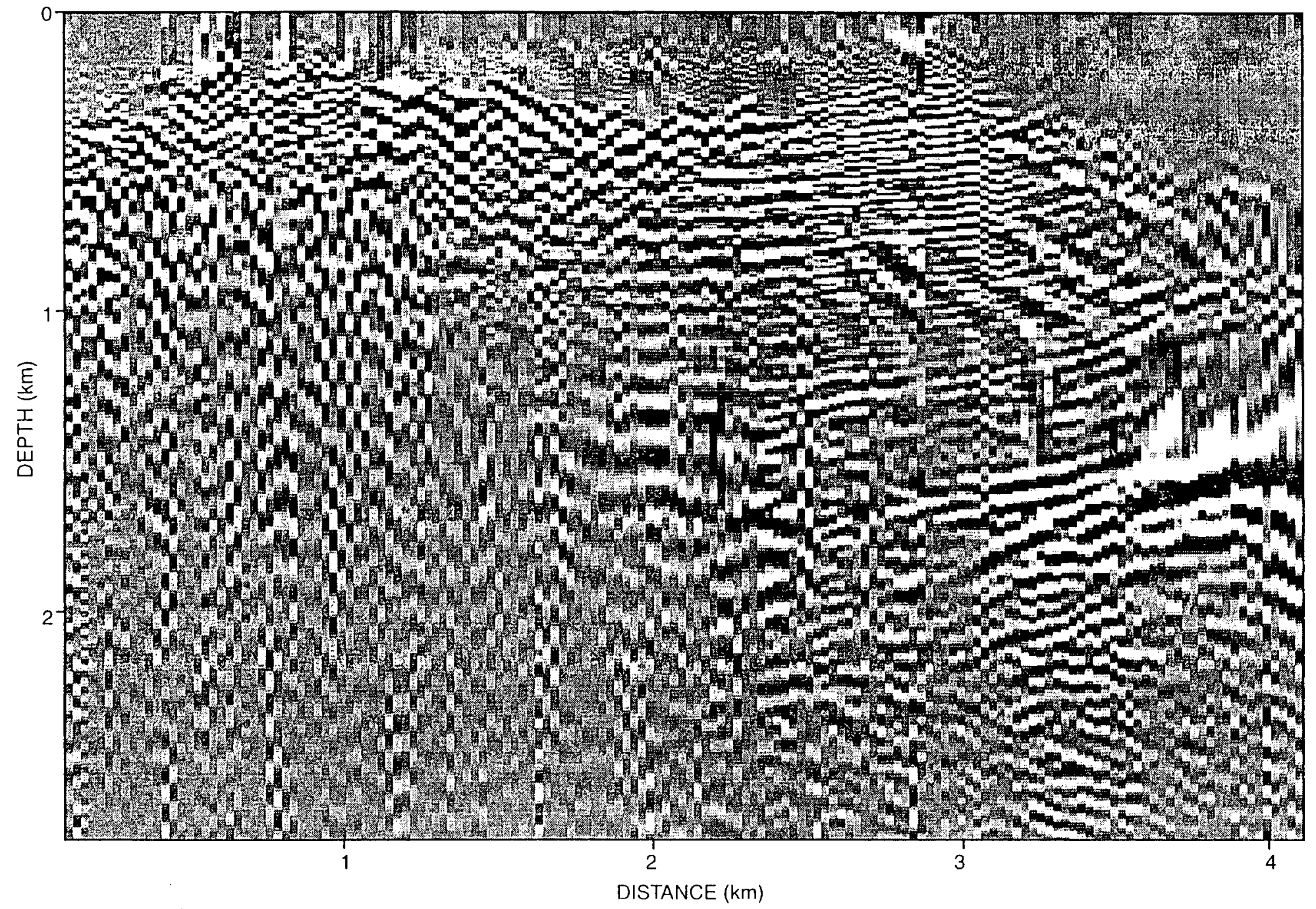

Figure 18. Prestack Kirchhoff migration, Seismic Line 10. 
The layered reflectors below $1.5 \mathrm{~km}$ depth at the east end of the profile can be traced westward to within about $1.5-2.0 \mathrm{~km}$ of the northwest end of profile, where they lose coherency or are truncated against acoustically-transparent rock. We interpret that the reflectors are truncated westward against a moderately to steeply east-dipping normal fault (Figure 19). The upward projection of this interpreted fault to the upper kilometer of the profile coincides with the location of the subvertical velocity boundary obtained from the velocity inversion (Figure 4; Section 3.1.3). We note that lack of sufficient data (only 15 shot gathers were available for processing) precludes imaging the fault directly as a steeply-dipping to subvertical feature on the reflection profile.

Additional evidence for the presence of the fault includes an apparent southeast-side down displacement of the lower boundary of a highly reflective layer in the upper $0.5 \mathrm{~km}$ of the northwest end of the profile (Figure 19). Although this layer is characterized by numerous high amplitude events and is distinctly more reflective than the relatively transparent rocks directly below, it lacks the laterally continuous, coherent horizontal layers observed to the southeast in the basin. We tentatively interpret the shallow, reflective layer to represent coarse, poorly-bedded alluvial fan deposits along the northwestern basin margin. If this interpretation is correct, stratigraphic relations imaged by the migrated data suggest that the alluvial fan deposits interfinger with the layered basin sediments southeast of the range front, and that the fan deposits may prograded eastward with time. The prestack migration image also shows a strong reflector at a depth of $1.45 \mathrm{~km}$ at the east end of the line deepening to a depth of $1.66 \mathrm{~km}$ westward. Because this reflector occurs at the subhorizontal boundary between well- and poorly-constrained velocity regions, we cautiously interpret this as the top of basalt.

\section{$\underline{3.2 .4 \text { Line } 101}$}

The pre-stack Kirchhoff migration of Line 101 images laterally-continuous, coherent layered reflectors along the entire length of the profile that extend to a minimum depth of $3.0 \mathrm{~km}$ (Figure 20). The reflectors are folded into a series of broad, open anticlines and synclines with wavelengths of approximately $3.0 \mathrm{~km}$ and amplitudes of several hundred meters. Two relatively abrupt northeast-down steps or flexures can be observed in the shallow layered reflectors near horizontal offset distances $10 \mathrm{~km}$ and $12 \mathrm{~km}$ (Figure 20). A relatively high amplitude reflector located in the depth range of 1.25 to $2.0 \mathrm{~km}$ appears to coincide with the top of the section of Neogene mafic volcanic rocks cut by Well 65-18 (Figure 20). 


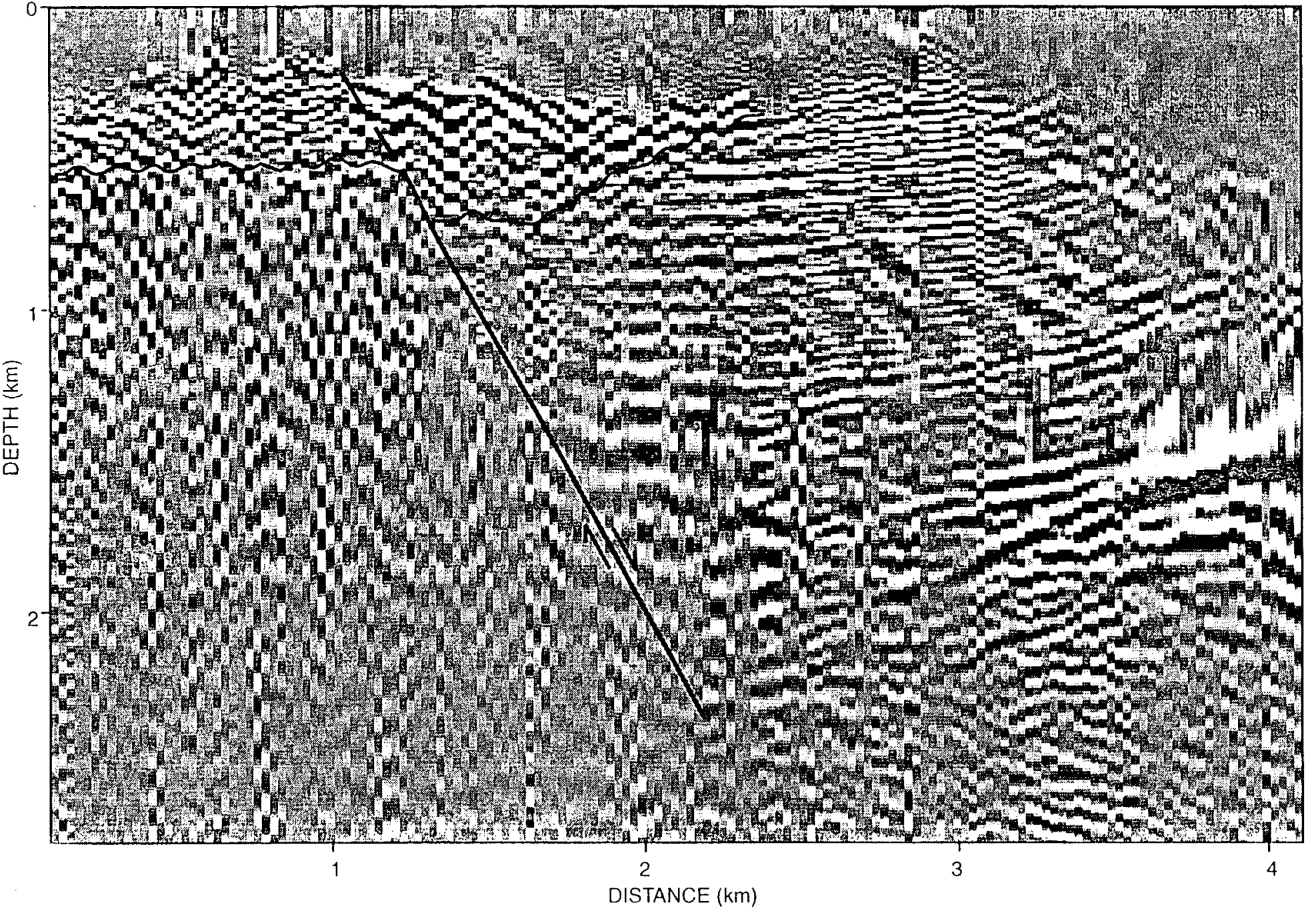

Figure 19. Interpreted prestack Kirchhoff migration, Seismic Line 10. 


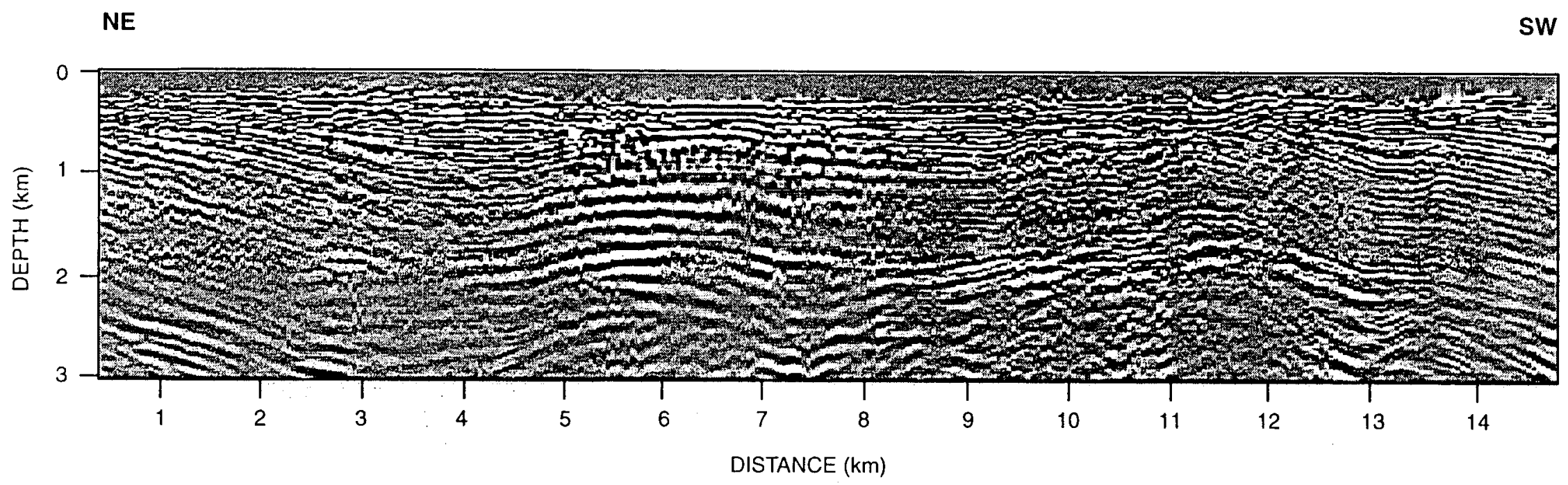

Figure 20. Prestack Kirchhoff migration, Seismic Line 101. 


\section{$\underline{3.2 .5 \text { Line } 103}$}

The pre-stack migration image of Line 103 (Figure 21) reveals laterally continuous, coherent layered reflectors that are recognizable to at least $2.0 \mathrm{~km}$ depth in the southeastern part of the profile. In the northwestern part of the profile, layered reflections extend to about $1.0 \mathrm{~km}$ depth, below which the rocks appear to be acoustically transparent, or very poorly reflective. The layered reflectors in the upper $2.0 \mathrm{~km}$ at the southeast end of the profile can be traced westward to within about $1.75-2.0 \mathrm{~km}$ of the northwest end of profile, where they lose coherency or are juxtaposed against acoustically-transparent rock. We interpret that the layered reflectors are sedimentary rocks of Dixie Valley basin that are juxtaposed against basement rock by a moderately to steeply eastdipping normal fault (Figure 19). The hanging wall of the fault is folded in an approximately $2 \mathrm{~km}$ wide syncline. The dip of folded reflectors in the syncline diverges with increasing depth, indicating syntectonic sedimentation. Some synformal folding or flexure of the sediments can be discerned in reflectors as shallow as approximately $300 \mathrm{~m}$ depth (Figure 21).

\section{$\underline{3.2 .6 \text { Line } 105}$}

The pre-stack migration image of Line 105 (Figure 22) reveals coherent layered reflectors extending to the base of the reprocessed data (i.e., about $2 \mathrm{~km}$ depth). The layered reflectors, which we interpret as Cenozoic basin fill strata and volcanic rocks, are moderately folded into a series of asymmetric anticlines and synclines. In particular, a distinct syncline located at a distance of about $1.5 \mathrm{~km}$ from the west end of Line 105 coincides with the low velocity trough seen in the velocity model (Figure 7). The apparent truncation at the upper left edge this structure is an artifact of the muting of first arrivals, which is a necessary processing step for prestack migration. Thickening of strata in the synclines and increasing bedding dips with depth provide evidence for syntectonic sedimentation and structural growth. Some apparent tectonic deflection can be discerned in strata as shallow as about 250 to $300 \mathrm{~m}$ in depth.

High amplitude reflectors are present at a depth of about $825 \mathrm{~m}$ and distance of $2.3 \mathrm{~km}$ from the west end of the line (Figure 22). Because these reflectors are in an area of poorly constrained velocities, however, they cannot be interpreted with any degree of certainty. Similarly, basalt layers seen along Line 10 at depths of 1.5 to $1.6 \mathrm{~km}$, if present on 105, probably would not be discernible due to the poor velocity constraints at these depths. 


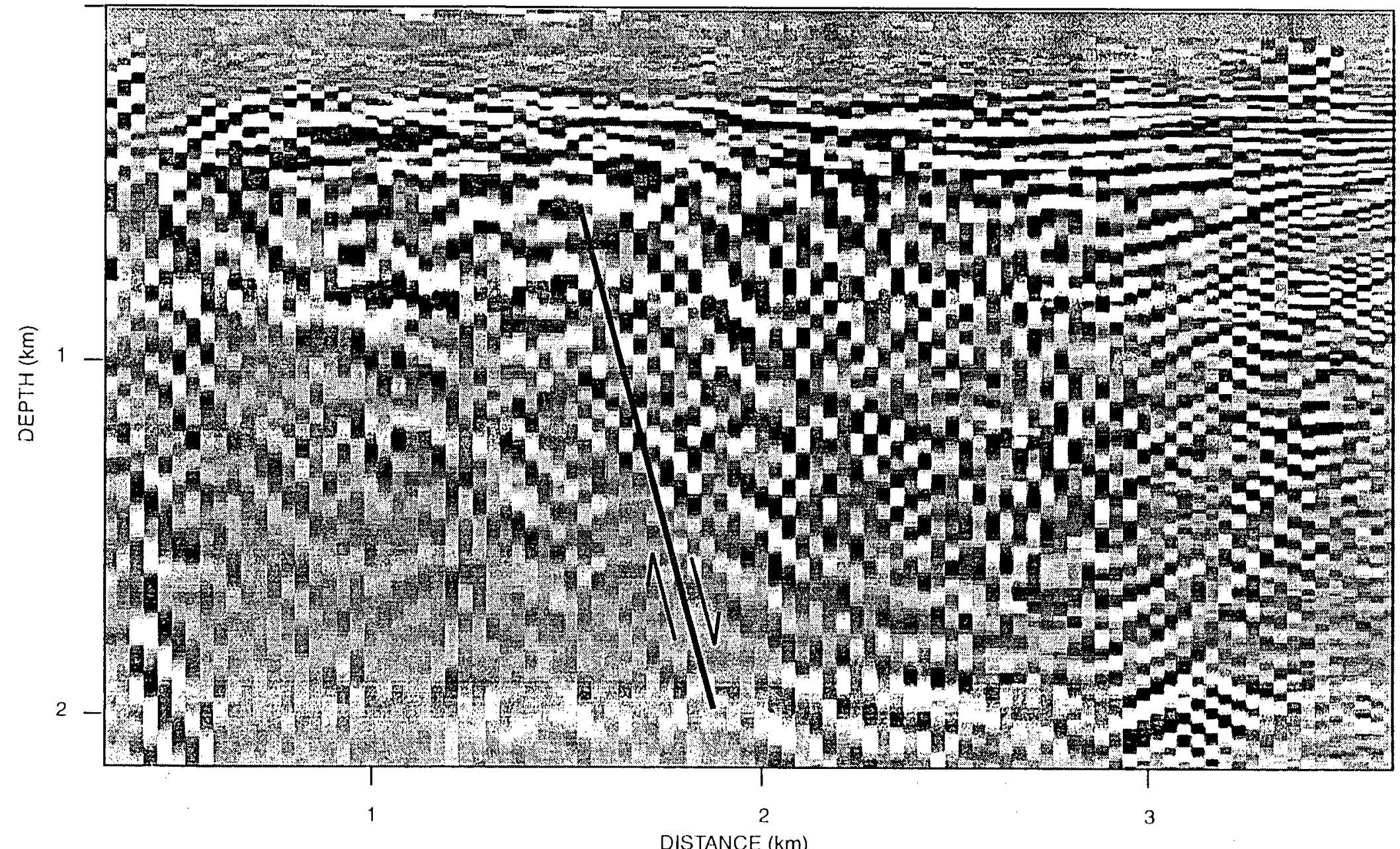

Figure 21. Interpreted prestack Kirchhoff migration, Seismic Line 103. 


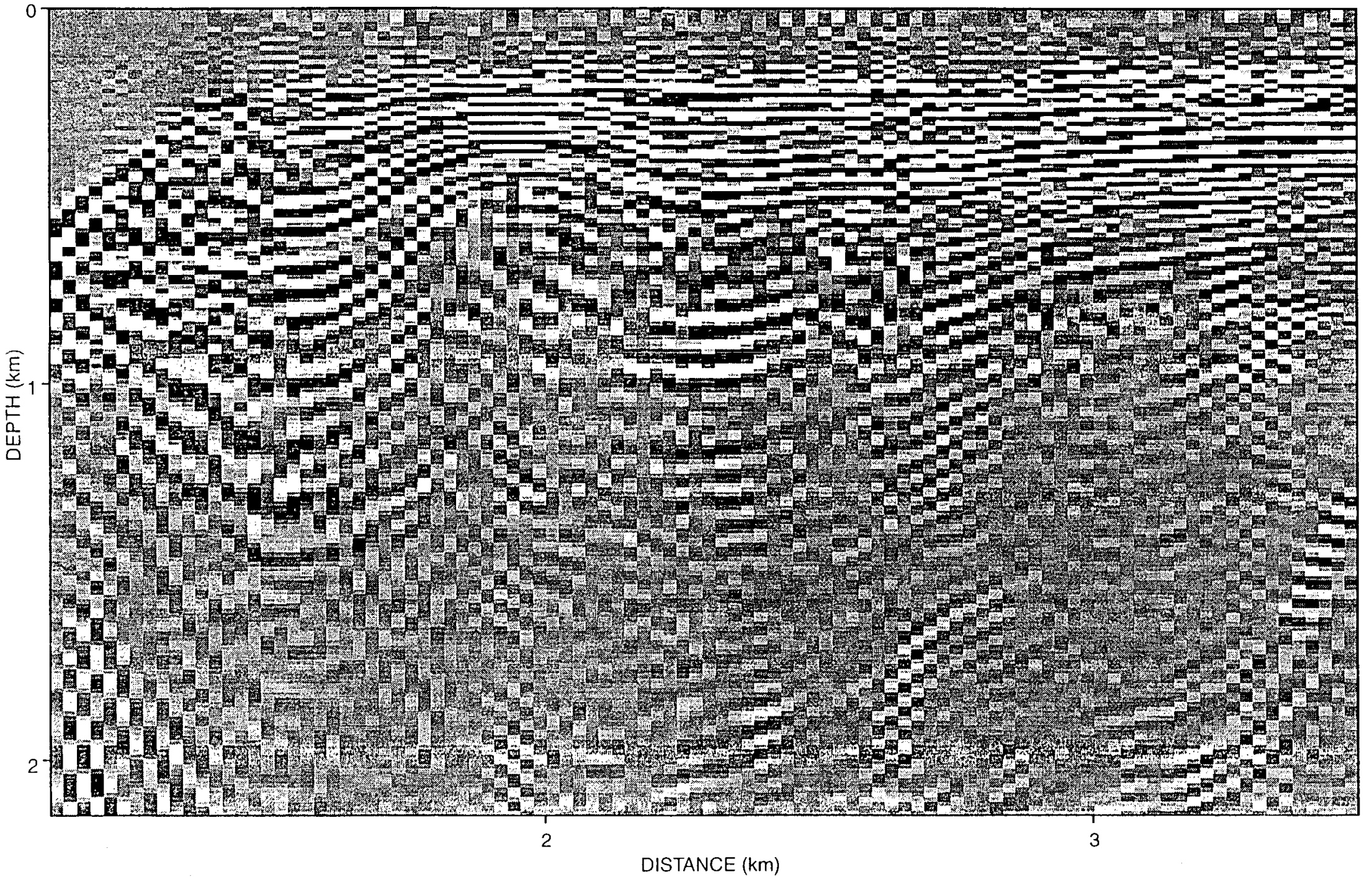

Figure 22. Prestack Kirchhoff migration, Seismic Linc 105. 


\subsubsection{Line SRCIS}

Prestack migration of data from Line SRC1S-A (Figure 23) shows horizontally layered reflectors extending to a depth of about $775 \mathrm{~m}$. Several bright reflectors at a depth of about $1.4 \mathrm{~km}$ can be traced from near the southwest end of the line to the northeast, where they appear shallow to a depth of $850 \mathrm{~m}$ at the northeast end of the image. Due to lack of coherency, the reflectors are not continuos along the entire length of the profile, and in particular they appear to drop out at distances of $2.4 \mathrm{~km}$ and $4.6 \mathrm{~km}$ from the southwest end of SRC1S-A. These reflectors may be layered basalts, but poor constraints on velocities below $1 \mathrm{~km}$ due to limited source-receiver offsets makes interpretation of structure at these depths problematic.

The prestack migration image of SRC1S-B (Figure 24) reveals an asymmetric syncline expressed in shallow reflectors at a distance of $2.6 \mathrm{~km}$ from the west end of the line. The apparent northwest-down tilting of reflectors within the syncline suggests that folding may have occurred in the hanging wall of a southeast-dipping fault bordering the northwest side of the structure; however, no fault is imaged by the data directly. Progressive increase in bedding dip with depth provides evidence for growth faulting. This structure probably is correlative with a small syncline imaged on other seismic lines that lies several $\mathrm{km}$ east of the Stillwater range front (Figure 1).

Another small syncline is imaged at a distance of $1.03 \mathrm{~km}$ from the west end of this line (Figure 24). High amplitude reflectors below about $800 \mathrm{~m}$ depth may be layered basalts. The reflectors appear to have an undulating structure at the west end of the line that may reflect folding, but clear imaging of fold structures is inhibited by poor velocity control in this region.

\subsubsection{Line SRCIN}

The prestack migration along Line SRCIN-A (Figure 25) reveals layered strata with no significant faulting or folding in the vicinity of wells 76-7, 82-7, 74-7 and 84-7. The lack of visible structural features in this line may indicate that the quality of the raw shot gather data is not sufficient to image details, or possibly that insufficient energy penetrated to depths where structures are well expressed in reflective rocks. In contrast, the migrated image along segment SRCIN-B reveals some structural complexity (Figure 26). There are folds or patterns of warping in layered reflectors between distances of $1.9 \mathrm{~km}$ and $2.3 \mathrm{~km}$ from the south-west end of the line, which is near the projection of Well 82-5 onto the plane of the section. These disturbances could be out-of-plane reflections from a fault or structure dipping to the east or west direction. A synclinal structure is apparent at offset $4.8 \mathrm{~km}$ on Figure 26. It is spatially correlated with the location of producing Well 45-33, at a distance of $3.6 \mathrm{~km}$ from the south-west end of Line SRC1N. 


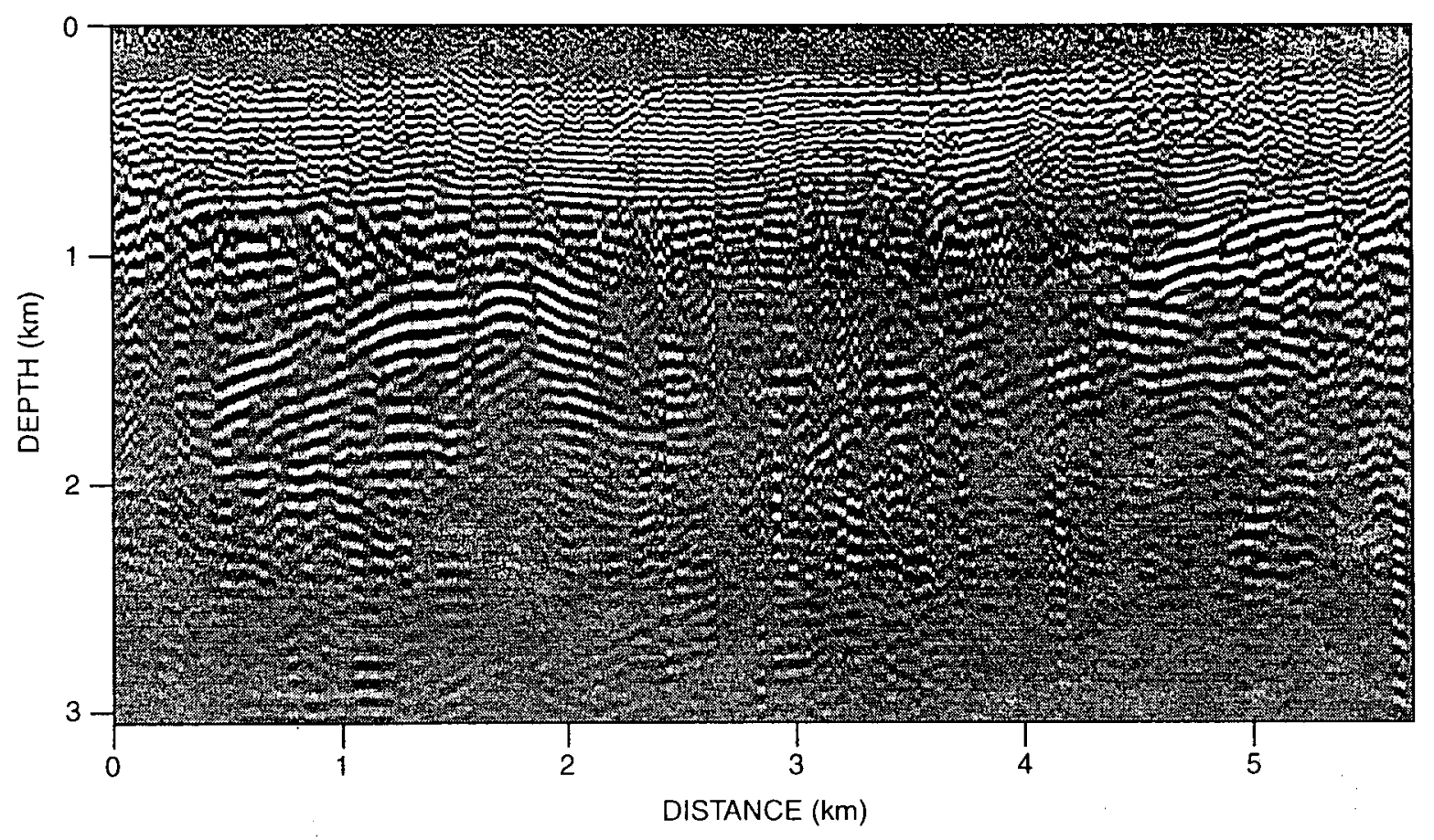

Figure 23. Prestack Kirchhoff migration, Seismic Line SRC1S-A. 
SW

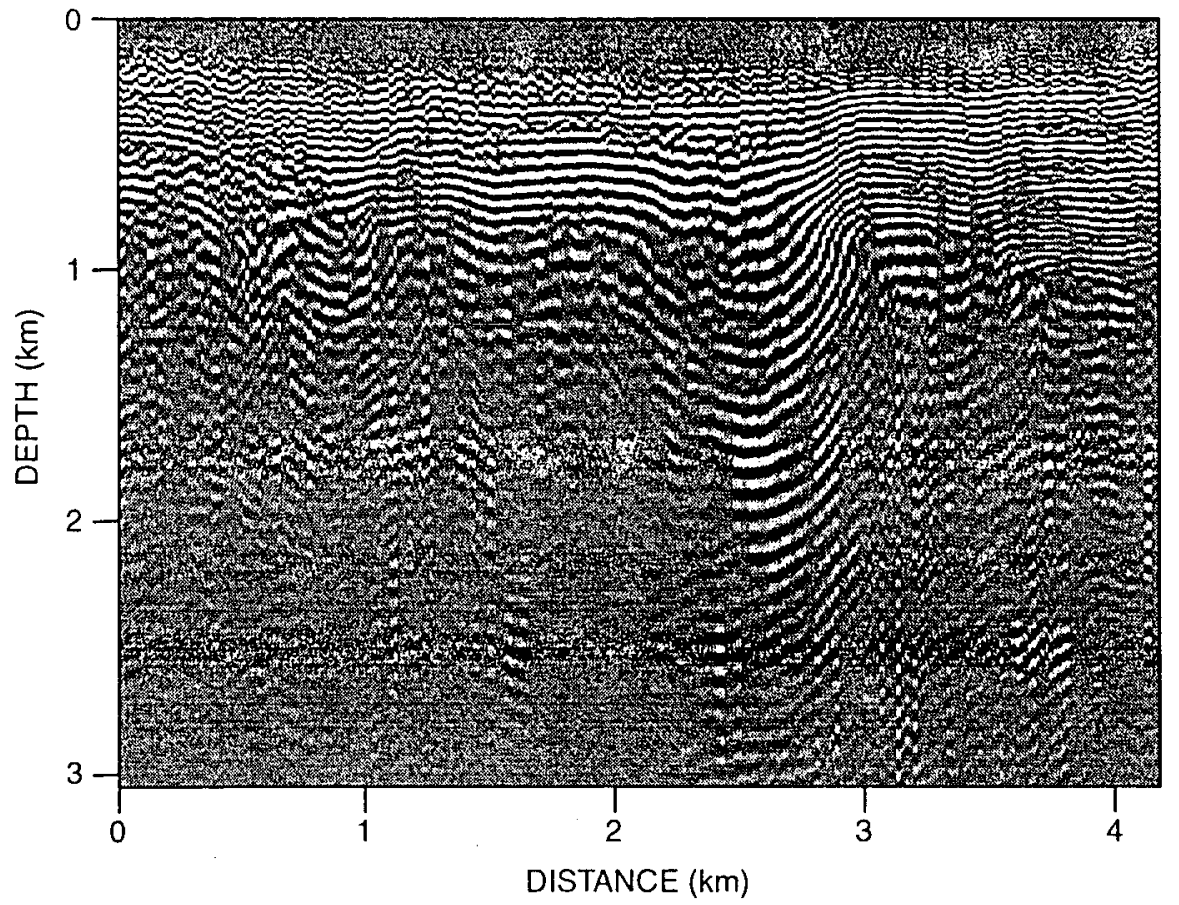

Figure 24. Prestack Kirchhoff migration, Seismic Line SRC1S-B 


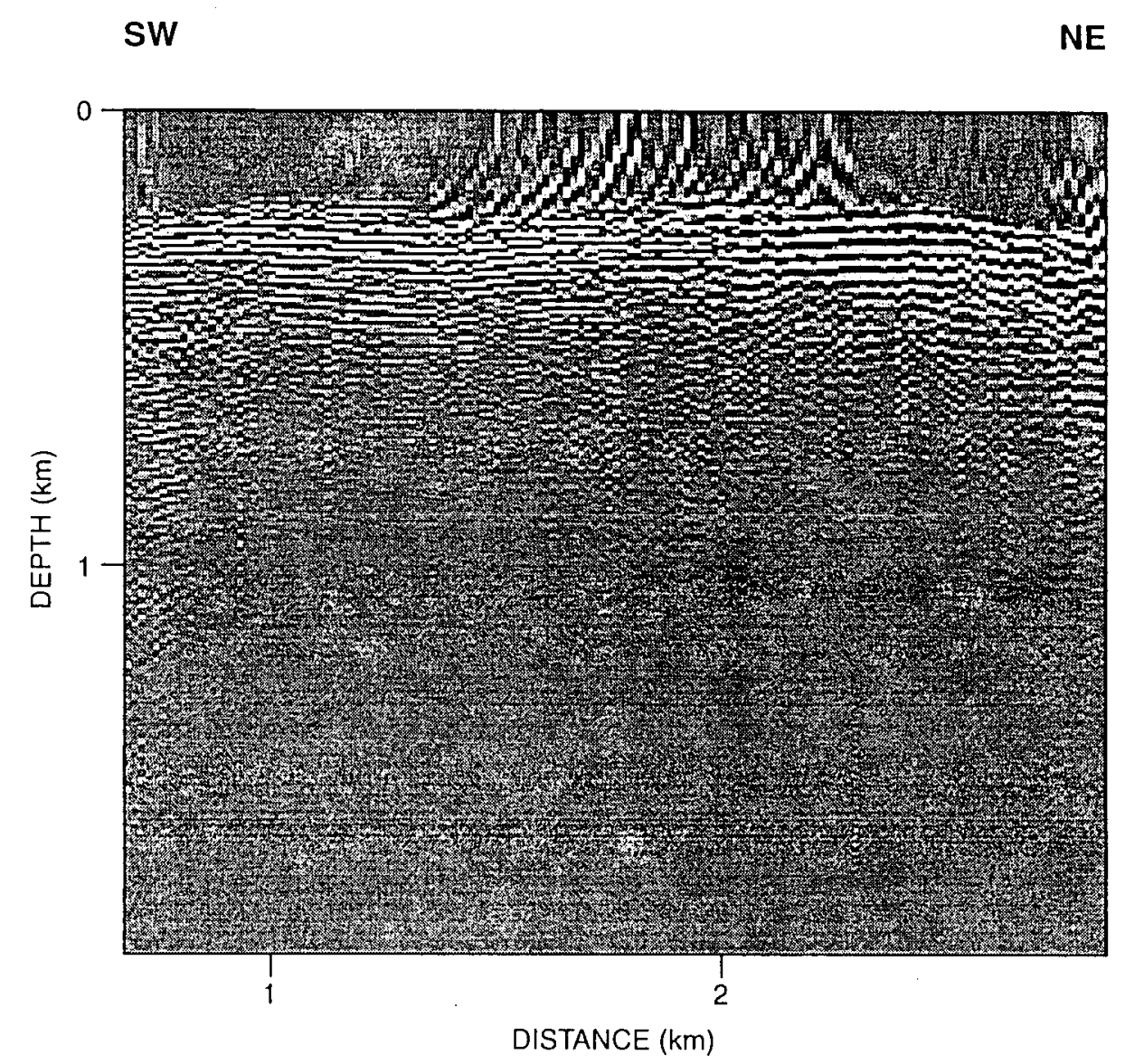

Figure 25. Prestack Kirchhoff migration, Seismic Line SRCIN-A. 
sw

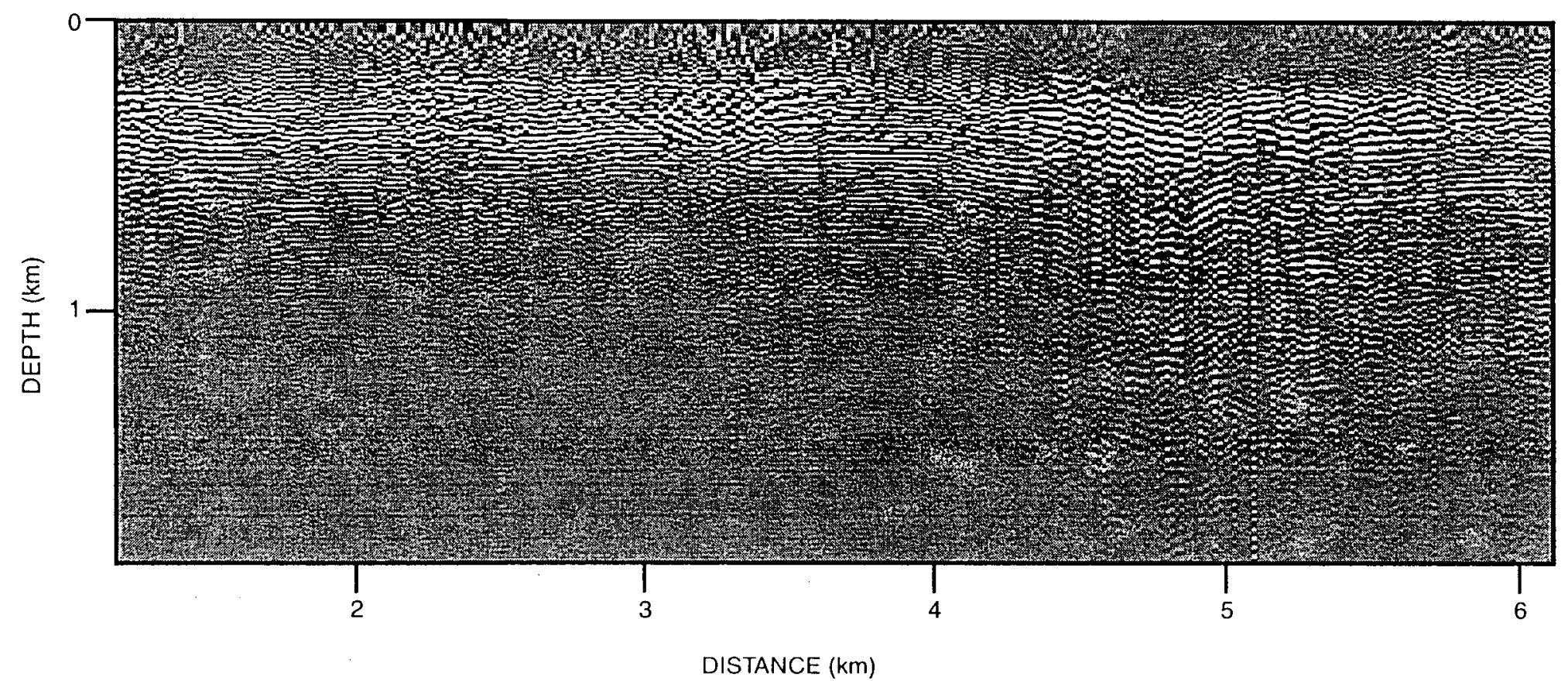

Figure 26. Prestack Kirchhoff migration, Seismic Line SRCIN-B. 
The lack of well-constrained velocities beneath $1 \mathrm{~km}$ leads to the absence of any focused energy below $500 \mathrm{~m}$ for SRC1N-A and below $750 \mathrm{~m}$ along SRC1N-B, thus making the lower parts of the images appear to be acoustically transparent.

\subsubsection{Line SRC3}

The migrated image of Line SRC3 reveals relatively continuous, coherent, layered reflections extending to depths of about 0.75 to $1.0 \mathrm{~km}$, and traceable along most of the length of the seismic line (Figure 27). We interpret these reflectors to be late Cenozoic sediments of the structural Dixie Valley basin. The seismic data indicate that the basin sediments are folded in an asymmetric syncline approximately $2.5 \mathrm{~km}$ southeast of the range front. Northwest-dipping reflections associated with the southeast side of the syncline extend to $2.0 \mathrm{~km}$ depth or greater. The dip of the folded strata increases with depth, suggesting that progressive subsidence of the syncline occurred during deposition of the basin fill. Some modest deformation of the basin strata within the syncline can be discerned in the uppermost layered reflectors imaged at a depth of about 300 to $500 \mathrm{~m}$.

The rocks on the northwest side of the syncline appear to be acoustically transparent below a depth of about $1.0 \mathrm{~km}$. In contrast, moderately northwest-dipping reflections are visible to depths of 2.0 $\mathrm{km}$ or greater on the southeast side of the syncline. We interpret the juxtaposition of the reflective rocks with the transparent rocks to be a southeast-dipping fault (Figure 28). The deeper reflectors below 1.5-2.0 km east of the syncline extend to the southeast end of the seismic line, and they coincide with layered reflections visible at similar depths in the central part of seismic Line 5 near the intersection with line SRC3 (Figure 16). We interpret these layered strata to be part of the Tertiary volcaniclastic sequence that unconformably overlies the Mesozoic crystalline basement in Dixie Valley. The top of the volcanic section was encountered at a depth of about $1.8 \mathrm{~km}$ in Well 82-5 near SRC3. By projecting the lithologic data from Well 82-5 onto the pre-stack Kirchhoff image (Figure 28), the section of volcanic rocks appears to correspond with the deeper layered reflectors. 


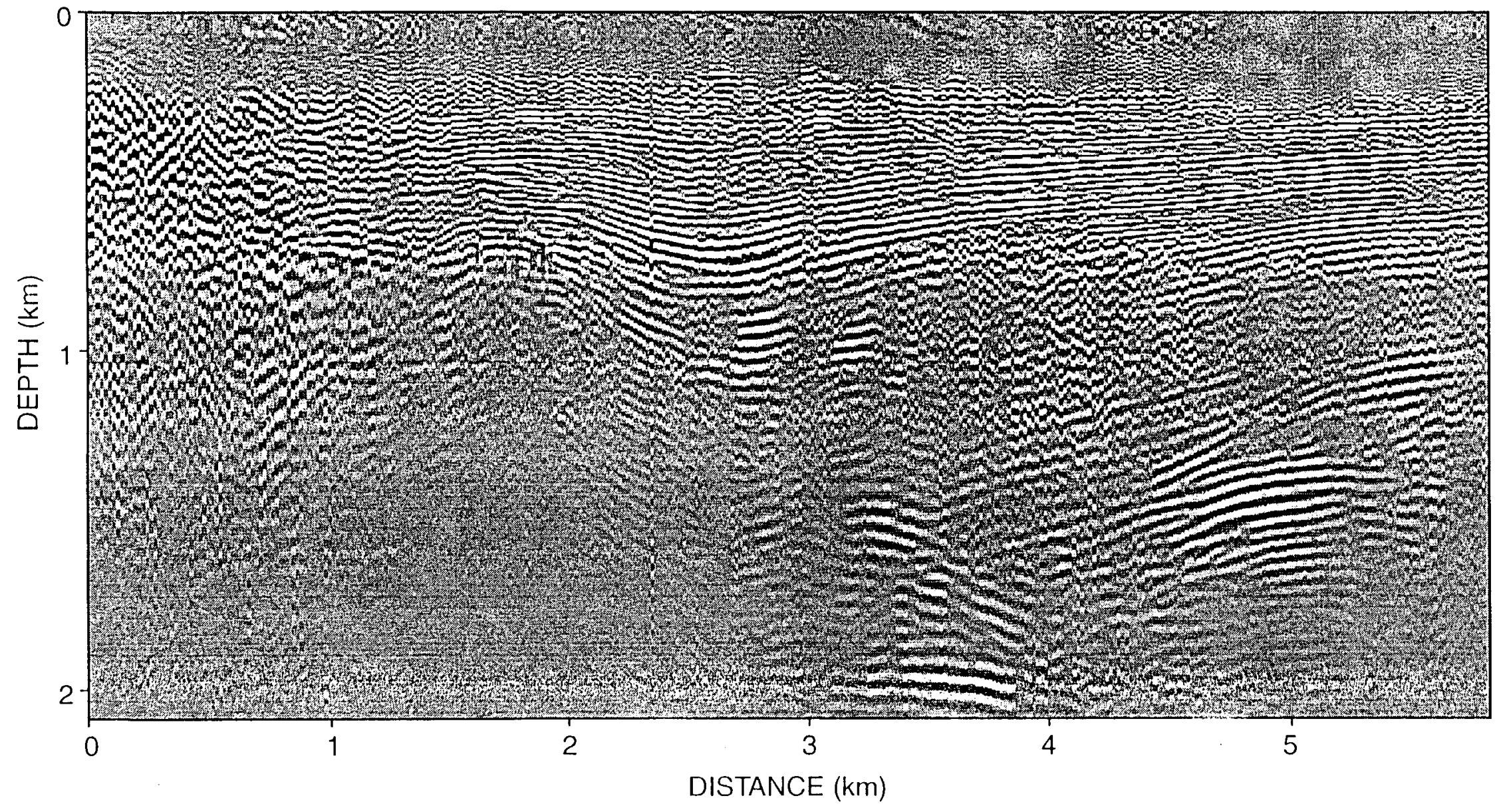

Figure 27. Prestack Kirchoff migration, Seismic Line SRC-3. 


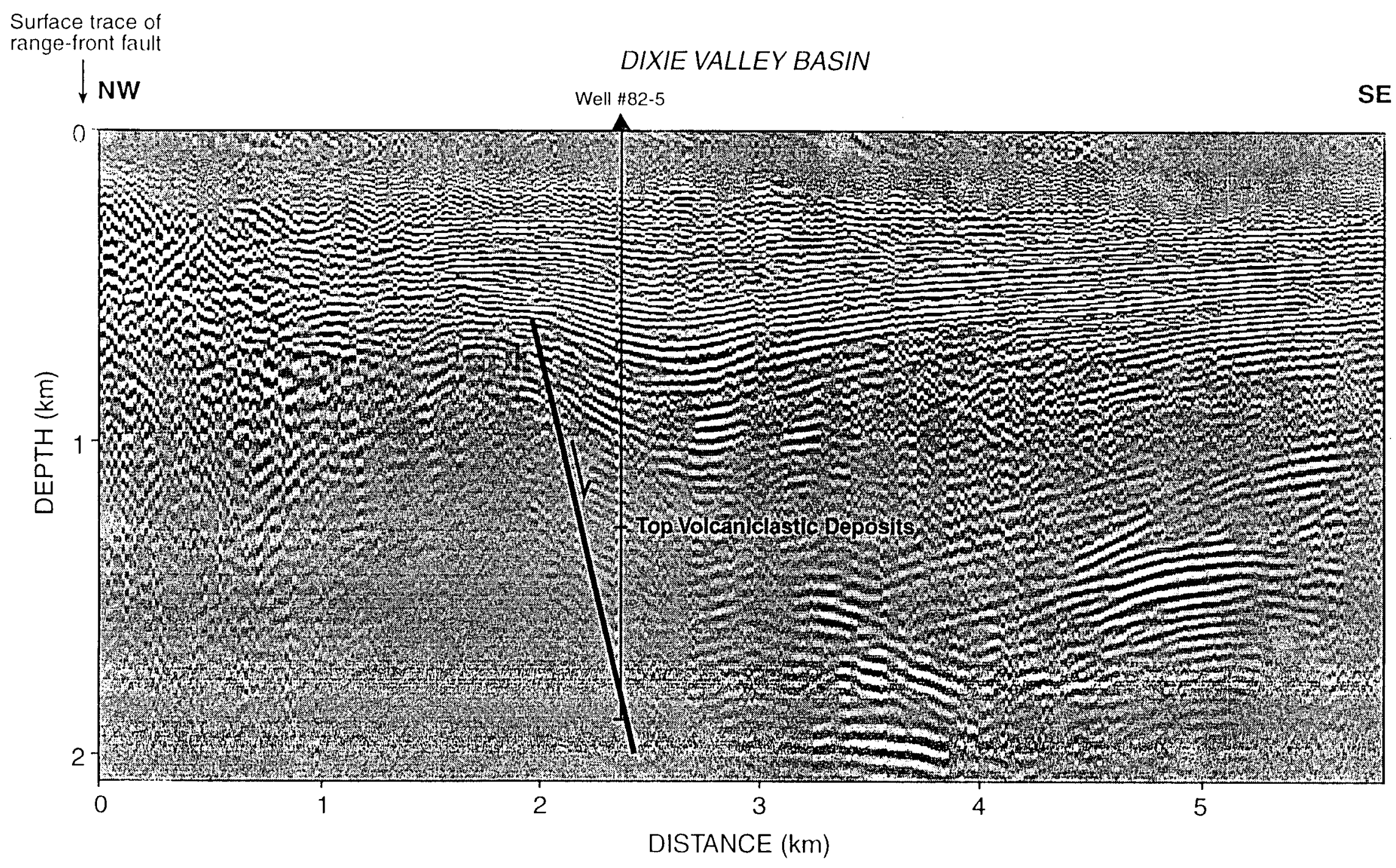

Figure 28. Interpreted prestack Kirchoff migration, Seismic Line SRC-3. Due to limited source-receiver offsets in the data, velow ics below about $1.8 \mathrm{~km}$ depth ar t... well

constrained, and hence the accuracy of the migrated image below this depth is not reliable. 


\subsection{Interpreted and Correlated 3-D Velocity Models}

We prepared three-dimensional models of the subsurface velocity structure by using a software package to interpolate the velocities on individual two-dimensional seismic lines shown in Figure

1. The first step in constructing these images consisted of choosing an appropriately-scaled area that includes all the seismic lines and wells used in the study (Figure 29). Next, the seismic line and well coordinates were transformed to the new frame of reference (Figure 29, bottom). The models are presented in the new frame of reference in Figures 30 and 31.

The small syncline located southeast of the range front, and clearly imaged by pre-stack migration of Line 5 and Line SRC3, is manifest on the 3-D block diagrams as a pronounced velocity low (blue, yellow, and green) inset into higher velocity material (brown and purple). The syncline and associated velocity low can be discerned in both 3-D models because the synclinal axis probably bends slightly in the vicinity of lines SRC3 and 103, thus crossing the visible faces of the 3-D models somewhat obliquely (the geometry of the syncline axis is discussed in Section 4.2, below). Producing Well 45-33 lies adjacent to a strong subsurface lateral change in velocity along the western margin of the syncline, where velocities that we associate with crystalline rocks in the footwall of the Dixie Valley fault are juxtaposed with velocities more similar to basin sediments and basin volcanic sequences. Based on stratigraphic and structural relations described in the previous chapter, we infer that these rocks are juxtaposed by an east- or southeast-dipping fault (Figures 30 and 31). Based on the velocity structure, displacement on the fault appears to increase with depth. The association of the fault and syncline with Well 45-33 and other producing wells within the Dixie Valley geothermal field suggest that these structures may play an important role in controlling subsurface permeability.

The shallow velocity structure in both block diagrams also shows good correlation with the distribution of near surface deposits. On Figure 30, lower velocities can be seen shallowing toward the northeast, consistent with the regional northwest tilt of Dixie Valley. At about offset 4 $\mathrm{km}$ from the northeast side of the basin, surface velocities increase from $1300-1850 \mathrm{~m} / \mathrm{s}$ to 1850 $2400 \mathrm{~m} / \mathrm{s}$, correlated with prograding fan deposits from the Clan Alpine Range into Dixie Valley from the northeast. Similarly, a body of low velocity rocks correlates directly with sediments being deposited at the mouth of Cottonwood canyon (Figure 31). 


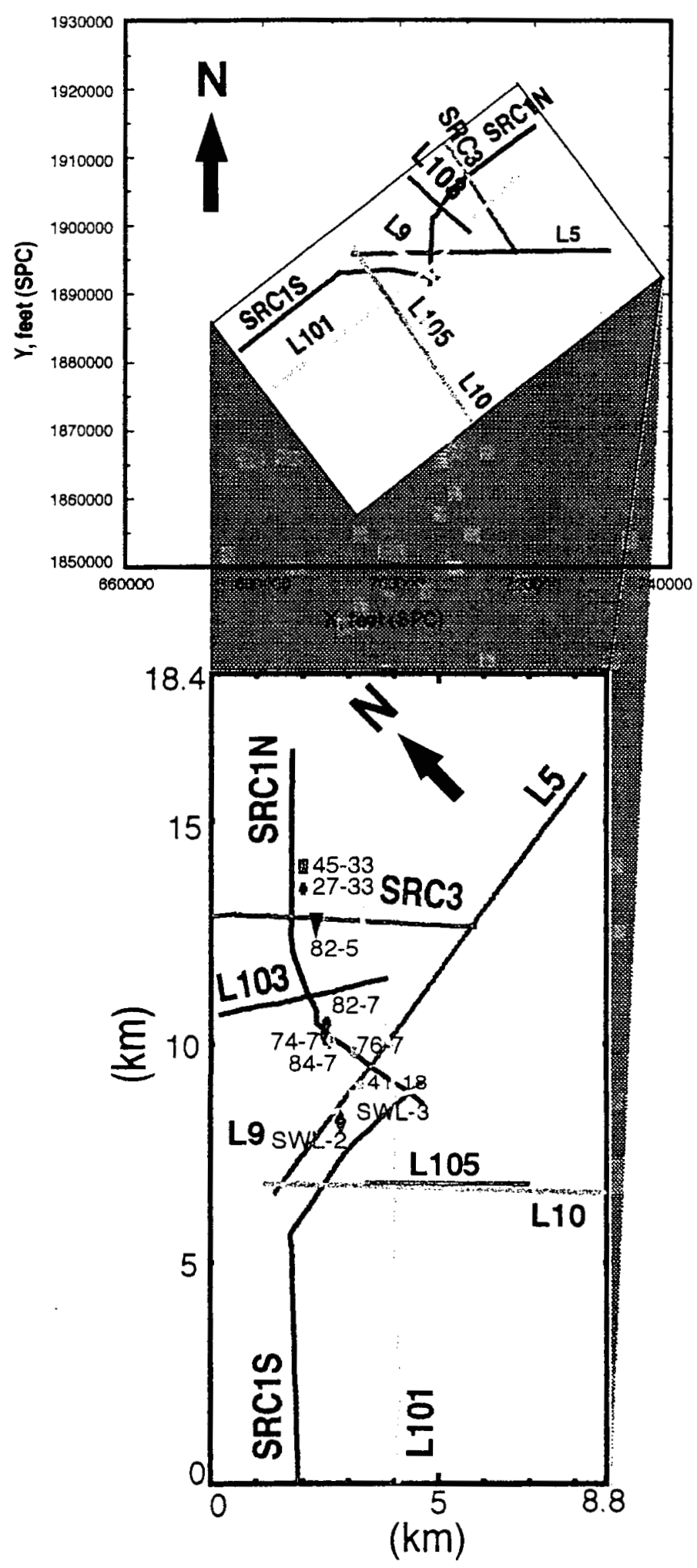

Figure 29. Area covered by the 3-D models (above), and local coordinate system used to project the data (below) 

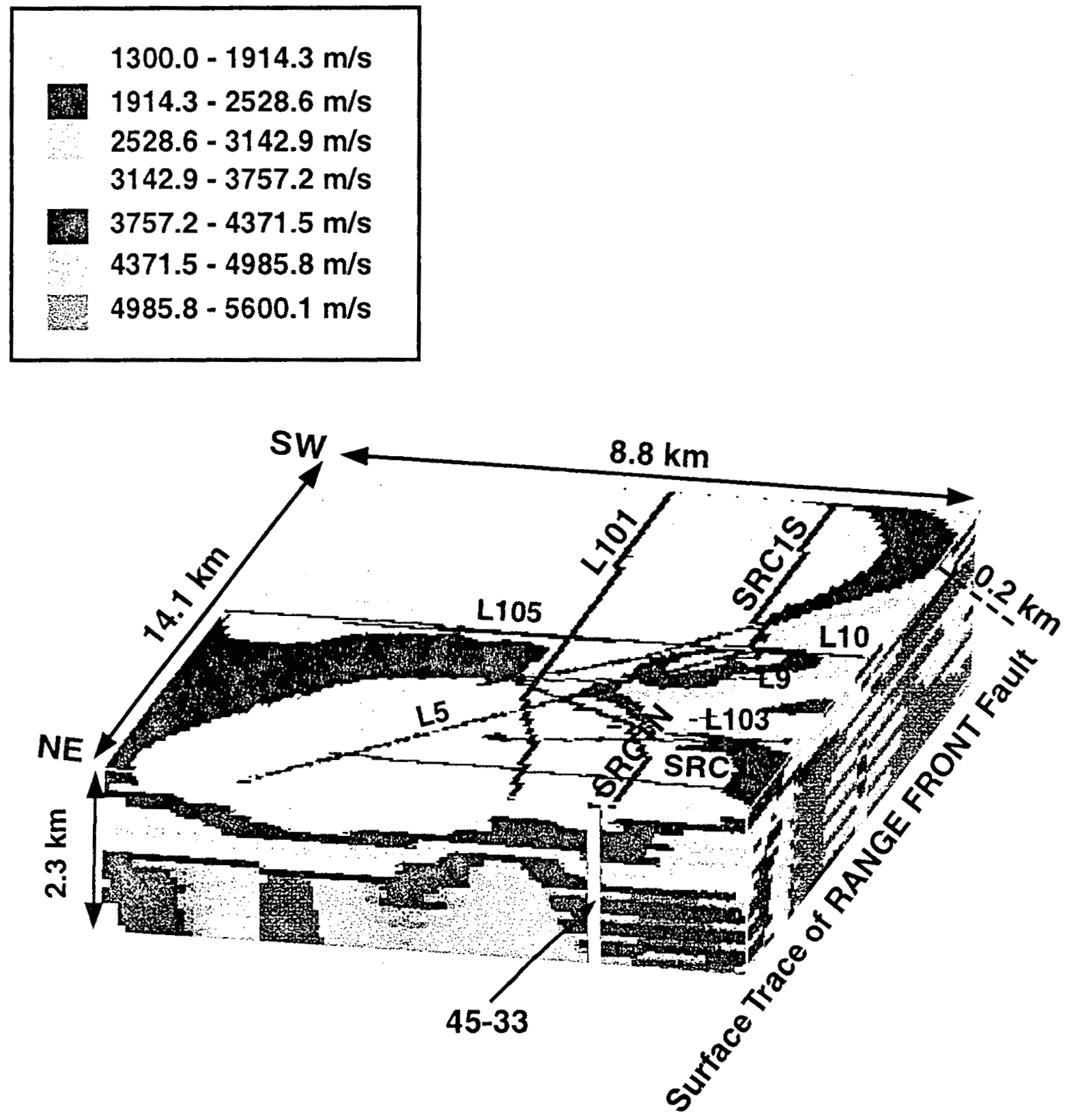

Figure 30. Northwest-Southeast section of three-dimensional representation of velocities obtained using simulated annealing optimization of first arrival travel time data, Dixie Valley, Nevada. East-west section at producing well 45-33 correlates with mapped lateral velocity discontinuity. 


\begin{tabular}{|c|}
\hline $1300.0-1914.3 \mathrm{~m} / \mathrm{s}$ \\
$1914.3-2528.6 \mathrm{~m} / \mathrm{s}$ \\
$2528.6-3142.9 \mathrm{~m} / \mathrm{s}$ \\
$3142.9-3757.2 \mathrm{~m} / \mathrm{s}$ \\
$3757.2-4371.5 \mathrm{~m} / \mathrm{s}$ \\
$4371.5-4985.8 \mathrm{~m} / \mathrm{s}$ \\
$4985.8-5600.1 \mathrm{~m} / \mathrm{s}$
\end{tabular}

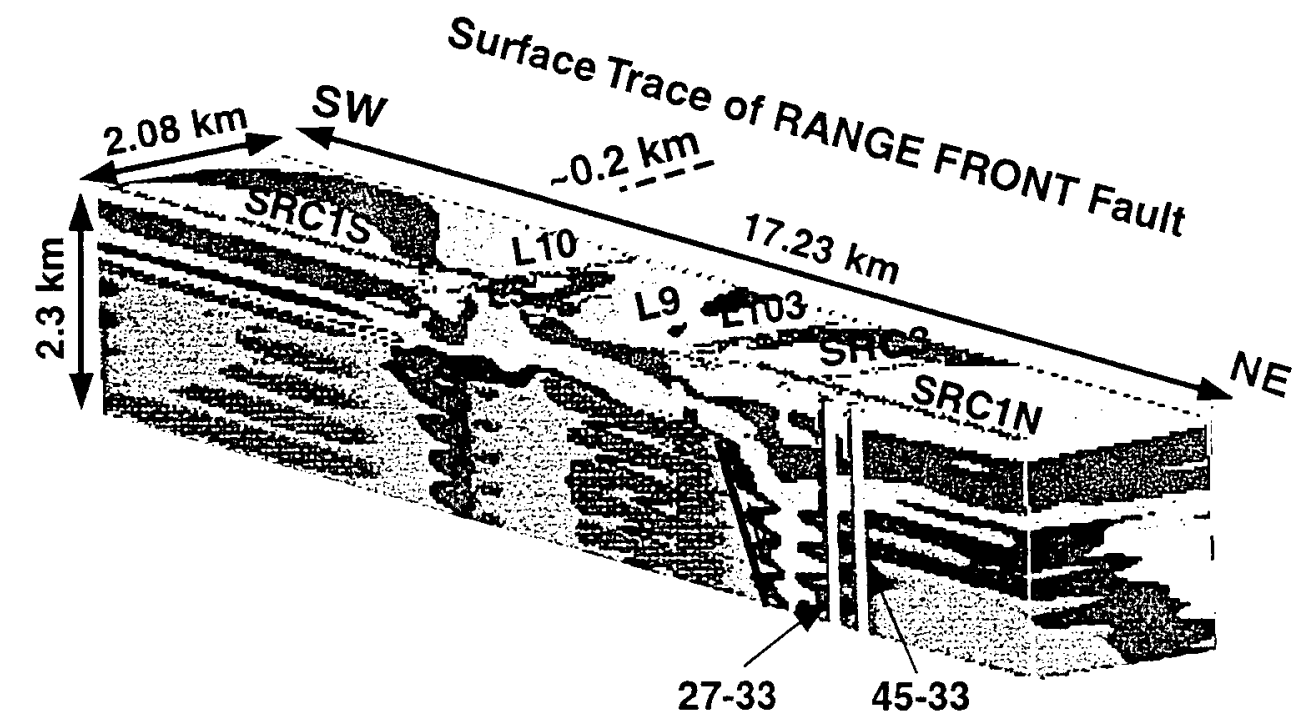

Figure 31. Northeast-Southwest section of three-dimensional representation of velocities obtained using simulated annealing optimization of first arrival travel time data, Dixie Valley, Nevada. Producing wells 45-33 and 27-33 correlate with the mapped lateral velocity discontinuity. 


\subsection{Piedmont Structure of Northwestern Dixie Valley}

Based on our analysis of reprocessed seismic reflection data, we interpret that basinward-dipping normal faults are present southeast of the major Dixie Valley range-front fault. These faults locally show evidence of deforming the stratigraphically-highest sediments imaged by the data (i.e., as shallow as $300-400 \mathrm{~m}$ depth). Similar structures were mapped in western Dixie Valley south of our study area by Bell and Katzer (1987), who referred to them as "piedmont faults" because of their location within the piedmont region adjacent to the Stillwater Range. The piedmont faults mapped by Bell and Katzer exhibit evidence for late Quaternary displacement, and locally produced scarps during the 1954 Dixie Valley earthquake (Caskey et al., 1996).

The most easily recognized and laterally-continuous piedmont structure in the three reprocessed seismic lines discussed above is an asymmetric syncline located approximately 2 to $3 \mathrm{~km}$ southeast of the Stillwater Range front in the northeastern part of the study area. The syncline is clearly imaged by lines SRC3, 103 and 5, and the asymmetry of the structure is apparent in lines SRC3 and 5. We interpret a prominent, steeply southeast-dipping feature imaged along the western margin of the syncline on Line 5 to be a fault. The fault plane is not well imaged on Lines 103 and SRC3, but we infer that the fault lies along the steeply-dipping boundary between folded reflectors in the syncline and a zone of less reflective rocks to the northwest. Based on our correlation, the southeast-dipping fault and asymmetric syncline appear to be spatially associated with the major producing wells of the Dixie Valley field (Figure 1).

Based on analysis of gravity data and modeling of the basement surface, Blackwell and Wisian (1997) concluded that several normal faults synthetic to the major range-front fault are present beneath the piedmont region in northwestern Dixie Valley. The asymmetric syncline and associated southeast-dipping fault that we infer from the reflection data coincides with a major southeast-side-down fault in the basement interpreted from gravity modeling (Figure 32). Blackwell and Wisian (1997) infer that an antithetic northwest-dipping fault may lie several hundred meters to the southeast, presumably based on the presence of a gravity gradient associated with the southeast side of the syncline. An antithetic fault in this location is not obviously imaged by the reflection data. If the syncline is asymmetric, however, an antithetic fault is not necessary to create a structural closure and associated gravity low. Thus, the gravity gradient associated with the southeast side of the syncline, which presumably formed the basis for Blackwell and Wisian's interpretation of an antithetic structure, need not be related to a discrete fault. 


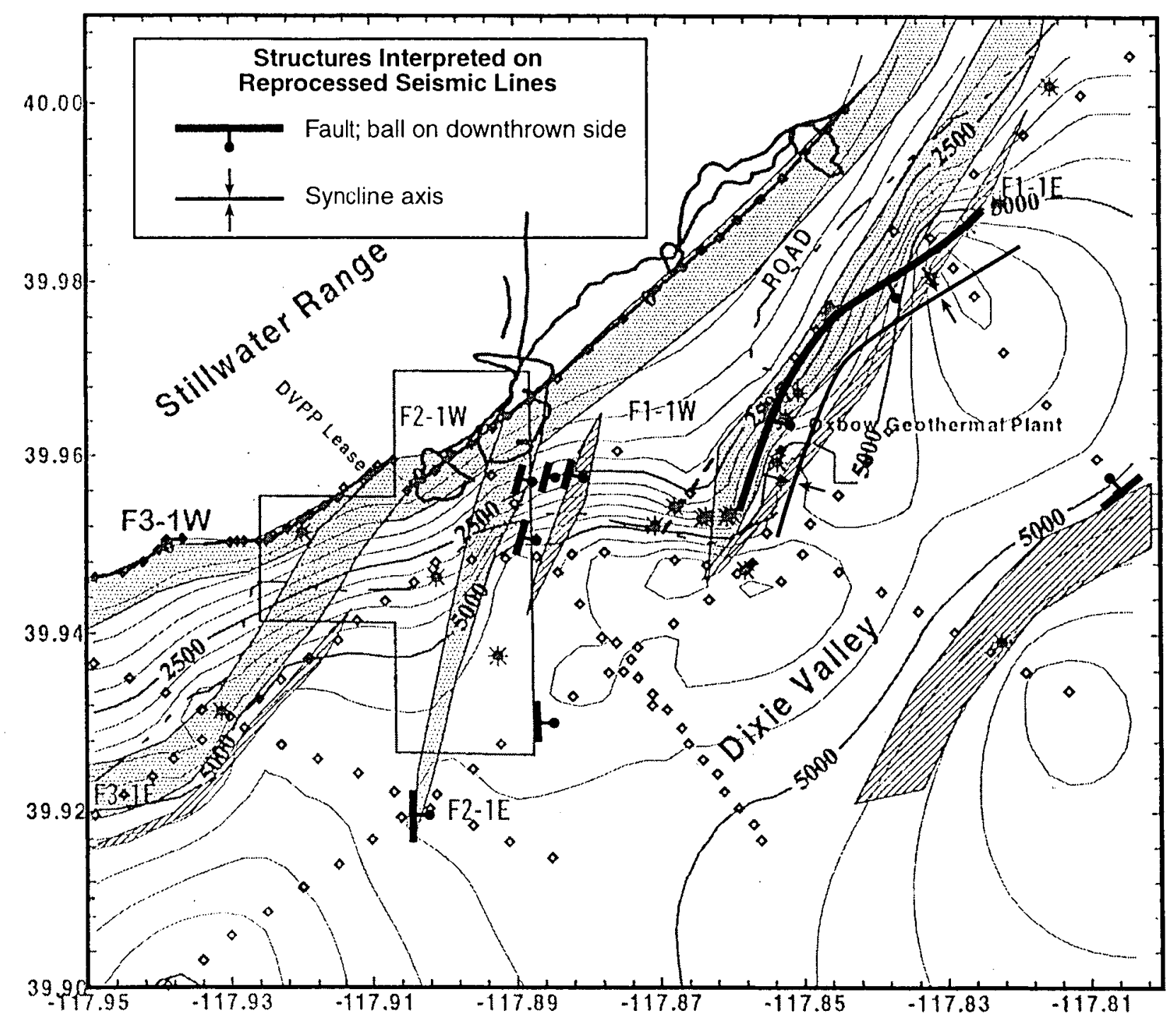

Figure 32. Comparison of seismic and gravity interpretations of piedmont structure in northern Dixie Valley. Base map from Blackwell and Wisian (1997) shows depth to basement interpreted from seismic data and locations of faults interpreted from gravity modeling (shaded faults dip southeast; hachured faults dip northwest). Structures interpreted from reprocessed seismic lines (this study) are shown by bold fault and fold symbols superimposed on the base map. 
In the piedmont area west of the syncline, several faults with small displacements that we infer on seismic lines 5,10 and 101 lie along the trace of a north-northeast-striking, east-dipping normal fault modeled by Blackwell and Wisian (1997) from the gravity data (Figure 32). It is important to note that the faults we interpret at the northwest end of Line 10 and the west end of Line 5 also appear to be associated with a southeast-down break in the basement surface determined by Blackwell and Wisian from analysis of conventionally-processed versions of these lines. Unlike the syncline and associated fault to the east, which are subparallel to the range front, the northnortheast-striking fault modeled by Blackwell and Wisian (1997) is oblique to the range front. It is not possible to determine from the seismic data alone what the orientation of the faults are, and thus we cannot determine whether they are associated with the break in the basement slope or the interpreted north-northeast-striking fault.

To summarize, the reprocessed seismic data provide evidence for the presence of normal faults in the piedmont region of the Stillwater Range southeast of the major range-front fault. The most prominent of these faults visible on the seismic lines is associated with the development of an asymmetric syncline beneath the western basin margin in the northern part of the study area. Independent geophysical evidence for this structure also is provided by gravity modeling (Blackwell and Wisian, 1997). The fault and asymmetric syncline are spatially associated with the major producing wells of the Dixie Valley field (Figure 32).

\subsection{Geologic Structure Imaged by Line SRC3}

Seismic line SRC3 is of special significance because (1) the western end of the line approaches to within about $150 \mathrm{~m}$ of the Dixie Valley range-front fault, and thus potentially constrains the downdip geometry of this structure; and (2) Well 82-5 is directly adjacent to SRC3, and the well penetrated a fault that juxtaposes basin fill rocks in the hanging wall with crystalline rocks in the footwall at a depth of approximately $2.7 \mathrm{~km}$. Because the range-front fault passes so close to the northwestern end of Line SRC3, it is possible that some reflections from the fault plane may be visible in the reflection data, provided that the fault is not a subvertical structure. Okaya and Thompson (1985) previously identified an event on their conventional stacked section that they interpreted as a reflection from the range-front fault plane. By hand migrating this event and connecting it by a straight line to the surface projection of the range-front fault, Okaya and Thompson (1985) concluded that the dip of the fault is approximately $50^{\circ}$. This value is similar to the approximately $47^{\circ}$ dip required to connect the surface trace of the range front fault to a fault penetrated at about $2780 \mathrm{~m}$ depth in Well $82-5$ at a horizontal distance of about $2.4 \mathrm{~km}$ southeast of the range front. 
During our analysis of the seismic data, we identified a negative move-out event in the individual shot gathers for Line SRC3 that we interpret to be a reflection from the range-front fault. We inverted arrival times from this event using the method of Pullammanappallil and Louie (1993) to obtain the local velocity structure along the western $2 \mathrm{~km}$ of the seismic line, as well as the horizontal position and depth of the event. The results are shown in Figure 33. There is excellent agreement between the velocities in this model and the velocity structure previously obtained for SRC3 by inverting P-wave arrival times along the entire length of the line (Section 3.1.9). The reflection points for the negative move-out event delineate a relatively well-defined planar feature dipping approximately $57^{\circ}$ to the southeast (Figure 33). If this feature is a fault-plane reflection, then the model suggests that it dips more steeply than the $47^{\circ}$ to $50^{\circ}$ dip for the range-front fault inferred from previous analysis of SRC3 and data from Well \#82-5.

Given the results of our modeling above, we consider two separate interpretations of the structure along the western basin margin in the vicinity of Line SRC3:

1) The range-front fault dips approximately $47^{\circ}$ to $50^{\circ}$ southeast and intersects well $\# 82-5$ at $2780 \mathrm{~m}$ depth (Figure 34); or

2) The range-front fault dips more steeply, as indicated by our inversion of the negative moveout event in Figure 33, and thus does not penetrate Well 82-5. If this interpretation is correct, then one or more piedmont faults must be present beneath the basin margin southeast of the major range-front fault, such that the basement surface is faulted down to the southeast across a series of discrete steps. In this model, the fault cut by Well $82-5$ is a piedmont fault, not the down-dip projection of the range-front fault. We tentatively interpret that the fault encountered in Well \# 82-5 may be the steeply southeast-dipping fault that bounds the northwest margin of the asymmetric syncline, as shown in Figure 35.

Although the seismic data do not provide unequivocal evidence for either model, we favor Model 2 (i.e., the interpretation of a steeply-dipping range-front fault and one or more piedmont faults; Figure 10) for several reasons. First, the asymmetric syncline southeast of the range-front is more directly explained by the presence of a steeply southeast-dipping fault along its western margin that is distinct from, and lies southeast of, the range-front fault. As discussed above, we believe that this fault is directly imaged to the southwest of Line SRC3 by Line 5 (Figure 16), and our interpretation of the location and extent of the fault is consistent with gravity modeling (Blackwell and Wisian, i997; Figure 32). Second, we interpret a possible fault offset of a subhorizontal 


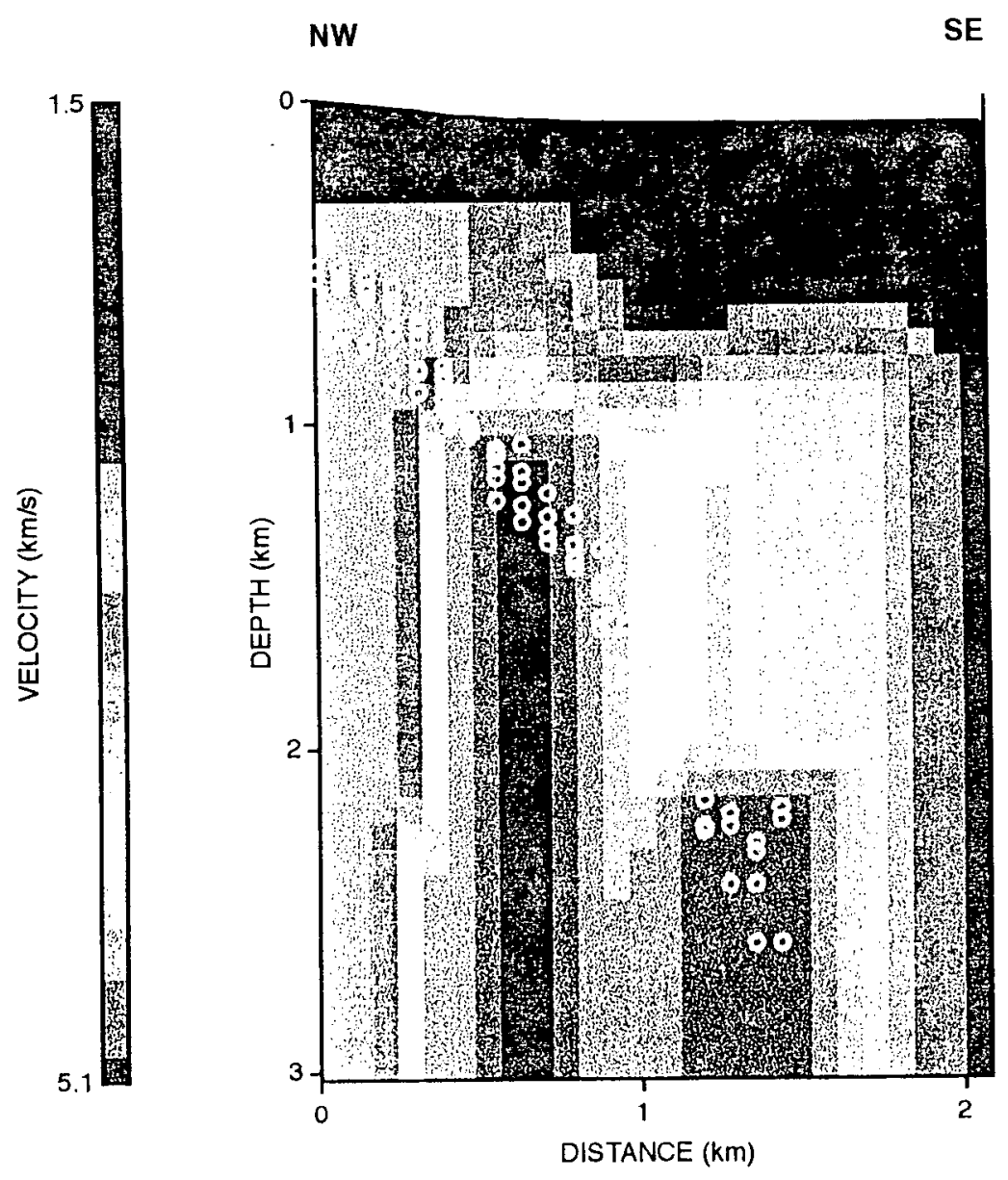

Figure 33. Velocity model and reflection points, Seismic Line SRC3. The reflection points are from a negative move-out event observed on individual shot gathers that is interpreted to be a reflection from the Dixie Valley range-front fault. The reflection points define a planar feature dipping about $57^{\circ}$ to the southwest. 


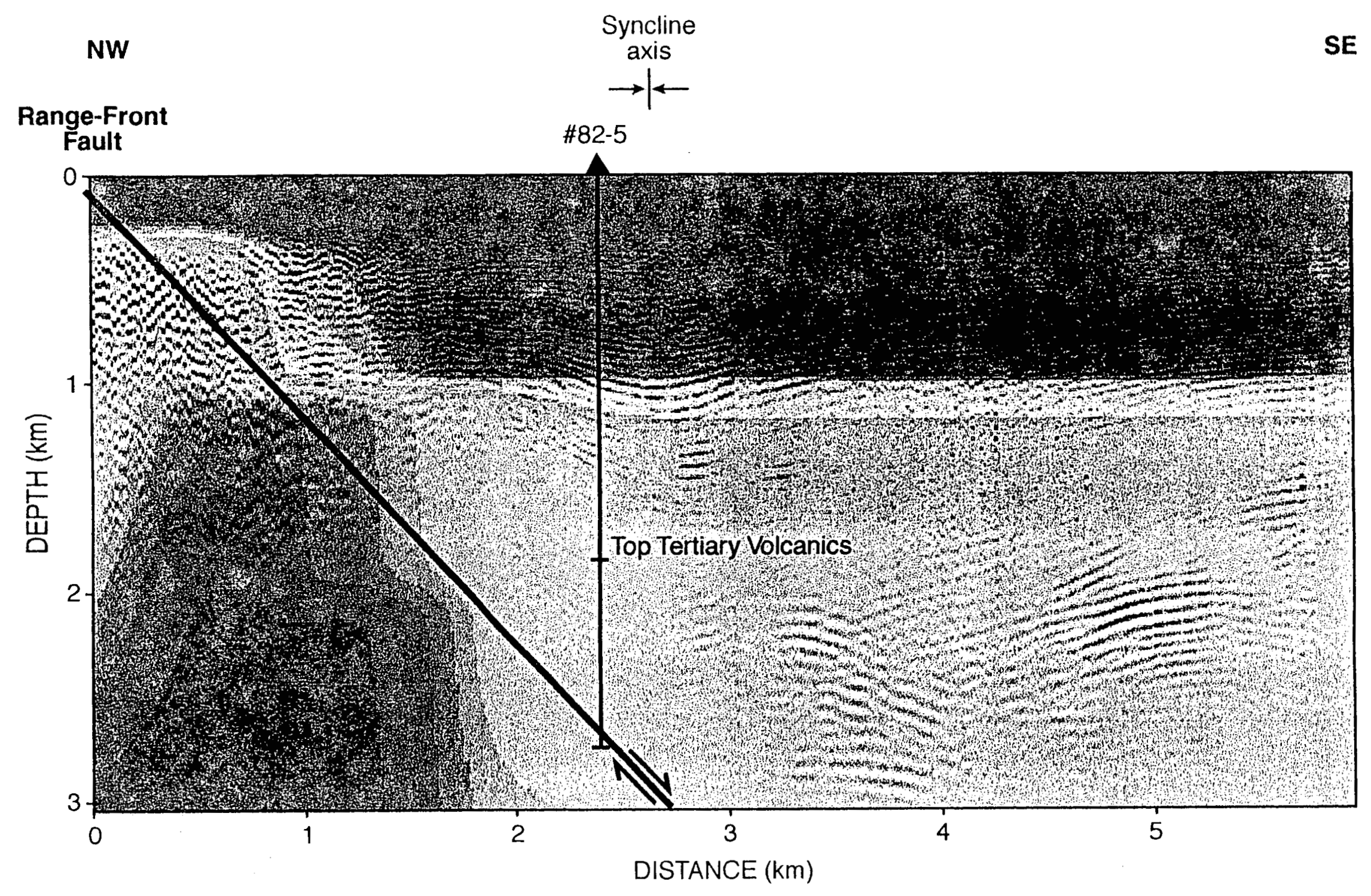

Figure 34. Velocity model superimposed over interpreted Kirchhoff migration of Seismic Line SRC3. Faults correspond to structural Model I, discussed in text. 


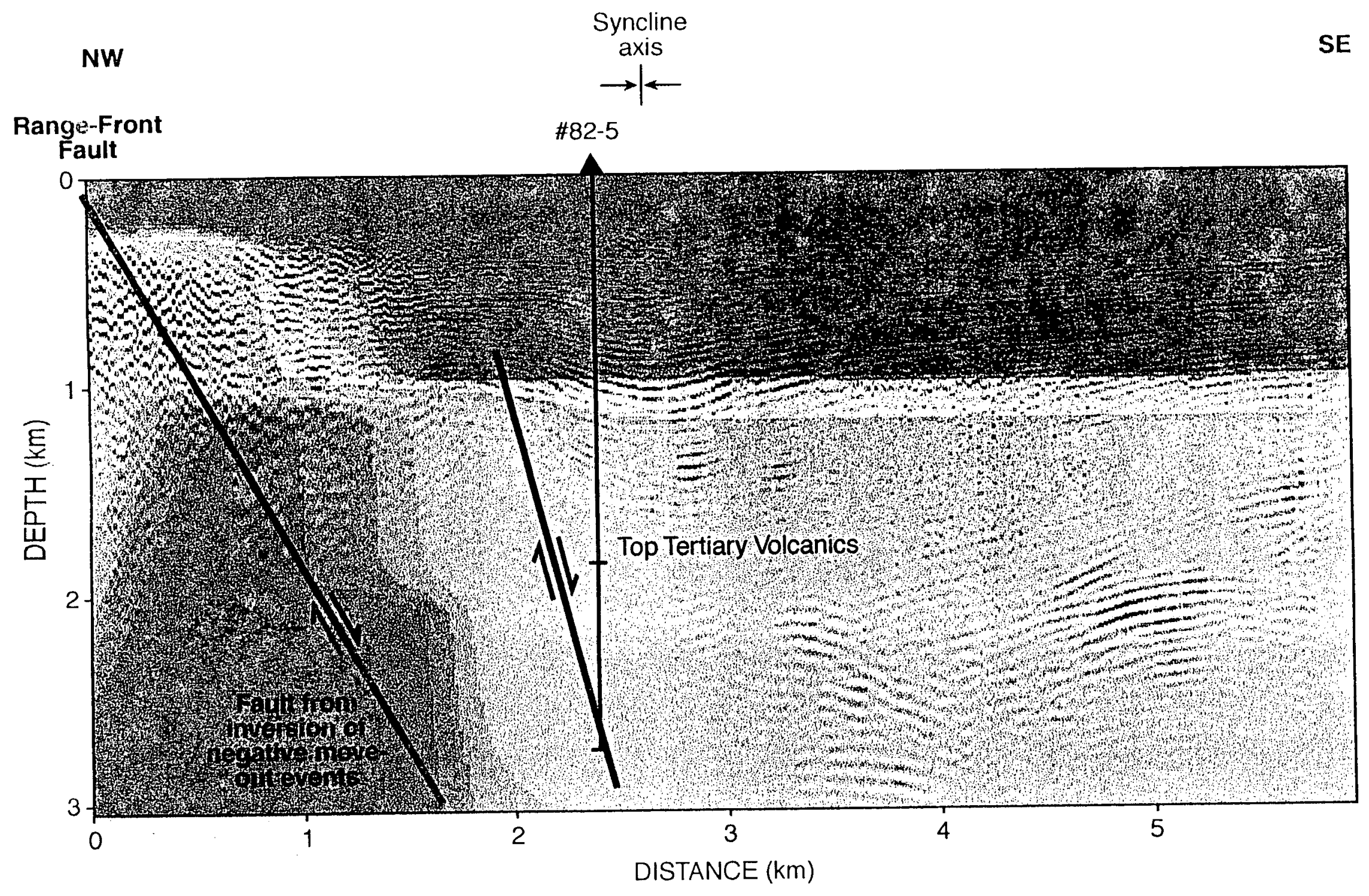

Figure 35. Velocity model superimposed over interpreted Kirchhoff migration of Seismic Line SRC3. Faults correspond to structural Model 2, discussed in lext. 
boundary between shallow reflective sediments and underlying, relatively transparent rock about 200 to $400 \mathrm{~m}$ from the northwest end of line SRC3. This possible offset is better correlated with the position of the range-front fault we obtained from inverting the normal move-out event, than with a projection of the fault plane that connects the surface trace to the fault penetration in Well 82-5. If our interpretation of this offset is correct, it further constrains the dip of the range-front fault to be greater than the $47^{\circ}$ dip necessary to intersect Well $82-5$ at $2.8 \mathrm{~km}$.

As a further assessment of the two models, we compared the fault locations and geometries to lateral velocity gradients obtained from inverting P-wave arrival times (Figures 34 and 35). The step-like geometry of the high velocity rocks on the west end of SRC3 are permissive of a range in fault geometries. For example, the single fault plane in Model 1 generally separates high velocity rocks in the footwall from lower velocity rocks in the hanging wall (Figure 34) by skirting the edges of the "steps" in the velocity model. The major misfit between the fault geometry and the velocity boundaries occurs at depth where lower velocity rocks appear to lie in the footwall. Similarly, the two fault planes in Model 2 (Figure 35) also appear to lie along steep velocity boundaries. As a distinction between the two models, however, we note that the piedmont fault in Model 2 lies along a distinct velocity boundary that separates layered rocks on the east from relatively transparent rocks to the west, and which also corresponds to the western margin of the asymmetric syncline. The transparent rocks west of the fault have relatively high velocities similar to those we correlate with crystalline rocks. Although the velocity structure matches gross features of both models, we conclude that Model 2 provides a better fit to the velocity structure in the vicinity of the syncline and Well 82-5.

Because the constraints on acoustic velocity from the seismic data are very poor below about 2-3 $\mathrm{km}$ depth, the reflection profiles cannot be used to reliably infer the deep geometry of faults along the western basin margin. If the fault geometry in Model 2 is correct, however, the piedmont fault that bounds the northwest margin of the syncline appears to dip more steeply than the range-front fault, and thus probably intersects the range-front fault in the depth range of 4 to $7 \mathrm{~km}$.

\subsection{Comparison of Conventional Processing with Simulated Annealing and Pre-Stack Migration Techniques}

\subsubsection{Imaging Implications}

The conventional, post-stack migration image of Line SRC-3 shown in Figure 36 (Okaya and Thompson, 1985) suggests the presence of the Dixie Valley fault through the truncation of seismic 

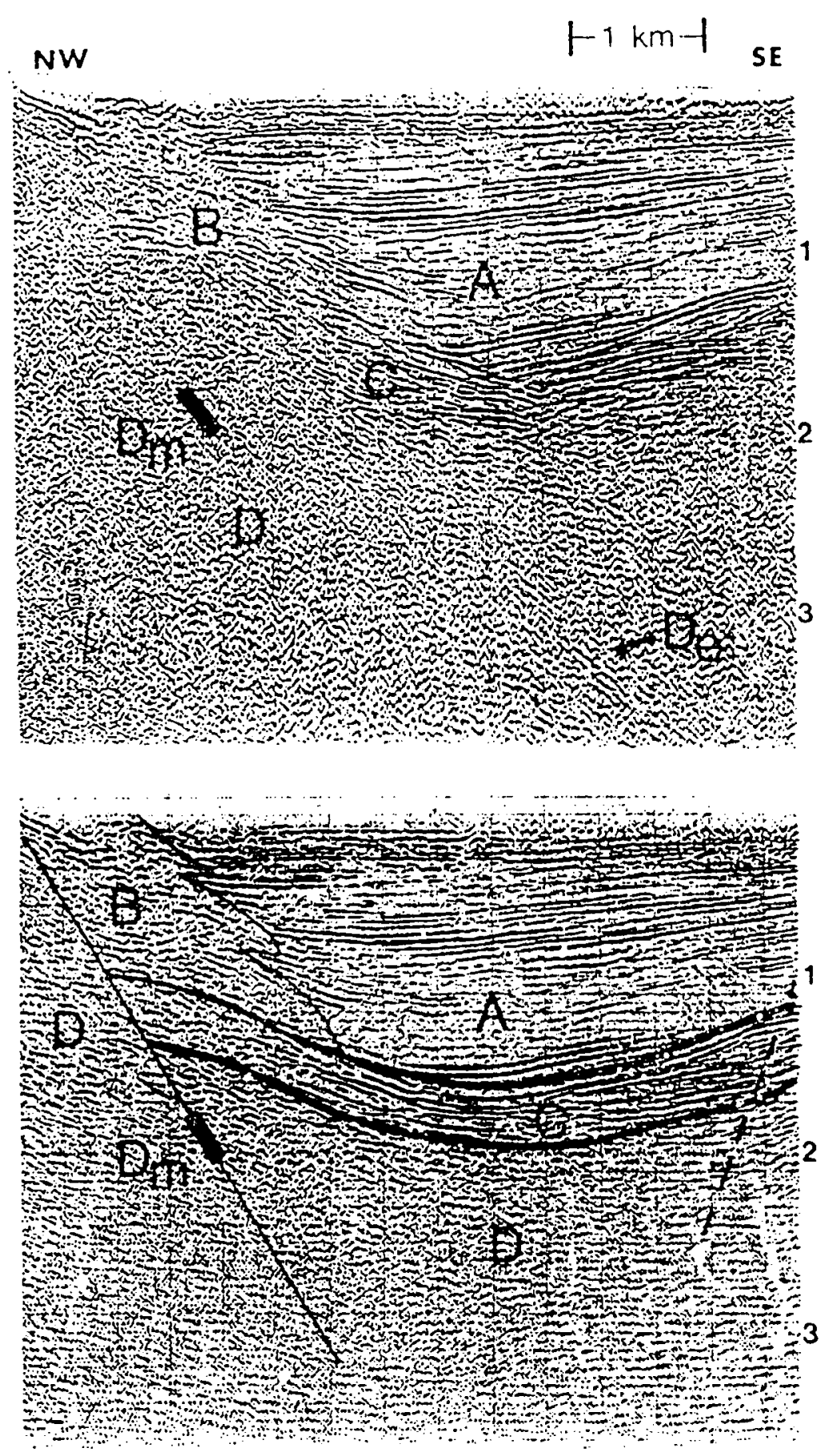

Figure 36. Seismic Line SRC-3 processed by Okaya and Thompson (1985) using conventional methods (stacked section on top; interpreted finite difference on bottom). Interpreted reflection symbols from Okaya and Thompson as follows: A, Lacustrine and playa deposits; B, Alluvial fan; C, Tertiary volcanic sequence; $\mathrm{D}$, Mesozoic basement; $\mathrm{D}_{\mathrm{e}}$, Steeply-dipping fault plane reflection; $\mathrm{D}_{\mathrm{m}}$, Hand-migration of event De. 
reflectors from about zero to one $\mathrm{km}$ offset toward the southeast (Figure 2 [B]). However, it is difficult to determine the location and geometry of the fault to the accuracy and precision for commercial applications. The presence of the Dixie Valley fault has been constrained by picking steeply-dipping events from the stacks (Figure 36, [De]), and migrating them northwestward to the implied location of the Dixie Valley fault (Figure 36, [Dm]). There are very few events to pick from the stacks, and it is difficult to constrain the location and geometry of the structure that produced the reflections.

Employing conventional post-stack migration techniques, Okaya and Thompson (1985) interpreted that the Dixie Valley fault dips at 50 degrees toward the southeast. Because conventional post-stack migration processing methods are time migrations and not depth migrations, the location and dip of the Dixie Valley fault, as well as other structural features, will vary depending on qualitative and laterally-averaged estimations of subsurface velocities. Averaged velocities will not take into account the lateral variations in velocity that, by definition, comprise laterally-complex geologic environments. Also, the structural detail revealed in the image shown in Figure 36 is not sufficient to consider the possibility of basinward faulting, which is implied in areas A and C. The reflector truncations within area B, Figure 36, are explained as coarse fan material being shed against layered basin sediments (Okaya and Thompson, 1985).

The simulated annealing velocity model of Line SRC-3 displays strong lateral velocity discontinuities northwestward toward the surface trace of the Dixie Valley fault (Figure 14). There is a large change in velocity from about 4 to $5 \mathrm{~km} / \mathrm{s}$, correlated with the velocity of rocks in the footwall of the Dixie Valley fault, to about 2 to $3.5 \mathrm{~km} / \mathrm{sec}$, which we correlate with basin sediment velocities. The velocity change is located between about 0.25 to $3.2 \mathrm{~km}$ depth, at around offset $0.75 \mathrm{~km}$. The velocity discontinuity is abrupt, and appears to dip very steeply toward the southeast, consistent with the inferred geometry of the Dixie Valley fault. There also appears to be a more shallow lateral velocity gradient from about $0.25 \mathrm{~km}$ depth to about $1 \mathrm{~km}$ depth from about 1 to $1.5 \mathrm{~km}$ offset toward the surface trace of the Dixie Valley fault. An abrupt horizontal change in velocity starts at about $1 \mathrm{~km}$ depth and extends to $1.9 \mathrm{~km}$ depth, basinward of the surface trace of the Dixie Valley fault. These velocities correlate with those of compacted basin sediments (Honjas et al., 1997a, b). At about $1.9 \mathrm{~km}$ depth, velocities increase to about $4.7 \mathrm{~km} / \mathrm{s}$. Velocities at $1.9 \mathrm{~km}$ depth correlate with the depth at which Tertiary volcanoclastic sequences of Dixie Valley basin are encountered in boreholes (Oxbow Geothermal drill logs).

Figure 33 shows the results of a simultaneous inversion for velocities and reflector characteristics from picks made on negative-moveout reflection hyperbolas (indicating reflection off a dipping 
interface). The velocity model exhibits the same lateral variation as that obtained from the first arrivals (Figure 14). The reflection midpoints (a reflector would be a collection of such points) lie along an interface that dips approximately 60 degrees and projects updip to the surface trace of the Dixie Valley fault. Velocities above this reflector are well constrained, but those below it are not because the reflection rays do not penetrate the interface. Such an optimization does not image multiple reflectors like a pre-stack Kirchhoff migration (Figure 28), but it has the ability to locate a single reflecting interface with relatively few reflection picks off few shot gathers (only 23 gathers were used in this case). It is a quantitative and more accurate way of performing the operation done by Okaya and Thompson (1985), where they pick steeply dipping reflections (De in Figure 36) and hand migrate them to determine reflector position (Dm). Their method is very sensitive to the velocities used, which was averaged from sonic logs and refraction studies. In contrast, the algorithm used in this study estimates the velocities and accounts for strong lateral variations as can be seen from Figure 33. The different velocity models could account for the difference in dip of the Dixie Valley fault between their estimate (about 50 degrees) and ours (about 60 degrees).

Figure 28 shows a pre-stack Kirchhoff migration of shot gathers collected along SRC3 using the velocity model shown in Figure 14. Due to limited source-receiver offsets in the data, velocities beneath $1.8 \mathrm{~km}$ are not well constrained and hence the accuracy of the pre-stack image beneath this depth is not very reliable. Above this depth the image shows structural complexity in great detail. A prominent synclinal feature is evident at an offset of $2.8 \mathrm{~km}$ and depth of $\sim 1 \mathrm{~km}$, and it coincides with an observed gravity anomaly (Figure 32). Toward the surface trace of the Dixie Valley fault, the shallow reflectors are less coherent. The fault trace obtained from reflection picks (Figure 33) is drawn on the pre-stack image (Figure 35) along with well 82-5 which has a fault intercept at about $2.9 \mathrm{~km}$. An estimated dip of 60 degrees on the Dixie Valley fault obtained from our study suggests that the fault intercepted in well $82-5$ is not the range front fault. Instead, the fault intercepted by the well could be associated with formation of the prominent syncline (Figure $35)$.

It is important to note that this discrete syncline is not imaged by the conventional post-stack migration (Figure 36), where one only sees a broad synformal "sag" of sediments increasing in thickness towards the fault. The syncline shown in Figures 28 and 35 also has been imaged as a consistent feature on several other seismic lines processed for this study, and can be clearly defined when the velocity models are extended into three-dimensional space (Figures 30 and 31 ). Our interpretation of this structure also is consistent with the findings of an independent gravity survey of the Dixie Valley geothermal field (Figure 32) (Blackwell and Wisian, 1997). Several 
production wells within the Dixie Valley geothermal field, including well 82-5, can be correlated with interpreted structure that seems to have controlled growth of the syncline.

\subsubsection{Geologic Implications}

The depth-migrated images obtained for this study suggest a significantly different geometry for northwestern Dixie Valley basin than interpretations based on analysis of conventionally-processed data. The time-migrated image of Seismic Line SRC3 prepared by Okaya and Thompson (1985) provides a basis for comparison with the Kirchhoff pre-stack migrated images developed with detailed 2-D velocity tomograms. The image obtained from conventional processing (Figure 36) suggests that the northwestern margin of the Dixie Valley basin is a broad 3- to 4-km-wide syncline. Okaya and Thompson (1985) infer a possible northwest-dipping fault with a small offset at the southeast end of the profile, but in general the synformal structure of the northwestern basin margin is attributed to broad sagging of the hanging wall of the range-front fault. In contrast, the pre-stack, depth-migrated image in Figure 36 indicates that the syncline is more limited in extent (less than two $\mathrm{km}$ wide), is asymmetric, and probably bounded by a southeast-dipping fault on its western side. The pre-stack migrated image also shows that reflectors in the piedmont area between the syncline and range-front fault are subhorizontal and undeformed except where displaced by discrete faults. Thus, the entire hanging wall of the range-front fault does not appear to be deformed except in the direct vicinity of piedmont faults.

Stratigraphic units imaged by the seismic data also differ in their appearance in the two different versions of SRC3. For example, in their interpretation of the conventionally-processed image (Figure 36), Okaya and Thompson (1985) infer that Tertiary volcanic and volcaniclastic rocks (i.e., their unit $\mathrm{C}$ ) extend to the western margin of the basin beneath alluvial fan deposits (their unit $\mathrm{B}$ ). In the pre-stack migrated image, reflectors associated with the volcanic rocks cannot be reliably traced to the basin margin west of the asymmetric syncline, and in fact appear to be juxtaposed against seismically transparent rocks on the northwest side of the syncline.

The "piedmont fault" model for subsidence of Dixie Valley (Figure 35) has implications for geothermal exploration. Based on the geomorphic evidence for repeated Quaternary surface rupture (Slemmons, 1956; Bell and Katzer, 1987; Caskey et al., 1996), the Dixie Valley rangefront fault probably extends to the base of the seismogenic crust and accommodates most of the extension across northwestern Dixie Valley. The piedmont faults may all root in the range-front fault at depth, and accommodate minor extension of the hanging wall of the range-front fault, perhaps manifested as minor triggered or sympathetic slip during moderate to large magnitude 
earthquakes on the range-front fault. In terms of the geothermal plumbing system, the range-front fault probably forms the major deep-seated pathway for heated fluids to rise convectively through the crust. At more shallow depths, fluids may encounter the piedmont faults at the intersection with the range-front fault, and migrate along the piedmont faults if the structures are sufficiently permeable. Also, the intersections of the range-front fault with the piedmont faults may form localized areas of high fracture density and relatively higher permeability.

The tectonic "sag" model developed based on analysis of conventionally-processed seismic data from Dixie Valley has been adopted for some other Basin and Range structures. In their overview of geothermal resources in the Basin and Range province, Zoback and Thompson (1983) observed that Fallon basin and Grass Valley also may examples of "sag" basins, and further noted that many of the high temperature hot spring systems in the Basin and Range province are associated with this style of deformation. Although some of these basins may indeed be characterized as broad "sags", it is possible that reprocessing seismic reflection data from these basins may reveal additional details of piedmont structure similar to what we observe in Dixie Valley. Such structures may present well-defined targets for additional geothermal exploration. 
Simulated annealing velocity models accurately predict subsurface velocity structure, which can be directly correlated with known geologic features. Based on interpretation of two- and threedimensional velocity structure, and Kirchhoff pre-stack migration images (Figure 5), the structure or structures associated with a syncline basinward of the range-front fault seem to affect the location of subsurface permeability within the Dixie Valley geothermal field. This interpretation is supported by borehole data, geologic data, and gravity data. The images produced using new seismic data processing techniques yield significantly more structural detail than images derived from conventional, post-stack migration processing techniques. The velocity models and images produced from this structure constrain the spatial location of subsurface tectonic deformation that appear to affect the location of permeability within the Dixie Valley geothermal field, using no $a$ priori data other than the seismic data itself. Thus, these techniques can provide economic and technical guidance for planning and executing drill programs within thermal anomalies that have no surface manifestations.

The new seismic data processing techniques used in this study represent a significant improvement over conventional approaches that have been used in previous investigations of subsurface structure in western Dixie Valley. Our results show that the basin margin is subsiding along discrete normal faults in the piedmont region, rather than deforming by broad "sagging" of the hanging wall of the Dixie Valley range-front fault. This reinterpretation of the structure of the basin margin is consistent with the results of recent gravity modeling (Blackwell and Wisian, 1997). Furthermore, the association of piedmont faults with producing wells in Dixie Valley suggests that these structures may be more important for understanding the migration of geothermal fluids than previously realized. Conventional array geometry and other parameters previously employed for acquisition of seismic data within geothermal fields are not adequate for using these techniques to image structural and stratigraphic features at reservoir depths. In order to make maximum use of these new processing techniques, and to allow for general commercial use of the seismic method for geothermal exploration and development, specific data acquisition parameters for imaging thermal anomalies at reservoir depths must be designed and tested. 
Bell, J.W., and Katzer, T., 1987, Surficial geology, hydrology, and late Quaternary tectonics of the IXL Canyon area, Nevada: Nevada Bureau of Mines and Geology Bulletin 102, 52 p. plus plates.

Benoit, W.R., and Butler, R.W., 1983, A review of high-temperature geothermal developments in the northern Basin and Range province: Geothermal Resources Council Special Report 13, p. 57-80.

Blackwell, D., and Wisian, K., 1997, Gravity analysis of the area of the Dixie Valley, Nevada, geothermal system: unpublished report prepared for Oxbow Geothermal Corporation, Reno, NV, and Caithness Resources, Inc., Denver, CO.

Caskey, S.J., Wesnousky, S.G., Zhang, P.S, and Slemmons, D.B., 1996, Surface faulting of the 1954 Fairview Peak (Ms-7.2) and Dixie Valley (Ms=6.9) earthquakes, central Nevada: Bulletin of the Seismological Society of America, v. 86, p. 761-787.

Dilek, Y.M., Moores, E.M., 1995, Geology of the Humboldt igneous complex, Nevada, and tectonic implications for the Jurassic magmatism in the Cordilleran Orogen, in Miller, D.M., and B. Cathy, eds., Jurassic magmatism and tectonics of the North American Cordillera: Geological Society of America Special Paper, v. 299, p. 229-248.

Fonseca, J., 1988, The Sou Hills; a barrier to faulting in the central Nevada seismic belt: Journal of Geophysical Research, B., Solid Earth and Planets, v 95, p. 475-489.

Hastings, D.D., 1979, Results of exploratory drilling, northern Fallon Basin, western Nevada, in Basin and Range symposium and Great Basin Field Conference, p. 515-522.

Honjas, W., Pullammanappallil, S. K., Lettis, W. R., Plank, G. L., Louie, J. N., and Schweichert, R., 1997a, Predicting shallow Earth structure within the Dixie Valley geothermal field, Dixie Valley, Nevada, using a non-linear velocity optimization scheme: Proc. 22nd workshop on Geothermal Reservoir Engineering, Stanford University, California, p.153-160.

Honjas, W., Pullammanappallil, S. K., Lettis, W. R., Plank, G. L., Louie, J. N., and Schweichert, R., 1997b, Predicting shallow Earth structure within the Dixie Valley geothermal field, Dixie Valley, Nevada, using a non-linear velocity optimization scheme: Geothermal Resources Council Bulletin, v. 26, p. 45-52.

Honjas, W., 1993, Results of post and pre-stack migrations imaging the Hosgri fault, offshore Santa Maria Basin, California [Master's Thesis]: University of Nevada, Reno, 109 p.

Hudson, M.R., and Geissman, J.W, 1991, Paleomagnetic evidence for the age and extent of middle Tertiary counterclockwise rotation, Dixie Valley region, west central Nevada: Journal of Geophysical Research, B, Solid Earth and Planets, v. 968, p. 3979-4006.

Okaya, D.A., and Thompson, G.A., 1985, Geometry of Cenozoic extensional faulting, Dixie Valley, Nevada: Tectonics, v. 4, p. 107-125.

Pullammanappallil, S.K., and Louie, J.N., 1993, Inversion of seismic reflection travel times using a nonlinear optimization scheme: Geophysics, v. 58, p. 1607-1620. 
Pullammanappallil, S.K., and Louie, J.N., 1994, A generalized simulated-annealing optimization for inversion of first-arrival times: Bulletin of the Seismological Society of America, v. 84, p. 1397-1409.

Savage, J.C.L., M., Svarc, J.L., Gross, W.K., 1995, Strain accumulation across the central Nevada seismic zone, 1973-1994: Journal of Geophysical Research, B, Solid Earth and Planets, v. 100, p. 20257-20269.

Silberling, N.J., and Roberts, R.J., 1962, Pre-Tertiary stratigraphy and structure of northwestern Nevada: Geological Society of America Special Paper 72, 58 p.

Slemmons, D. B., 1956, Geologic setting for the Fallon-Stillwater [Nev.]: earthquakes of 1954, in The Fallon Stillwater earthquakes of July 6, 1954, and August 23, 1954: Seismological Society of America Bulletin, v. 46.

Speed, R.C., 1976, Mesozoic and Cenozoic tectonic evolution of the western Great Basin: Econ. Geol. 71, v. 3, p. 703.

Wallace, R.E., and Whitney, R.A., 1984, Late Quaternary history of the Stillswater seismic gap, Nevada: Bulletin of the Seismological Society of America, v. 74, p. 301-314.

Zoback, M.L., and Anderson, R.E., 1983, Style of Basin-Range faulting as inferred from seismic reflection data in the Great Basin, Nevada and Utah: Geothermal Resources Council Special Report 13, p. 363-381.

Slemmons, D.B., 1967, Pliocene and Quaternary crustal movements of the Basin and Range province, USA [with discussion): in Sea level changes and crustal movements of the Pacific during the Pliocene and post Pliocene time, Osaka Univ., Journal of Geosciences, v. 10, p. 91103. illus. 